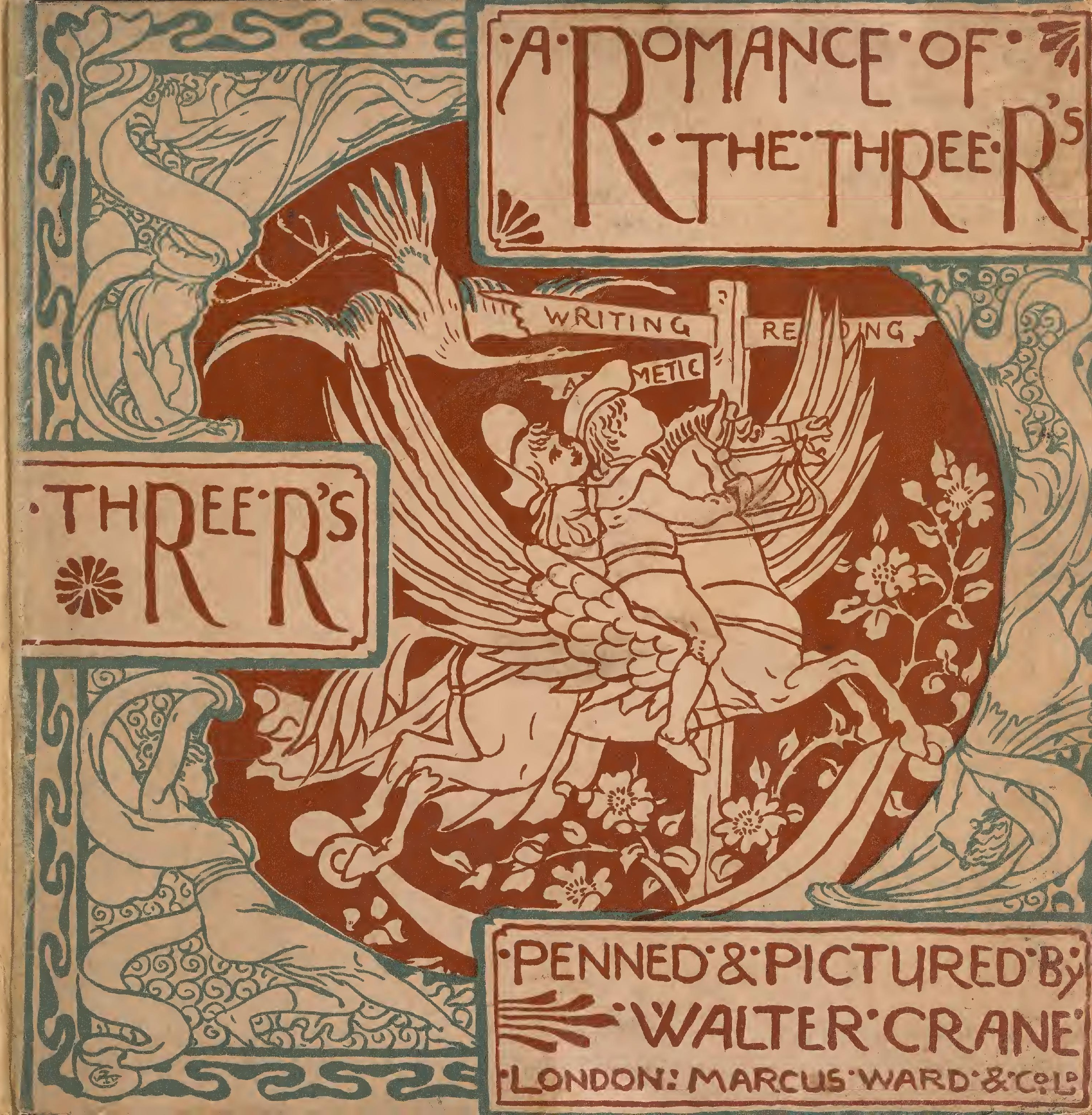




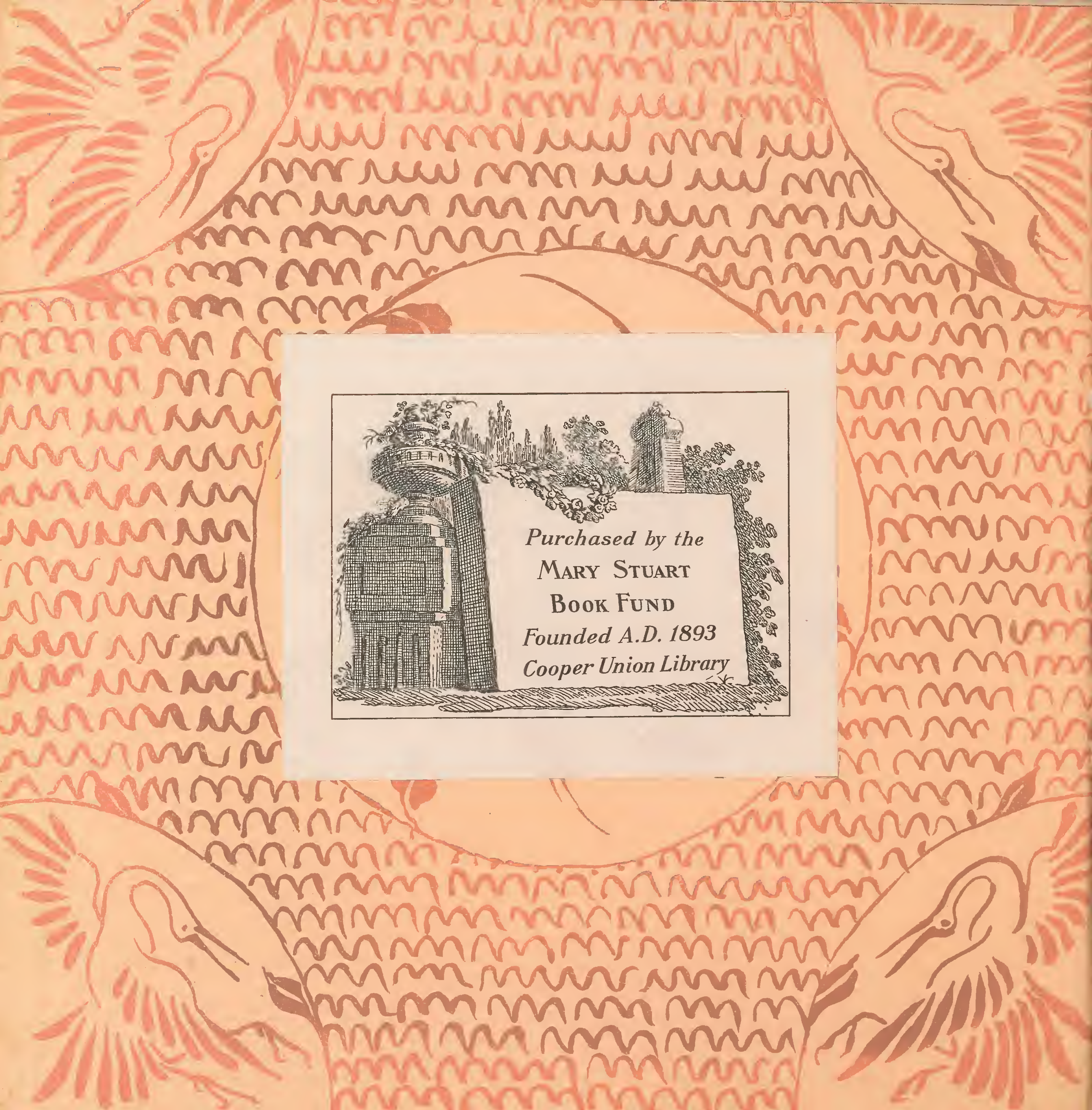




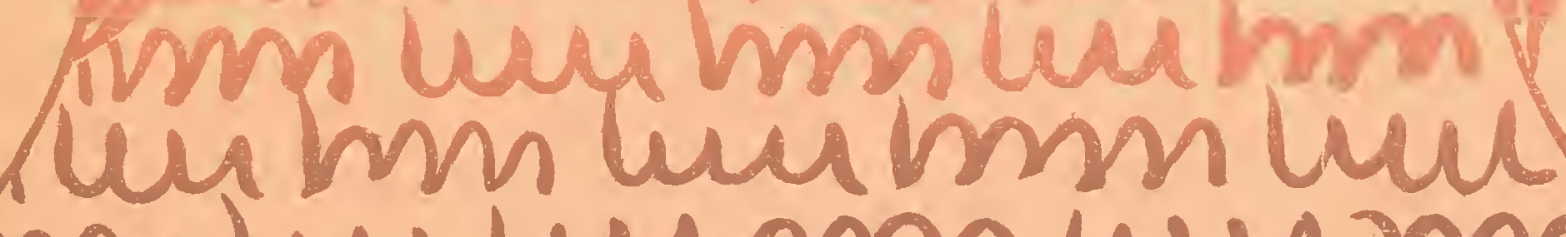
minum um wurm cuminerminimins minn mminuy miming

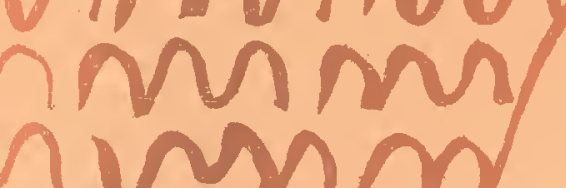
imim mim mins mimis mim min (1)

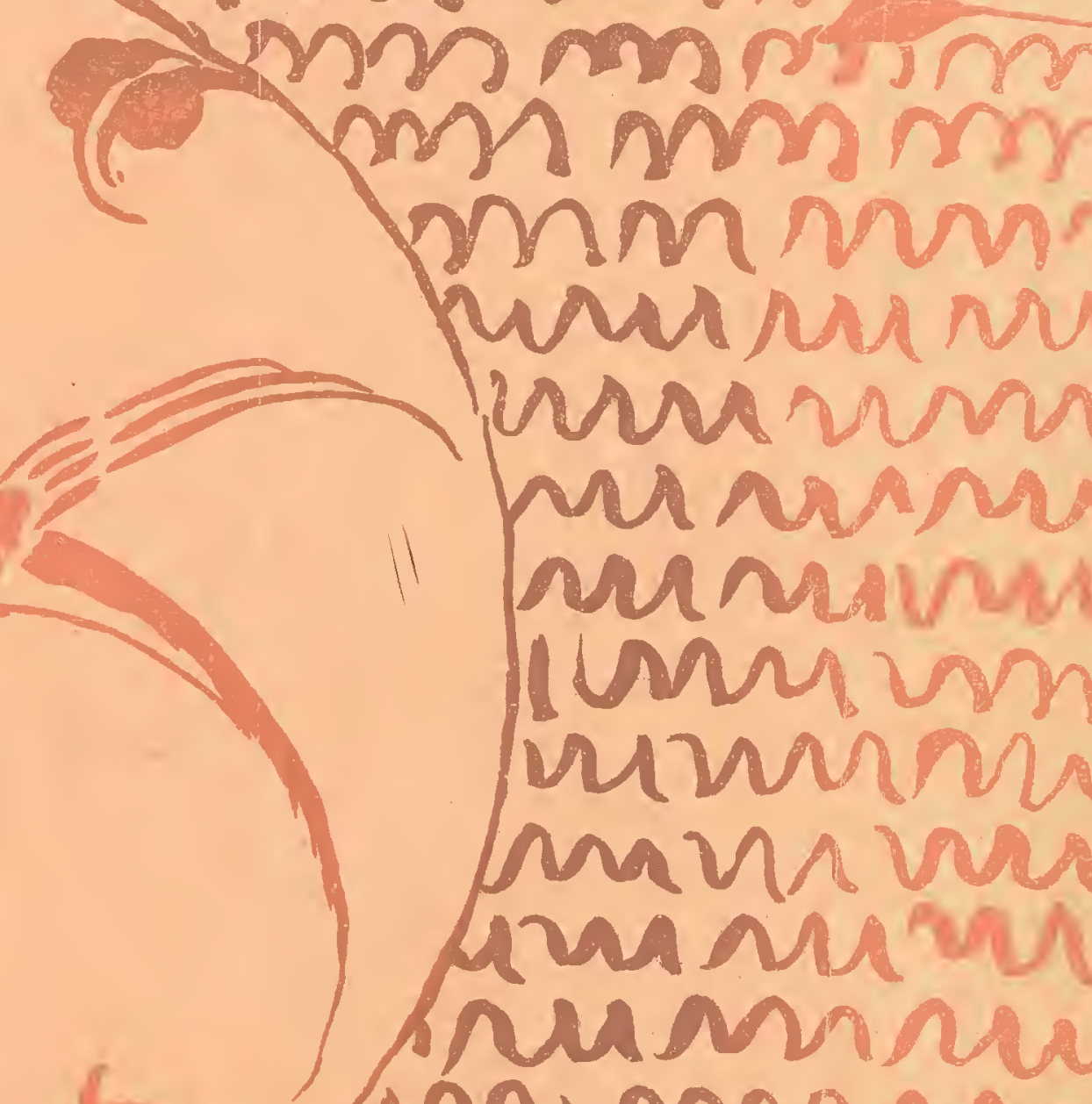
vinur eminima nimma

(s. musvininimm

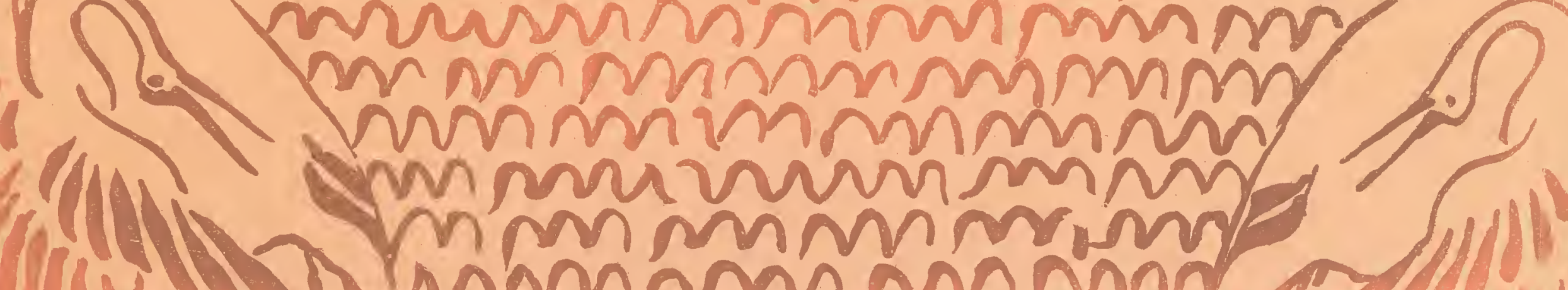
minn man 
हn

\section{: PREFACE:}

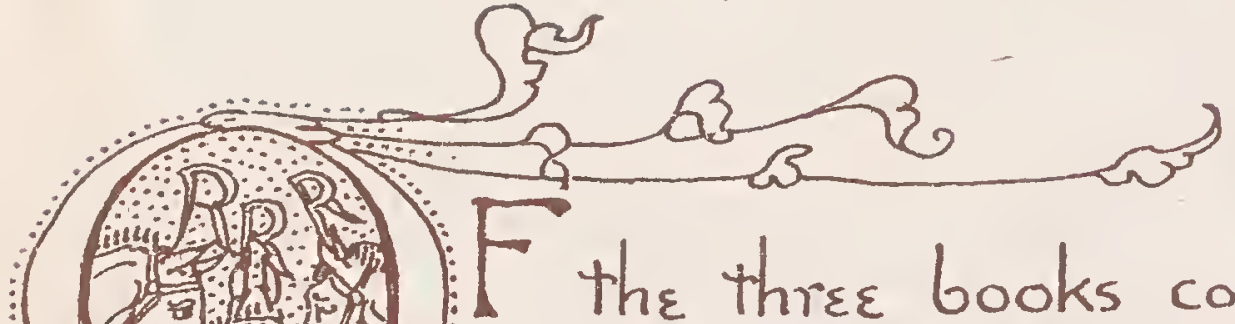

- the three books composing this volume, which can also be had separately,"SLATE= "ANDPENCILVANIA" appeared last year. It was originally intended to issue them to = - Esther, but it has not besn found practicable to complets the set unitil now.

If my hobby-horses serve in any degres to help little folks over the rough stones of the road to $R$ sading, WRiting, and $A R=$ -ithmetic, or afford pleasant pastime by the way, They will not have besn ridden in vain. Ar any rats, if wishes were horses, this book should be, in the spirit of its cover-device, a Pegasus to all littls passengers aspiring to run, and read, or writs.

Sept: 1886

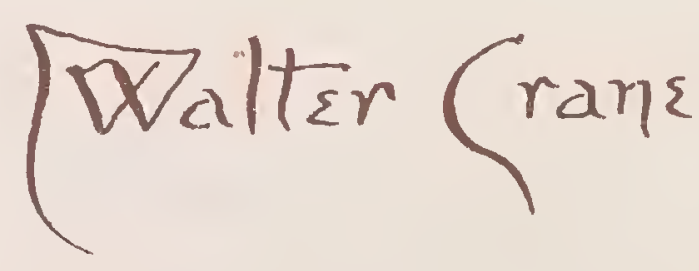




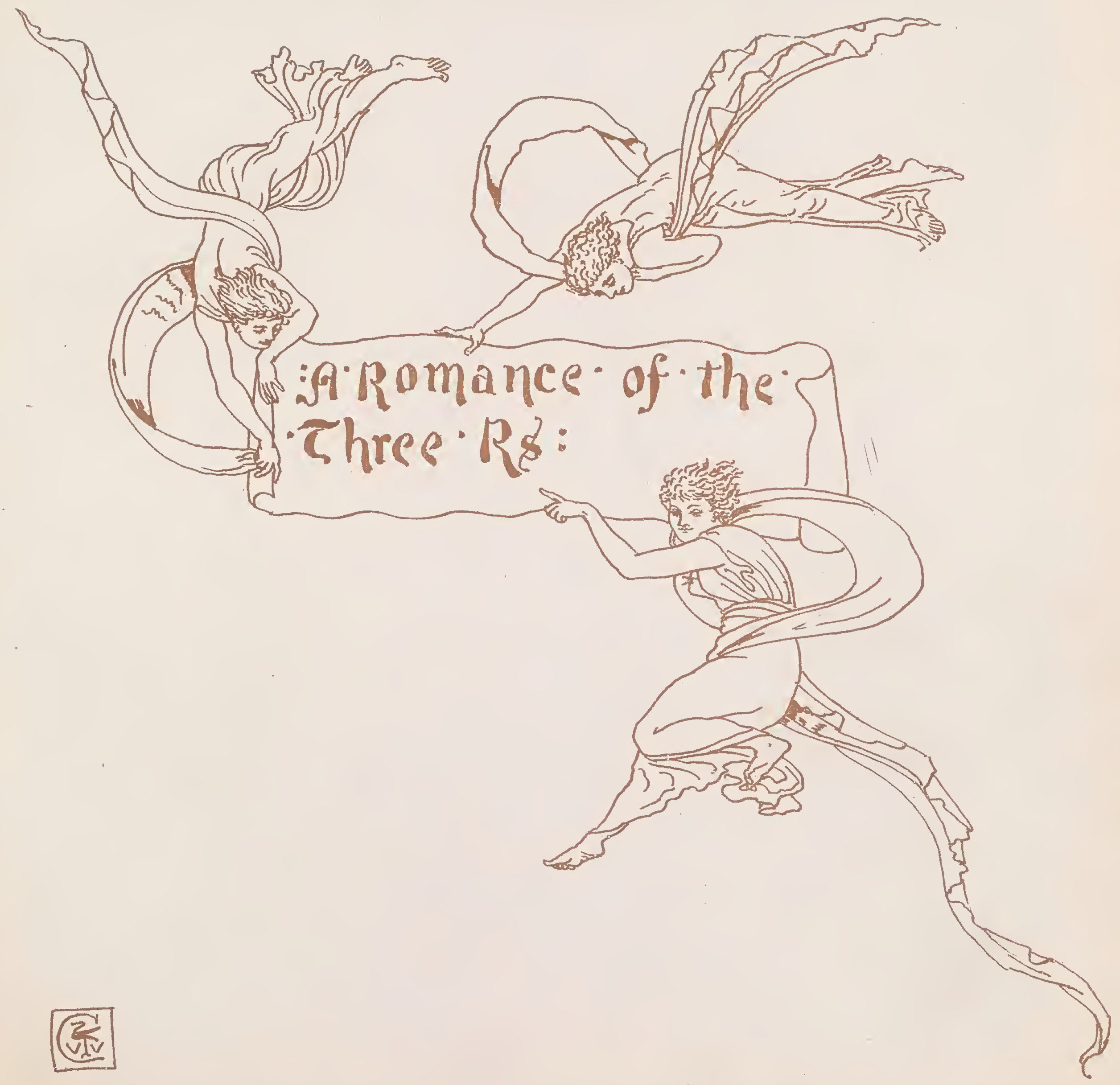




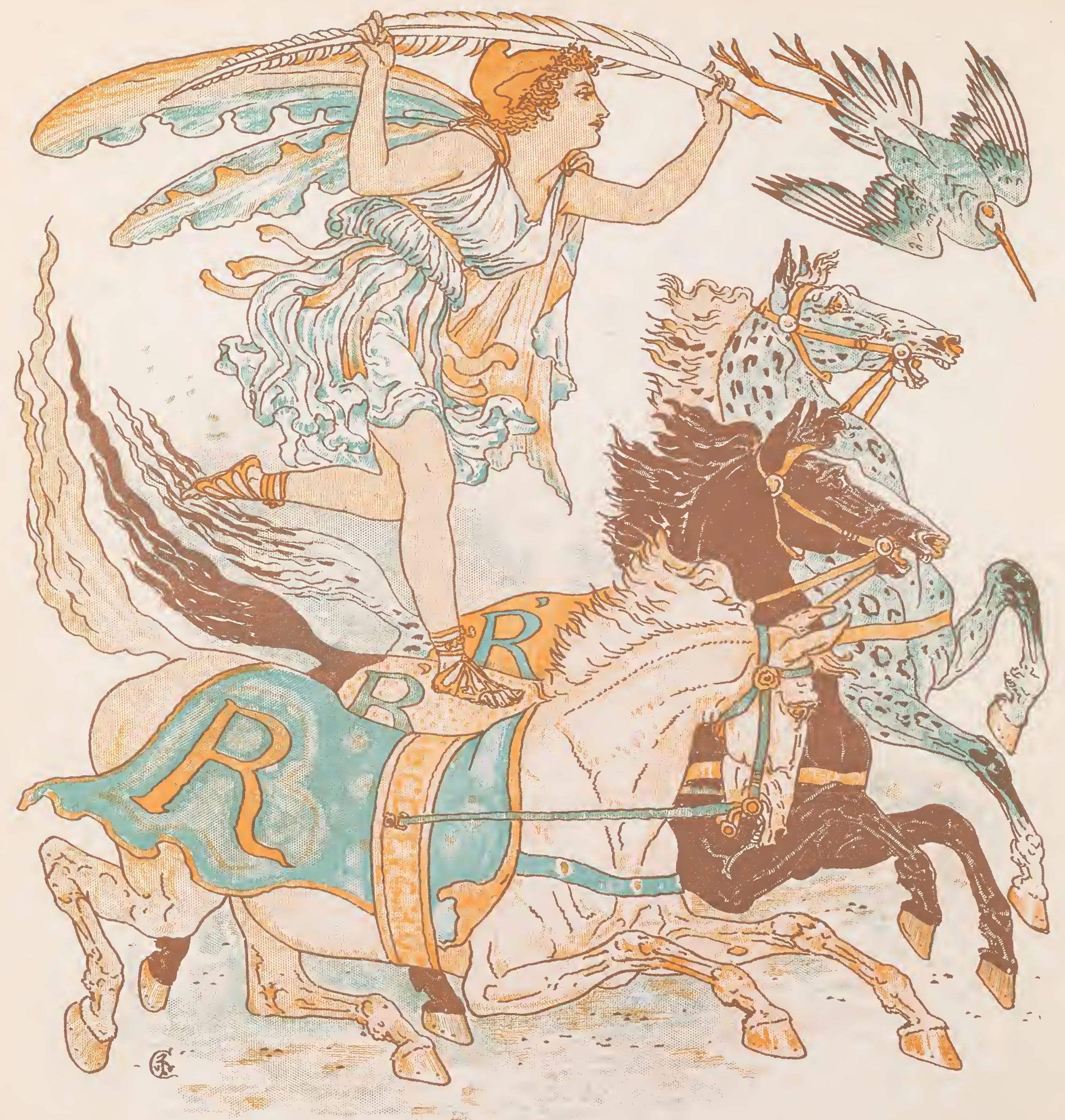




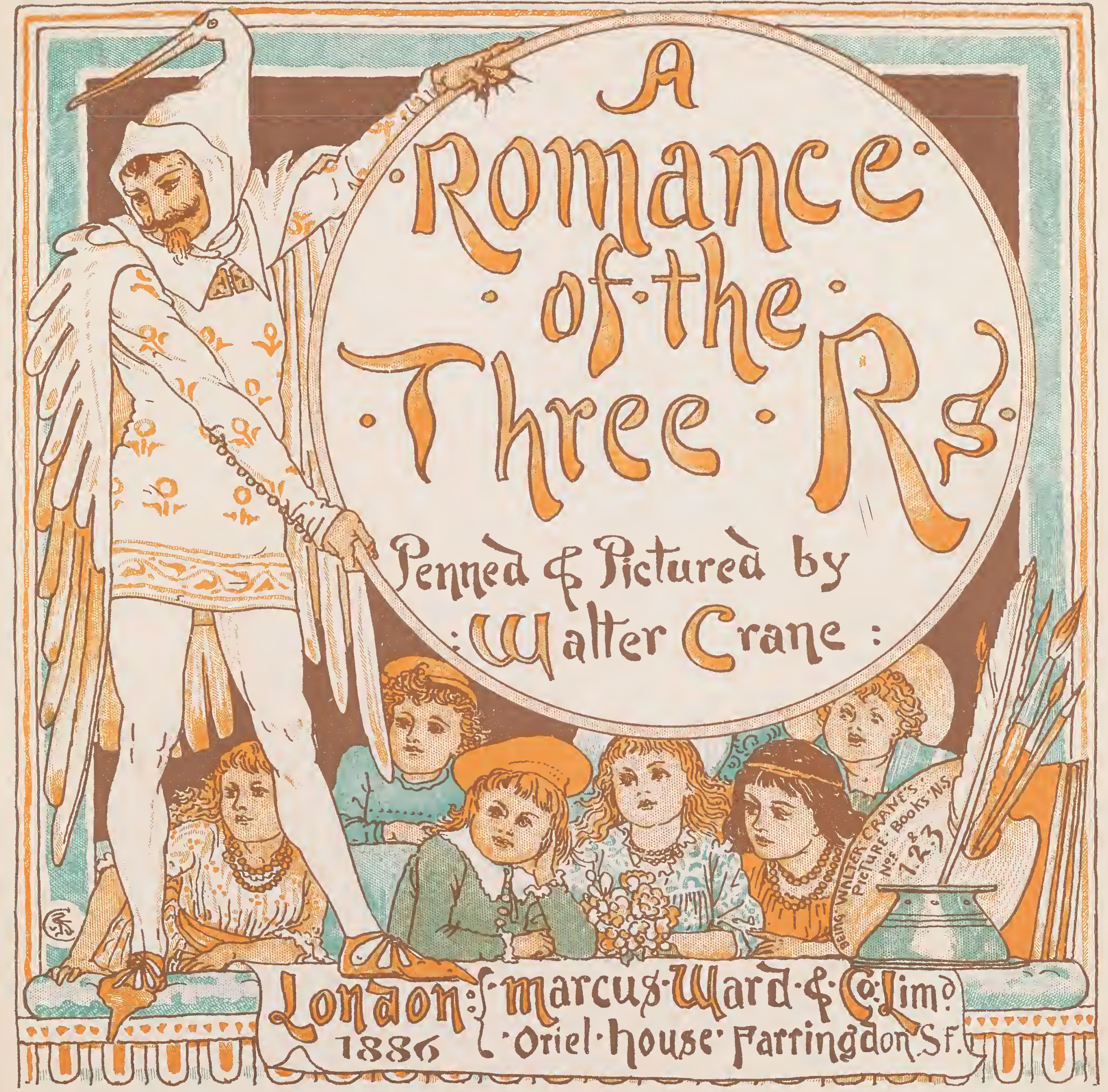




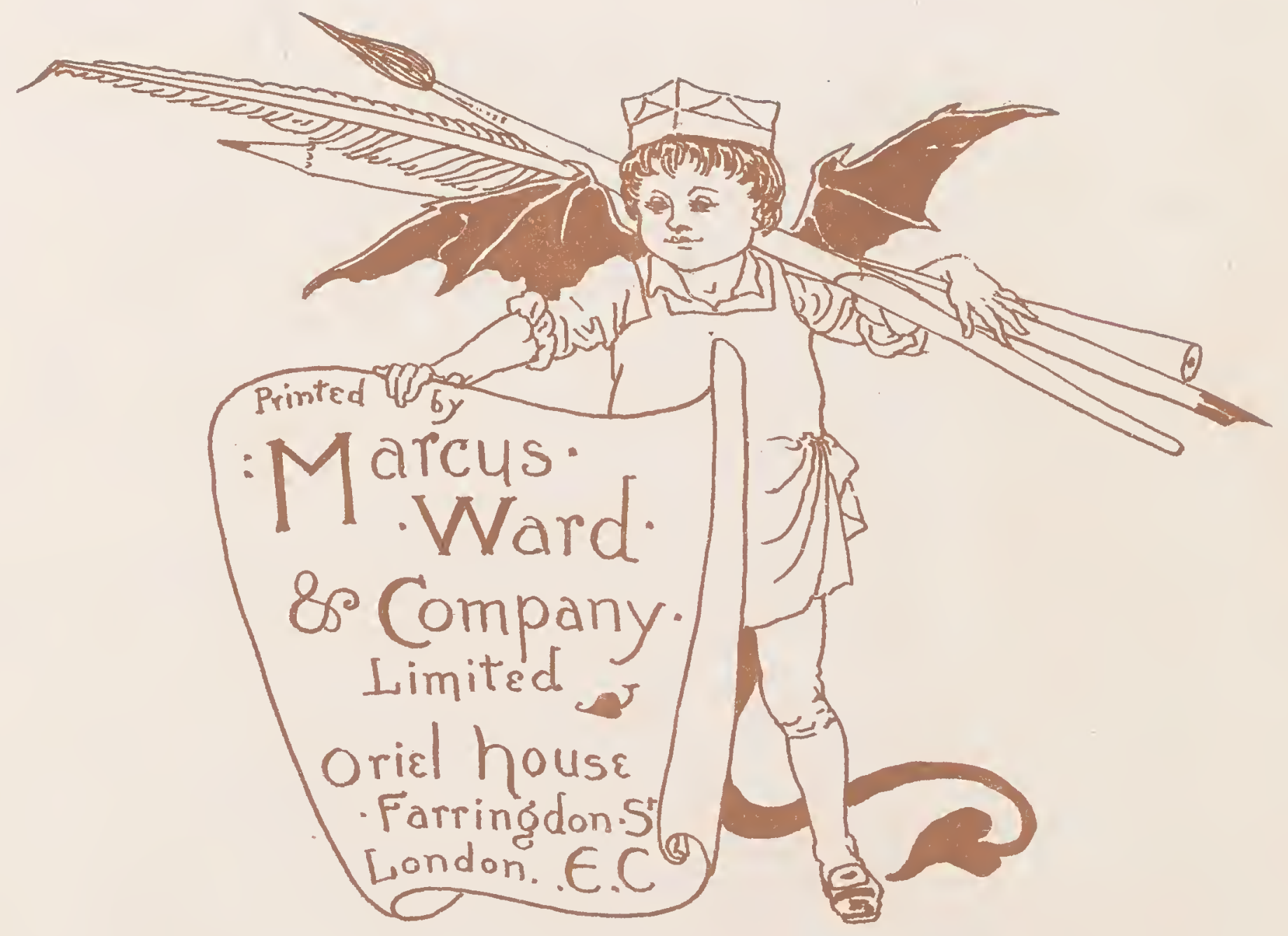




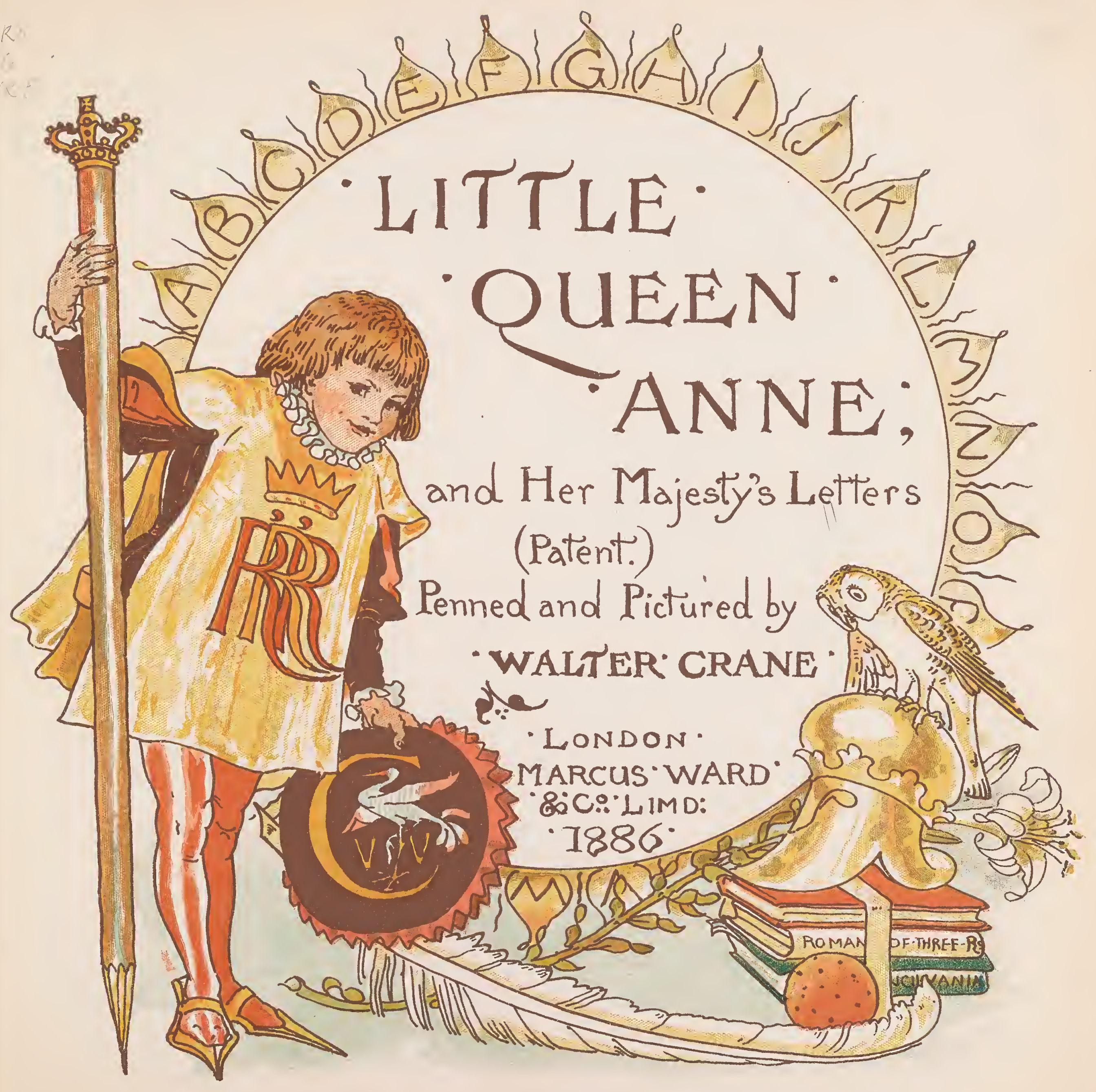

1707 


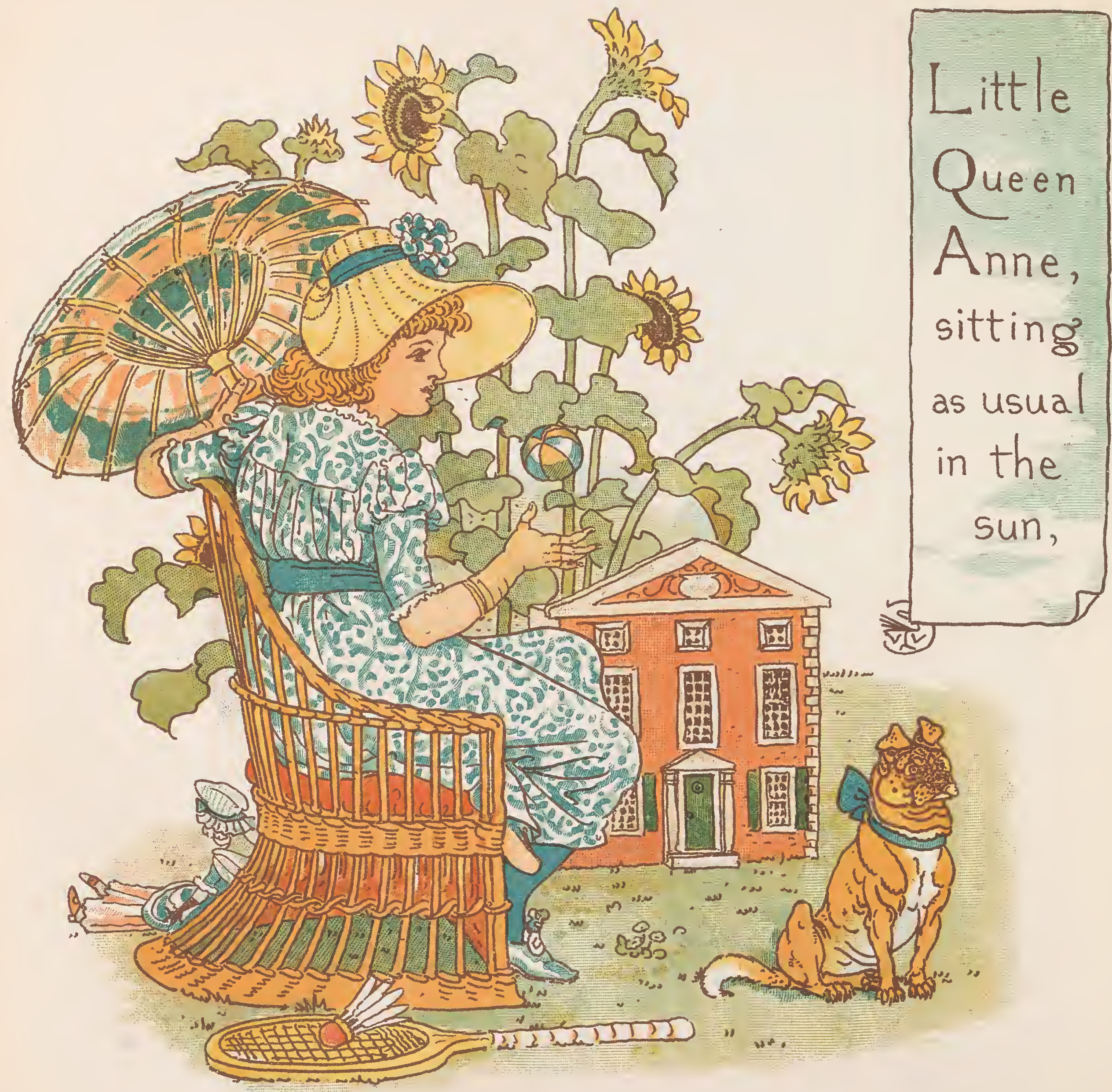




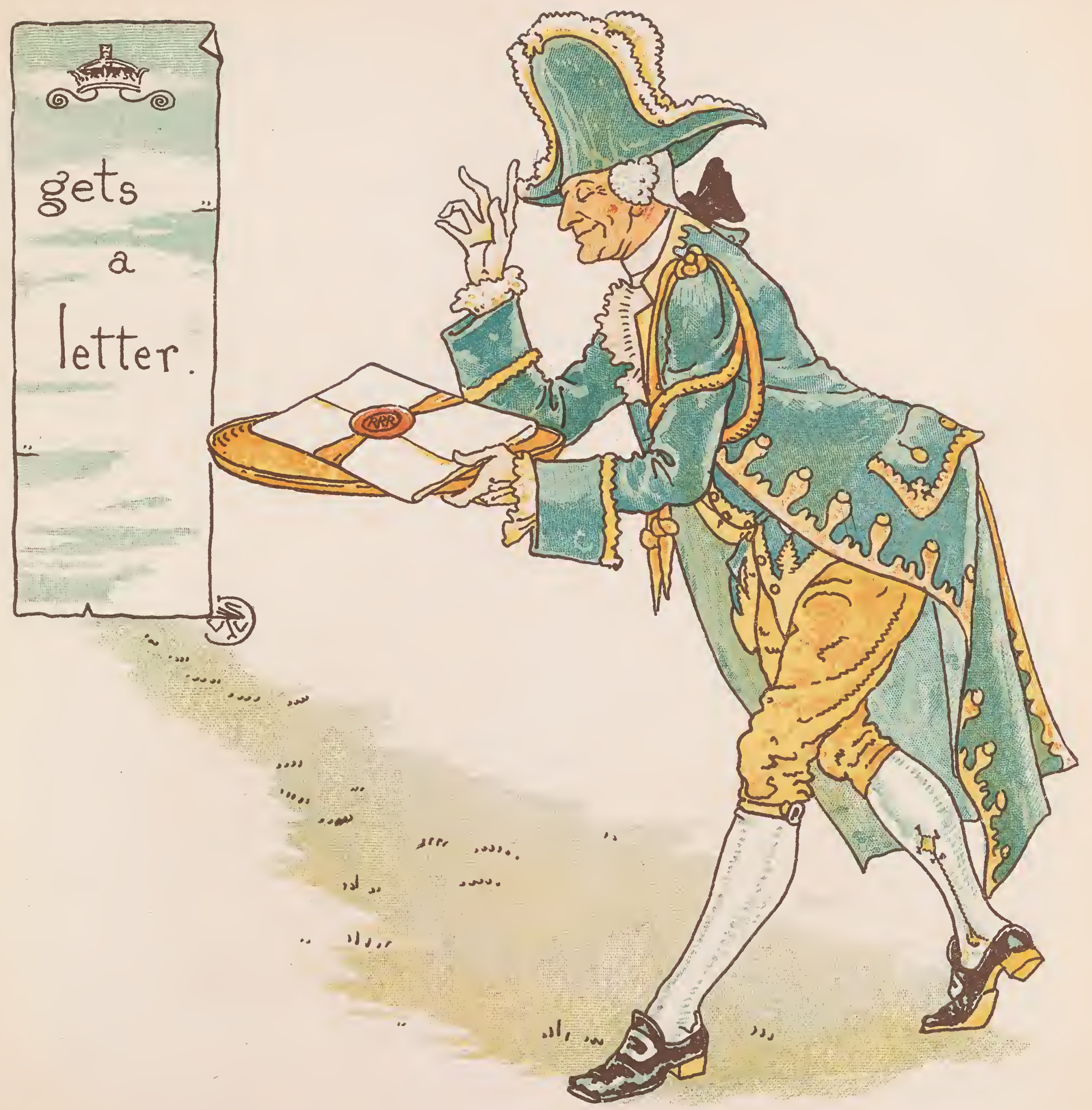




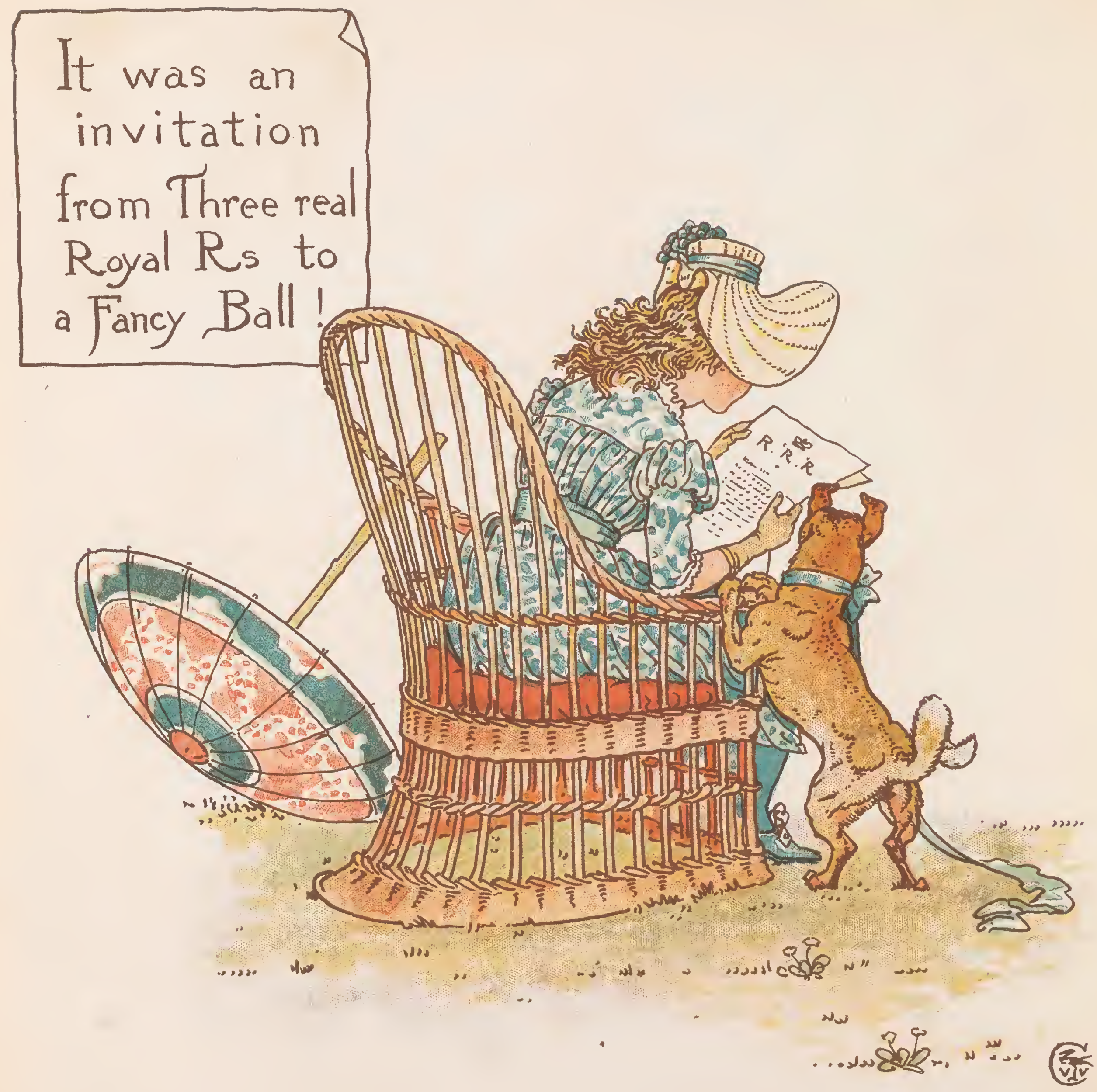




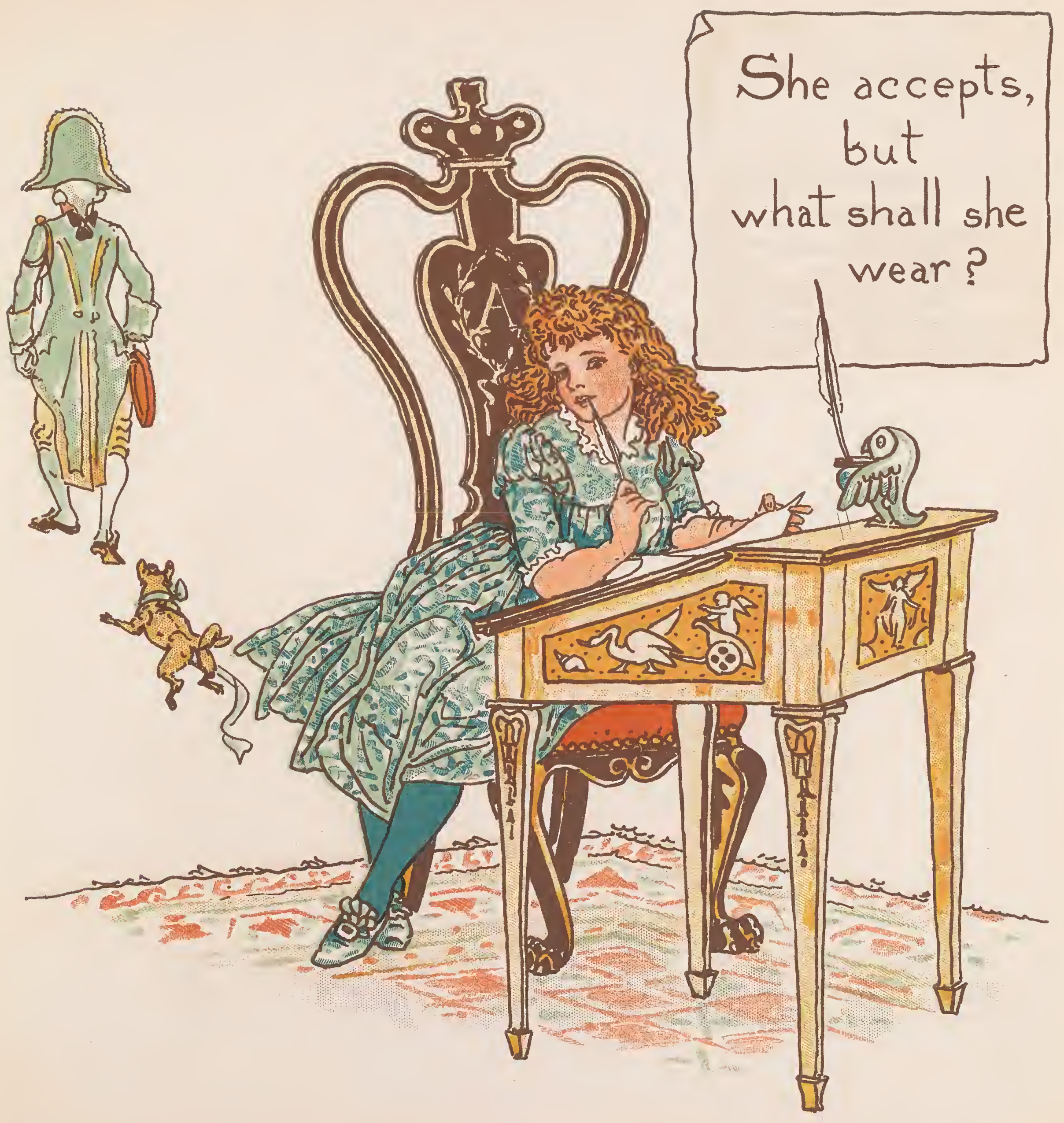




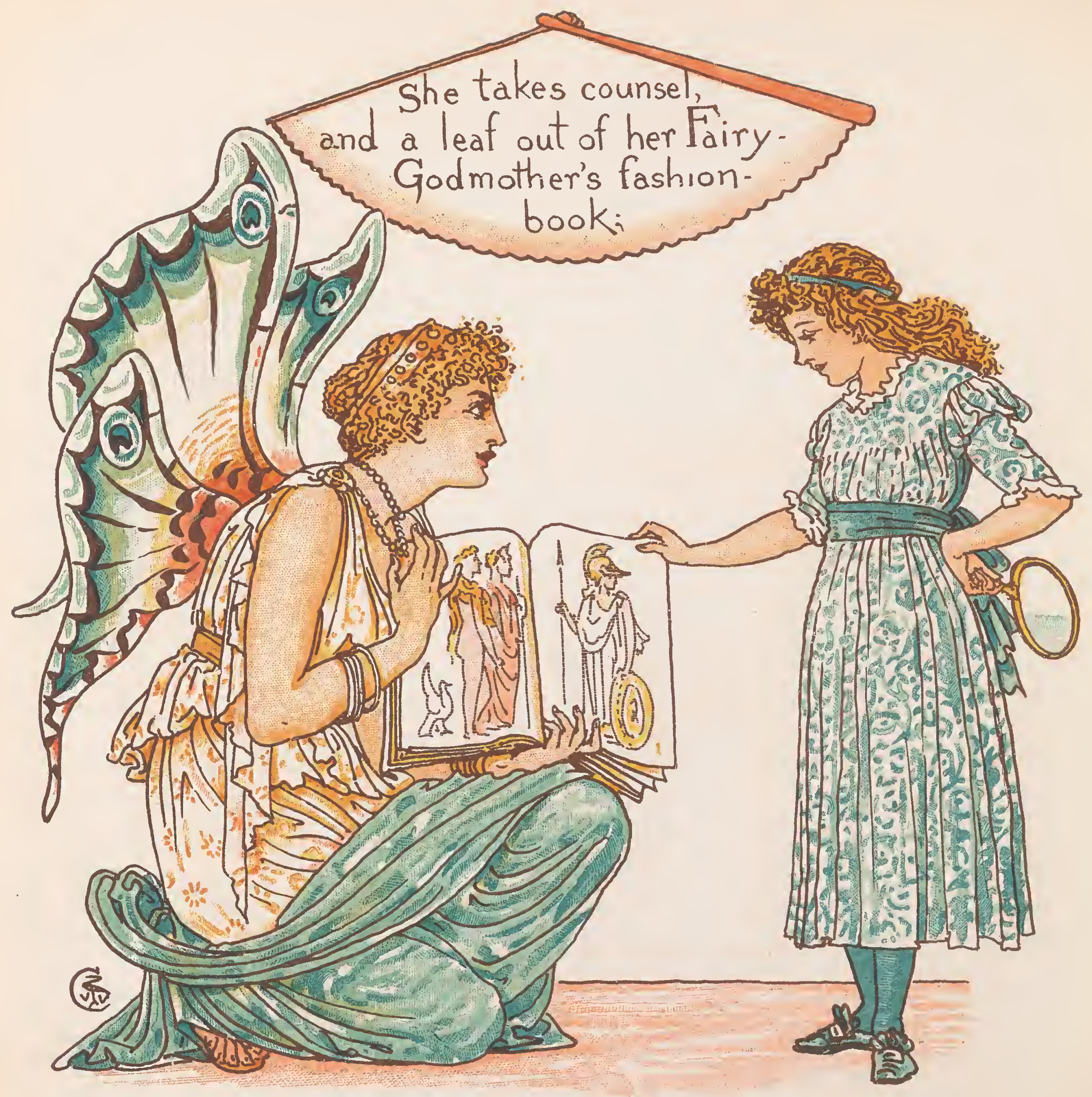




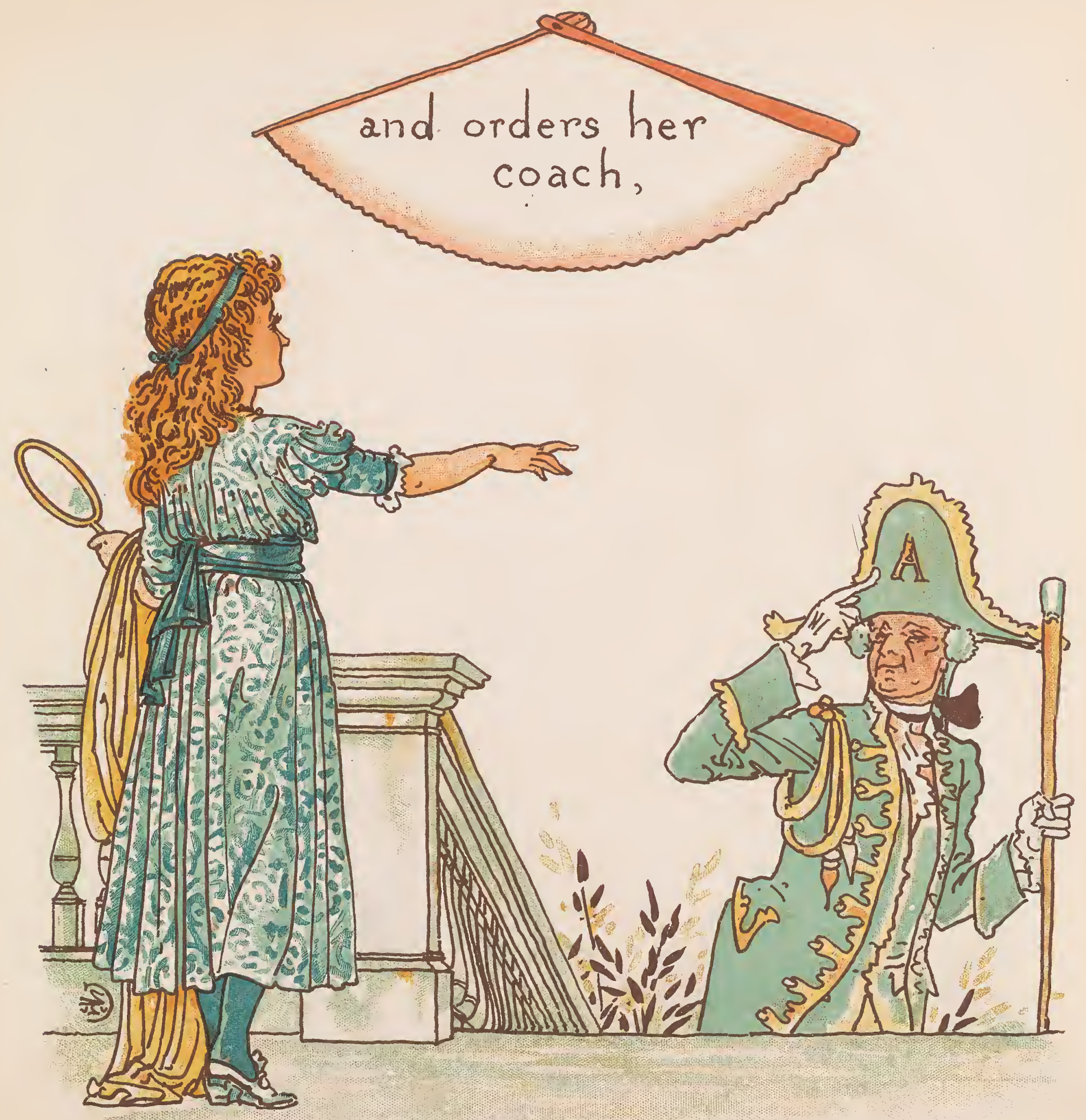




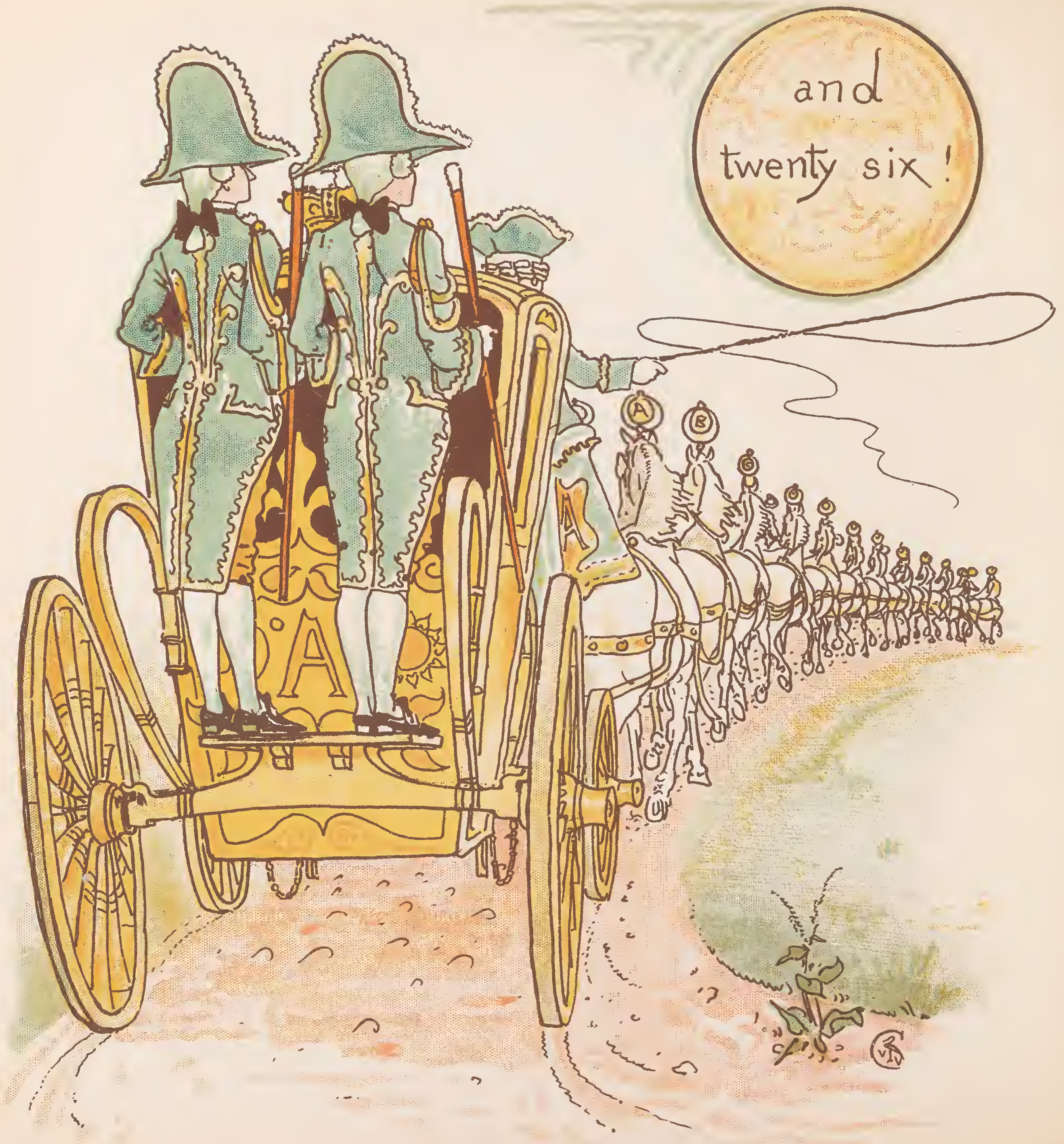




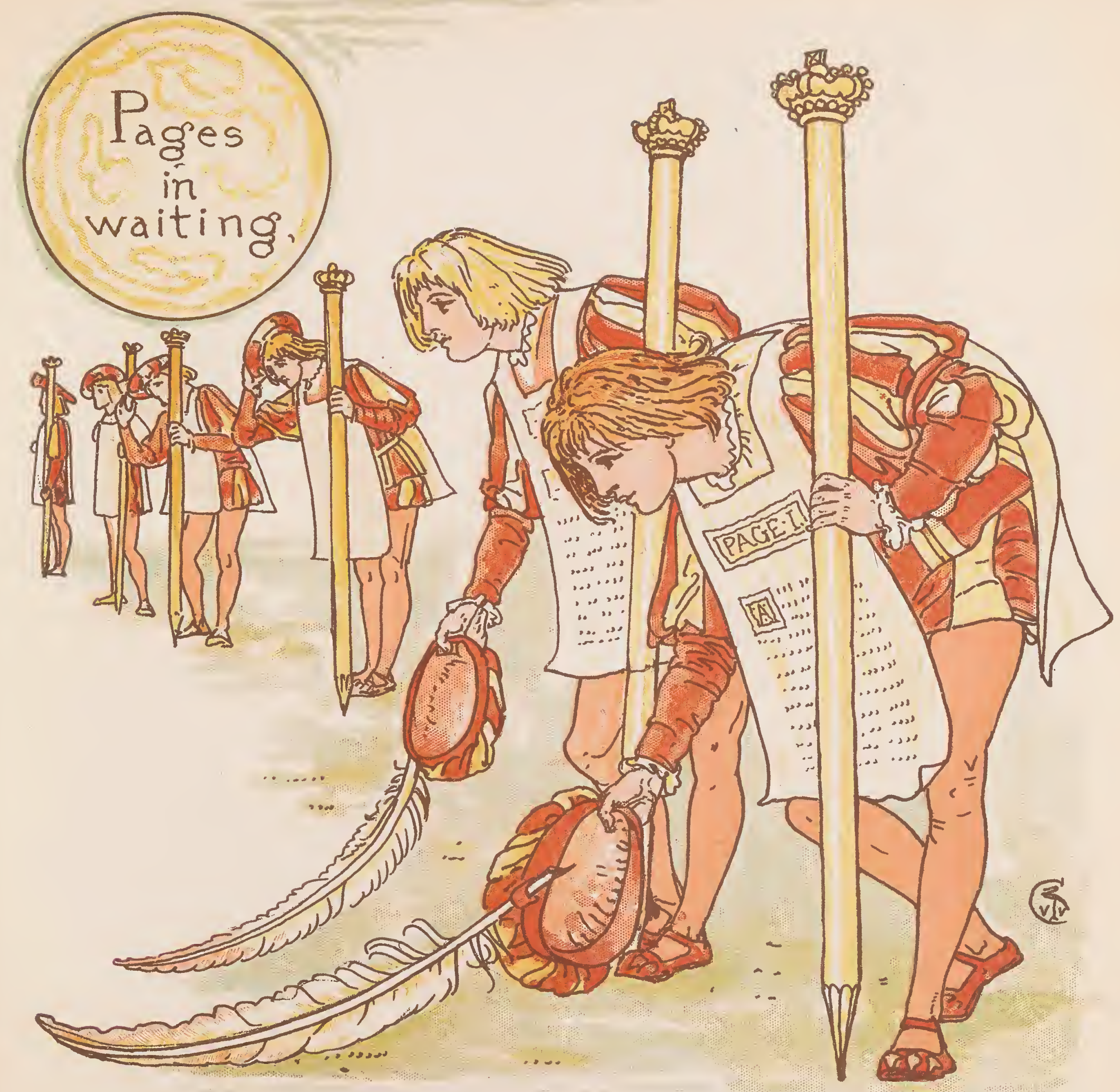




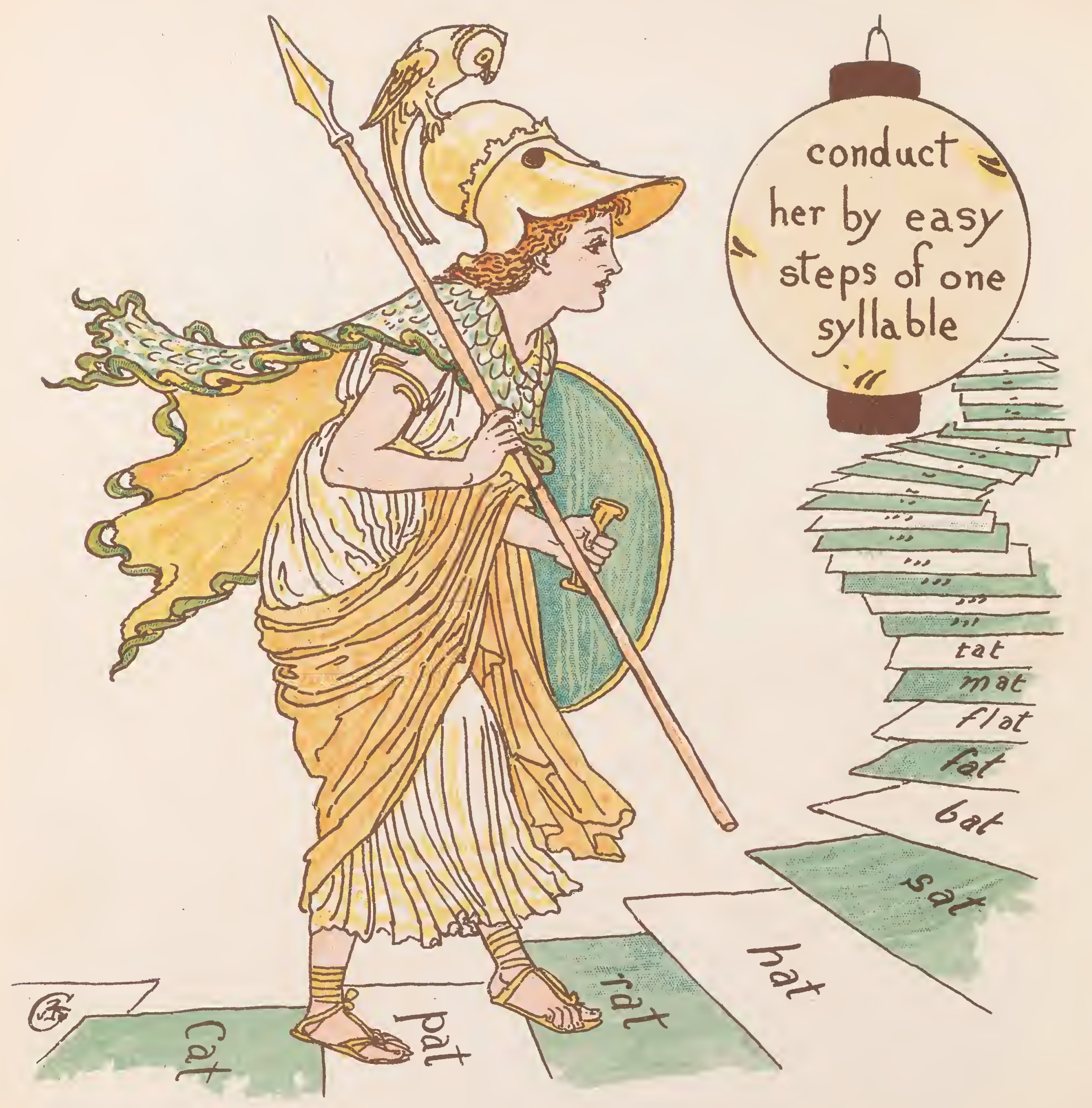




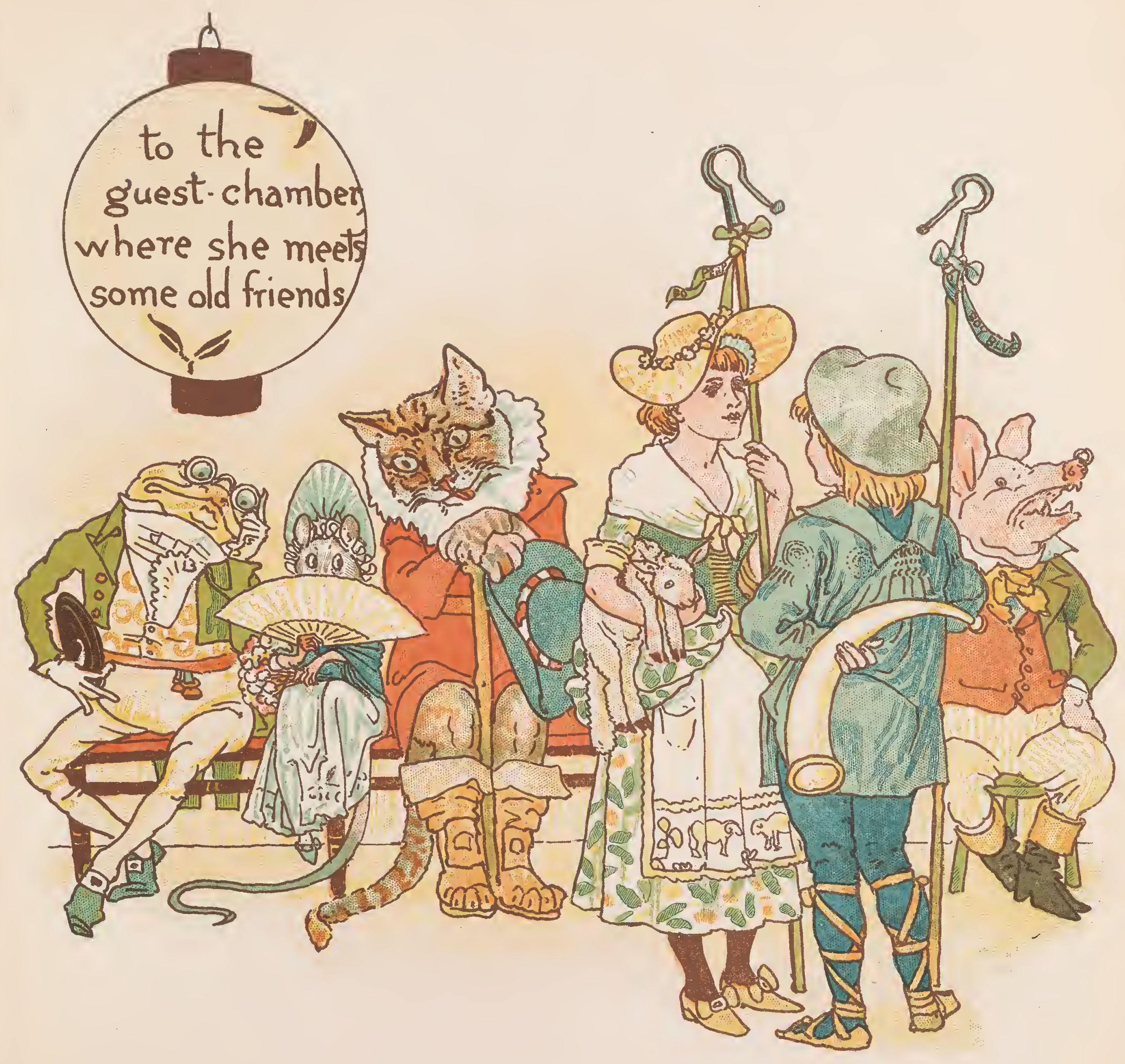




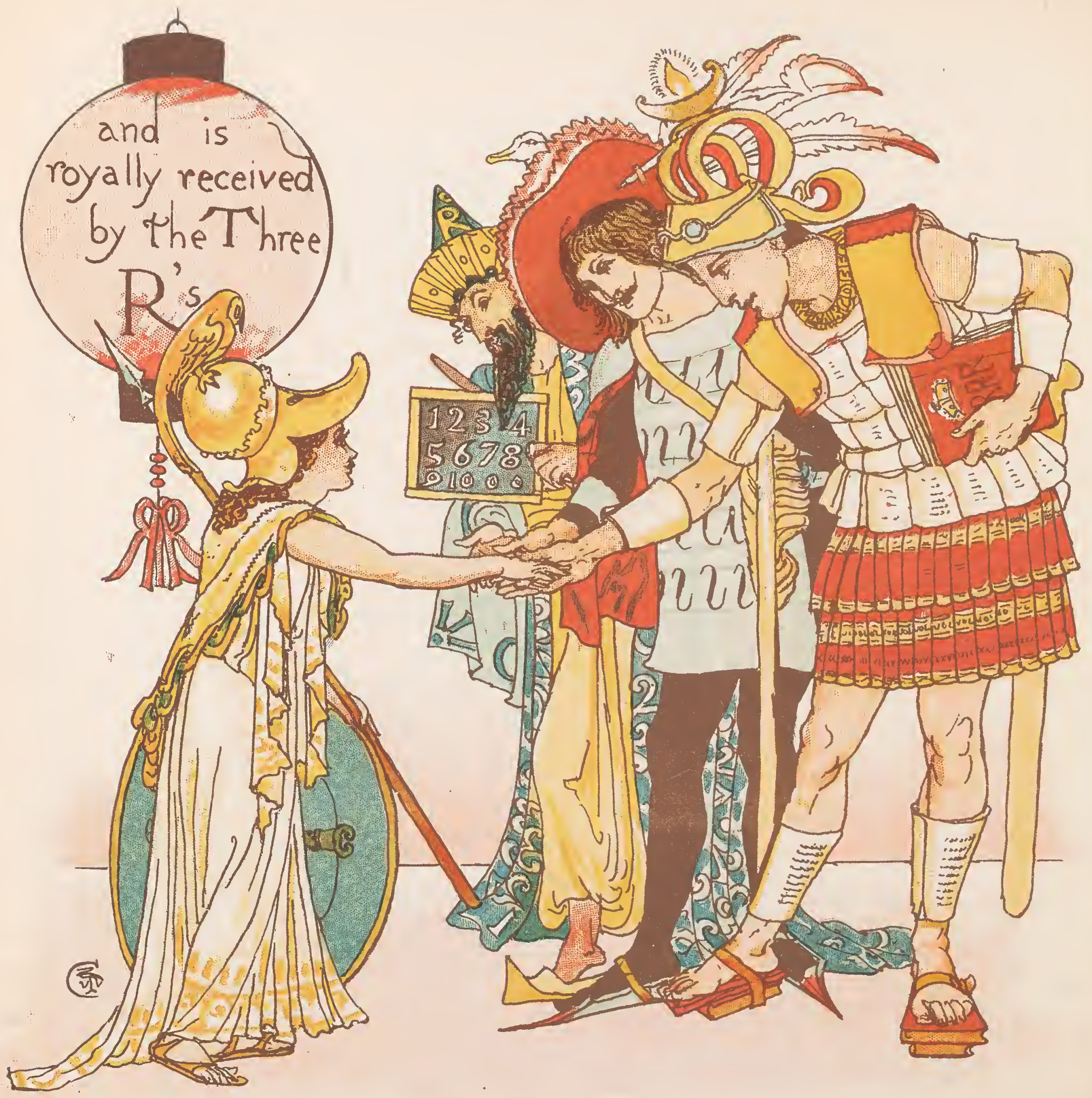




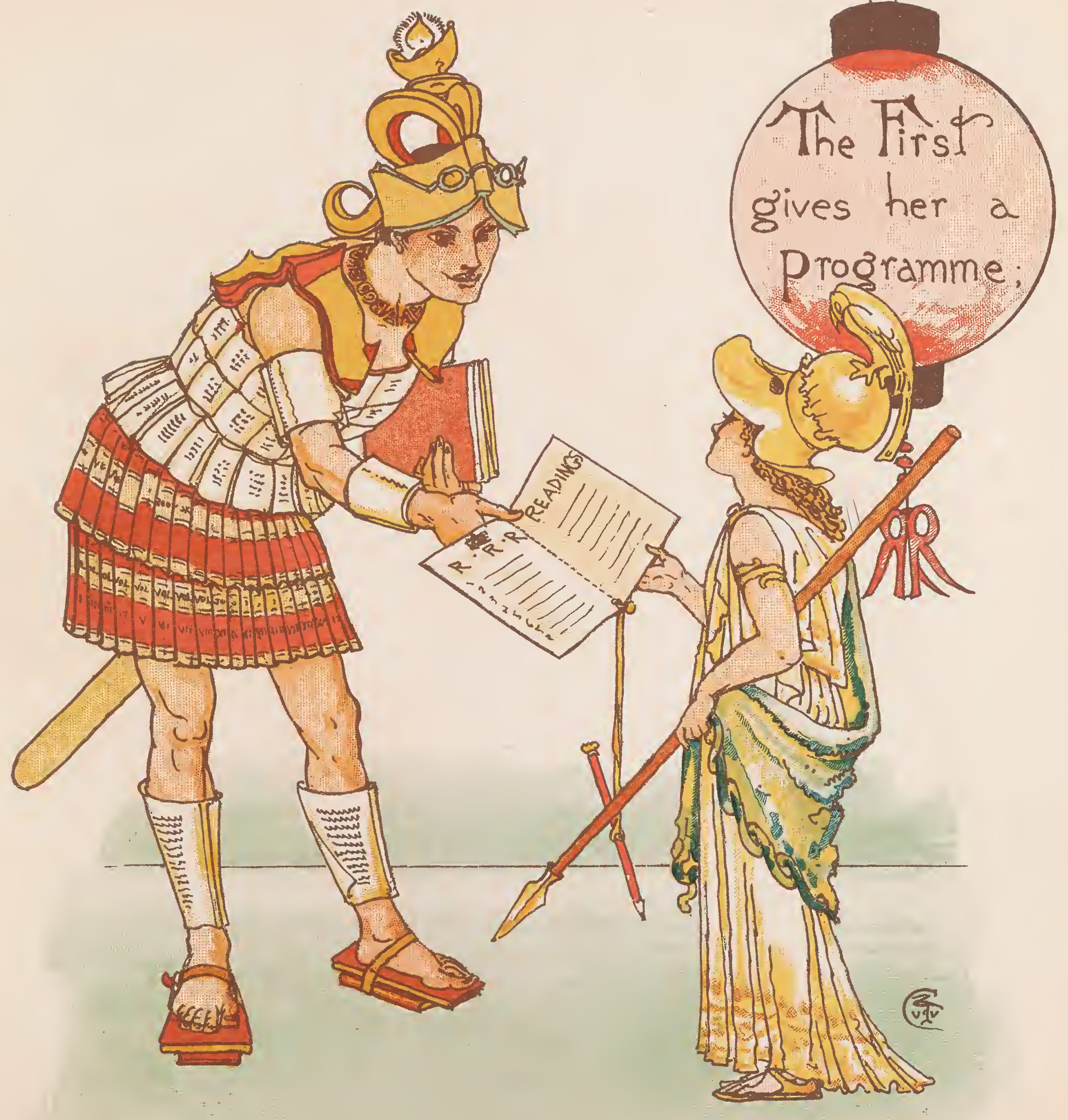




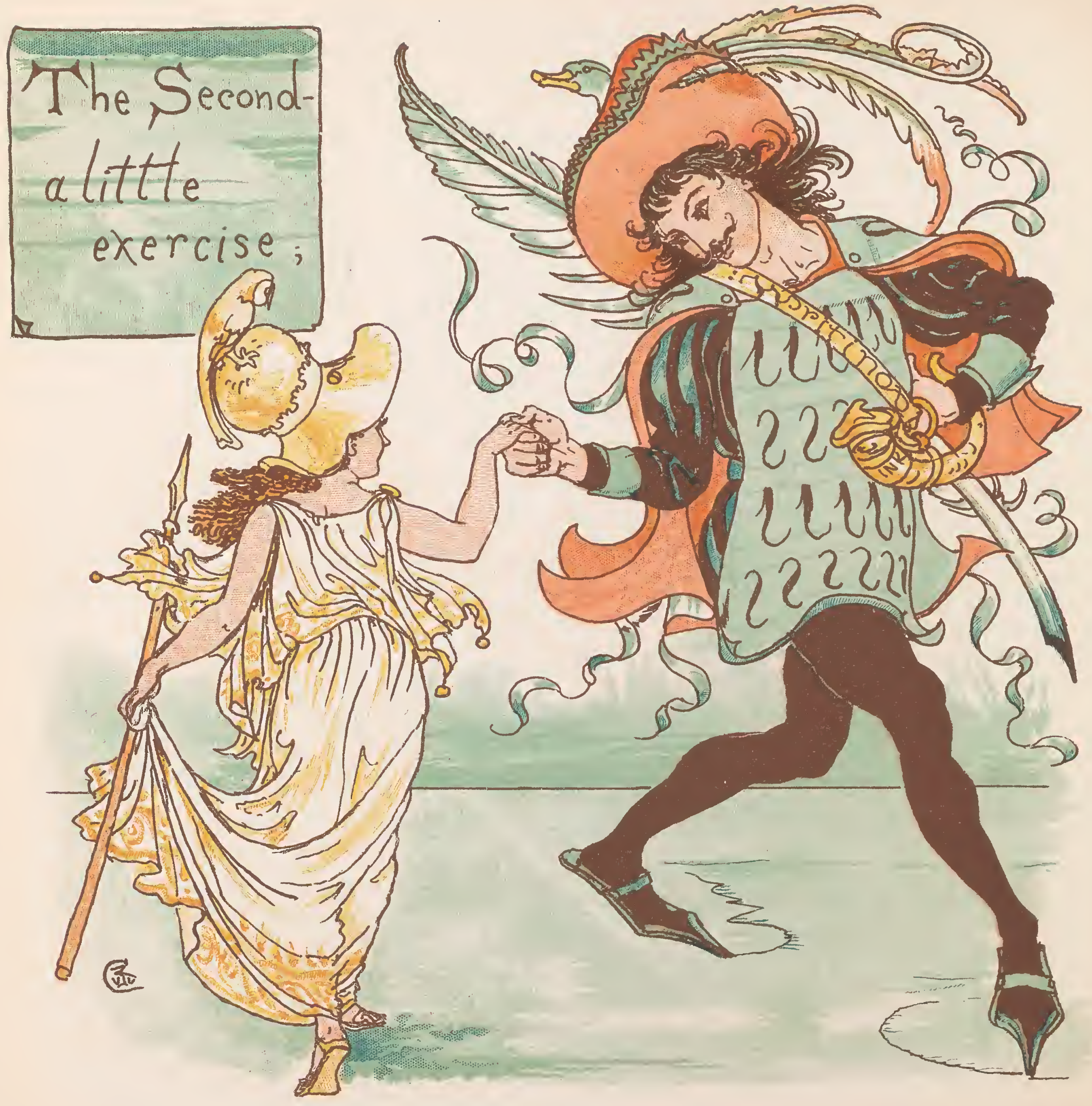




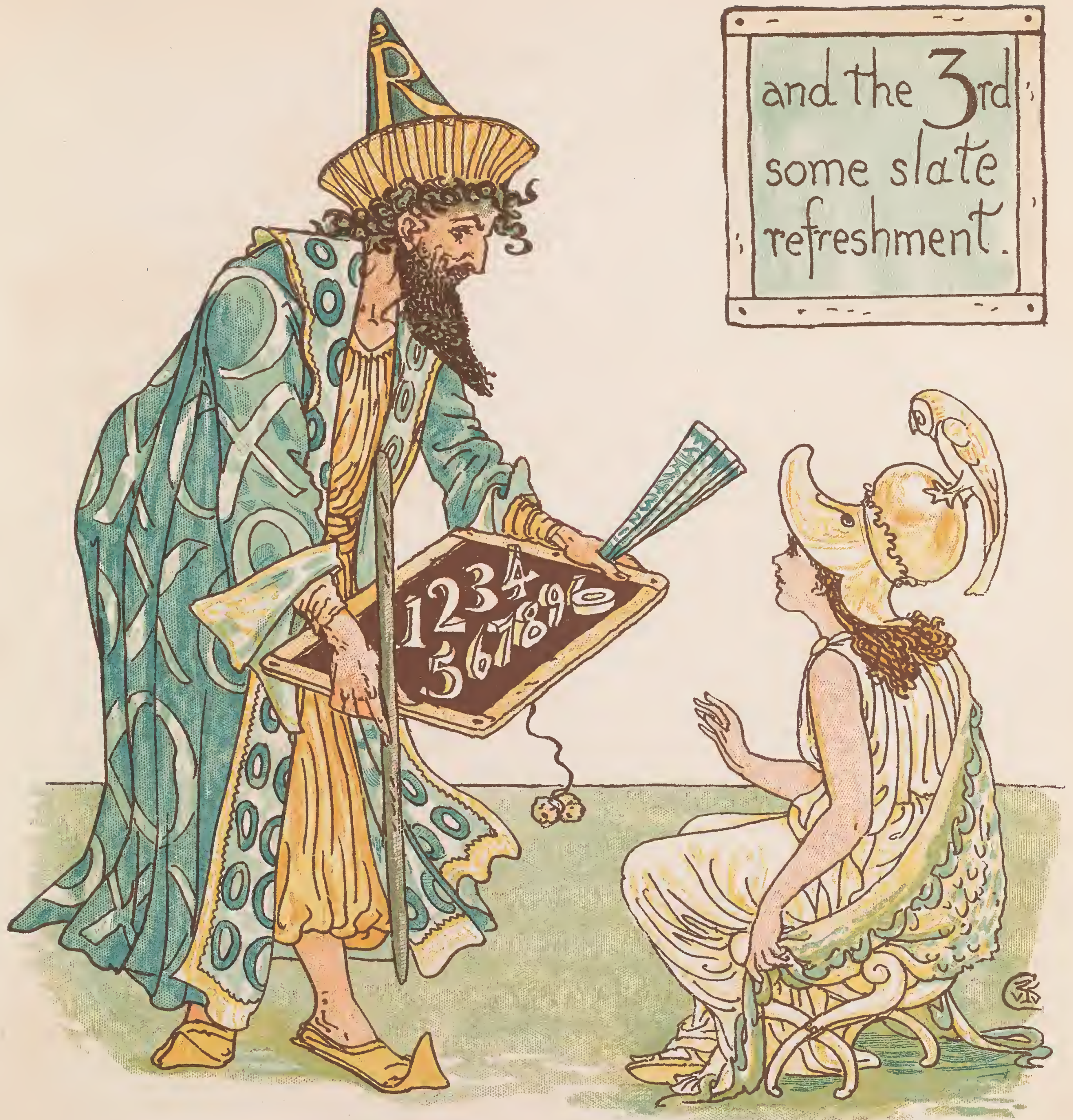




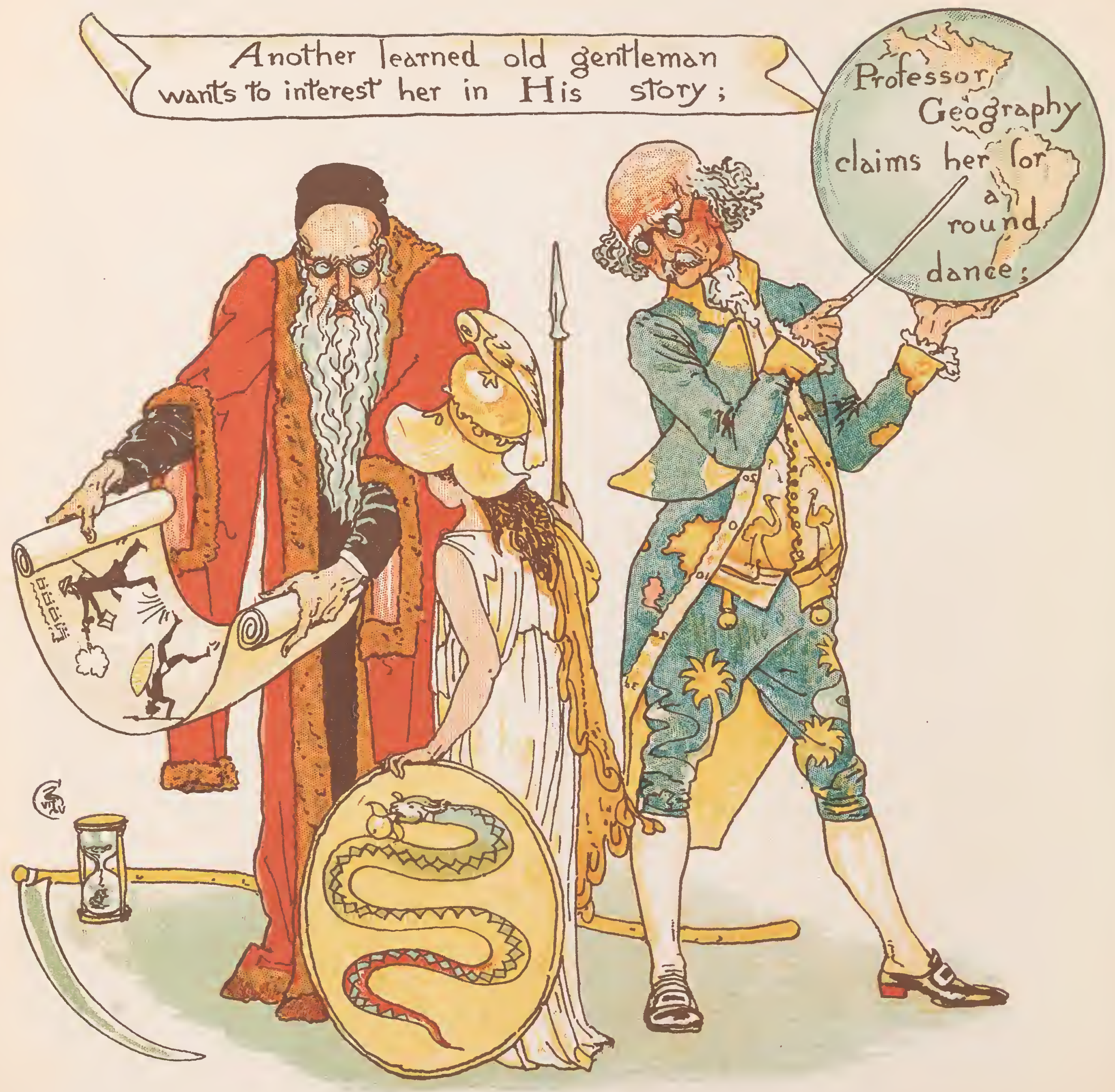




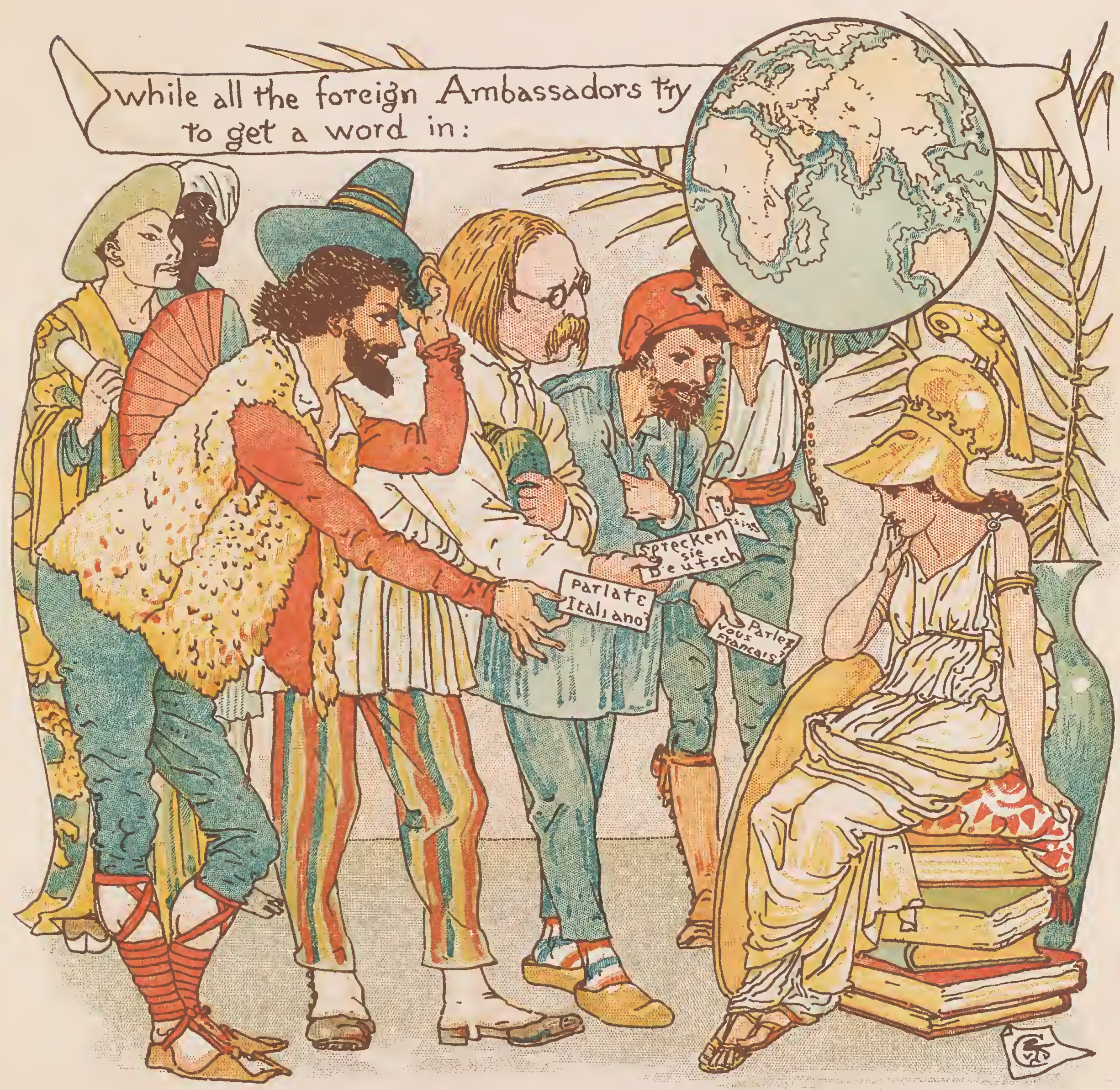




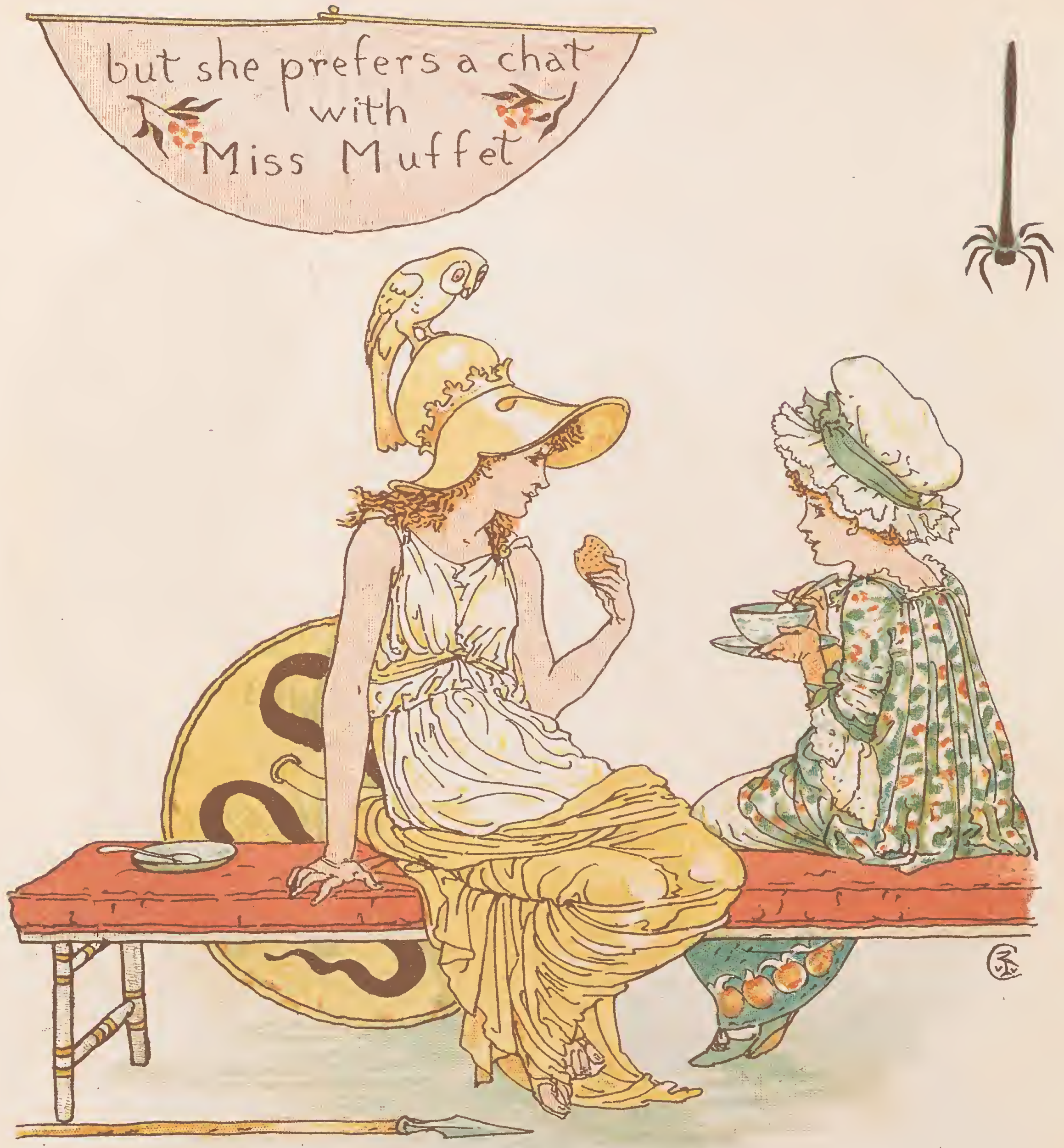




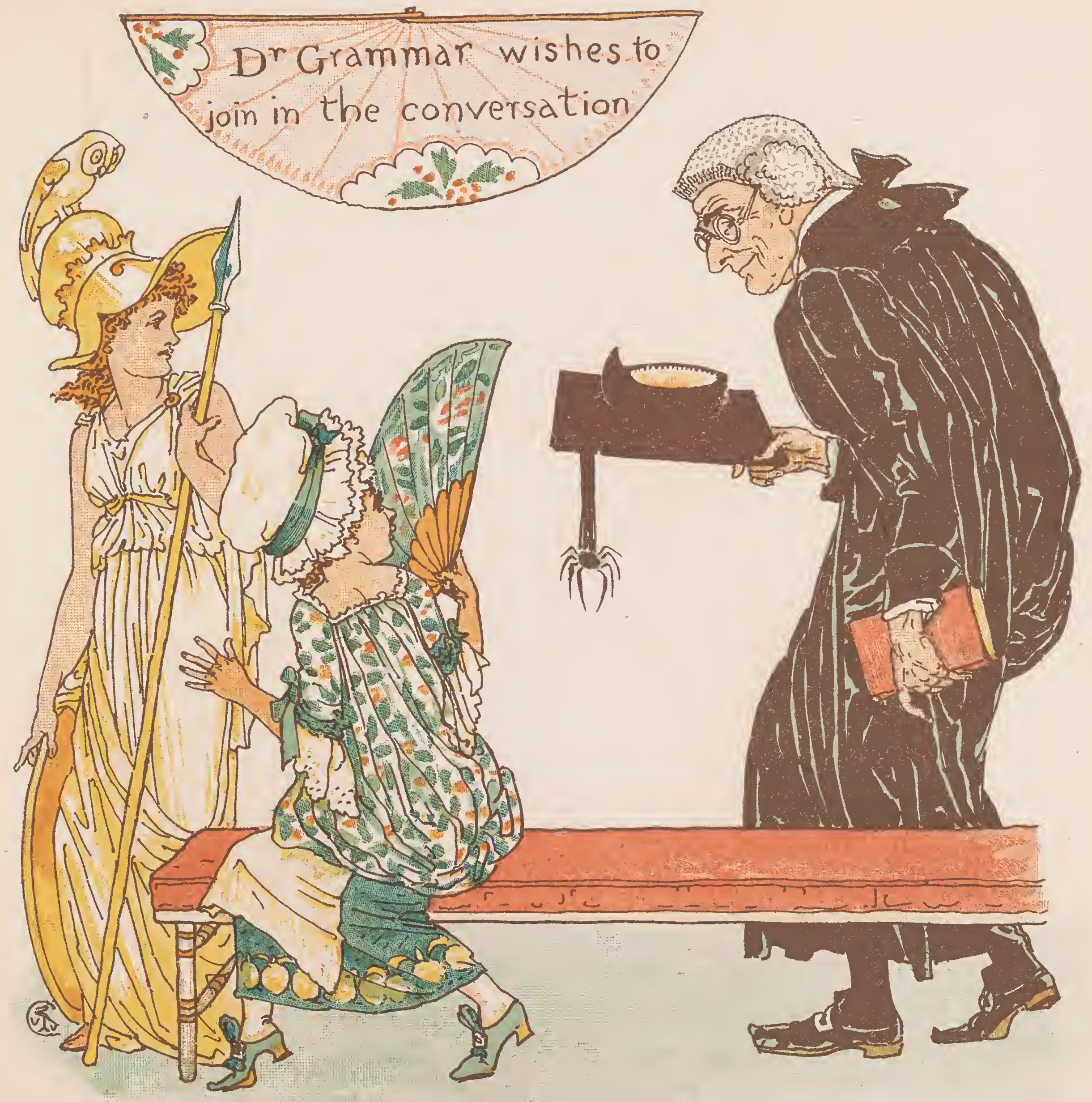




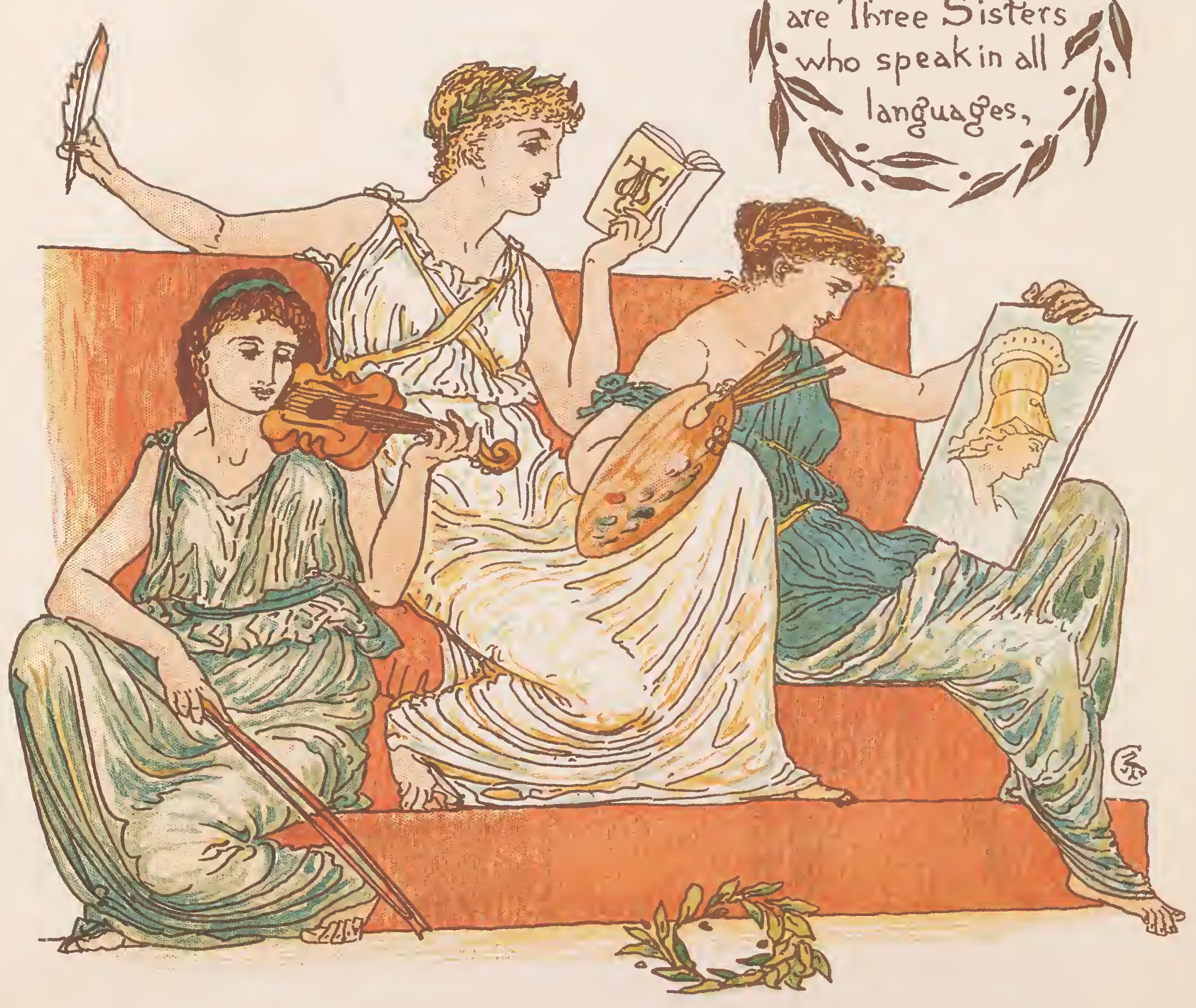


She finds them ${ }^{\prime \prime}$ It is time for all good little constitutional so interesting that Queegs to be in bed": she forgets how rime goes, unil MrsGrundy/ Po (an old lady who minds everybody's 1. business) says
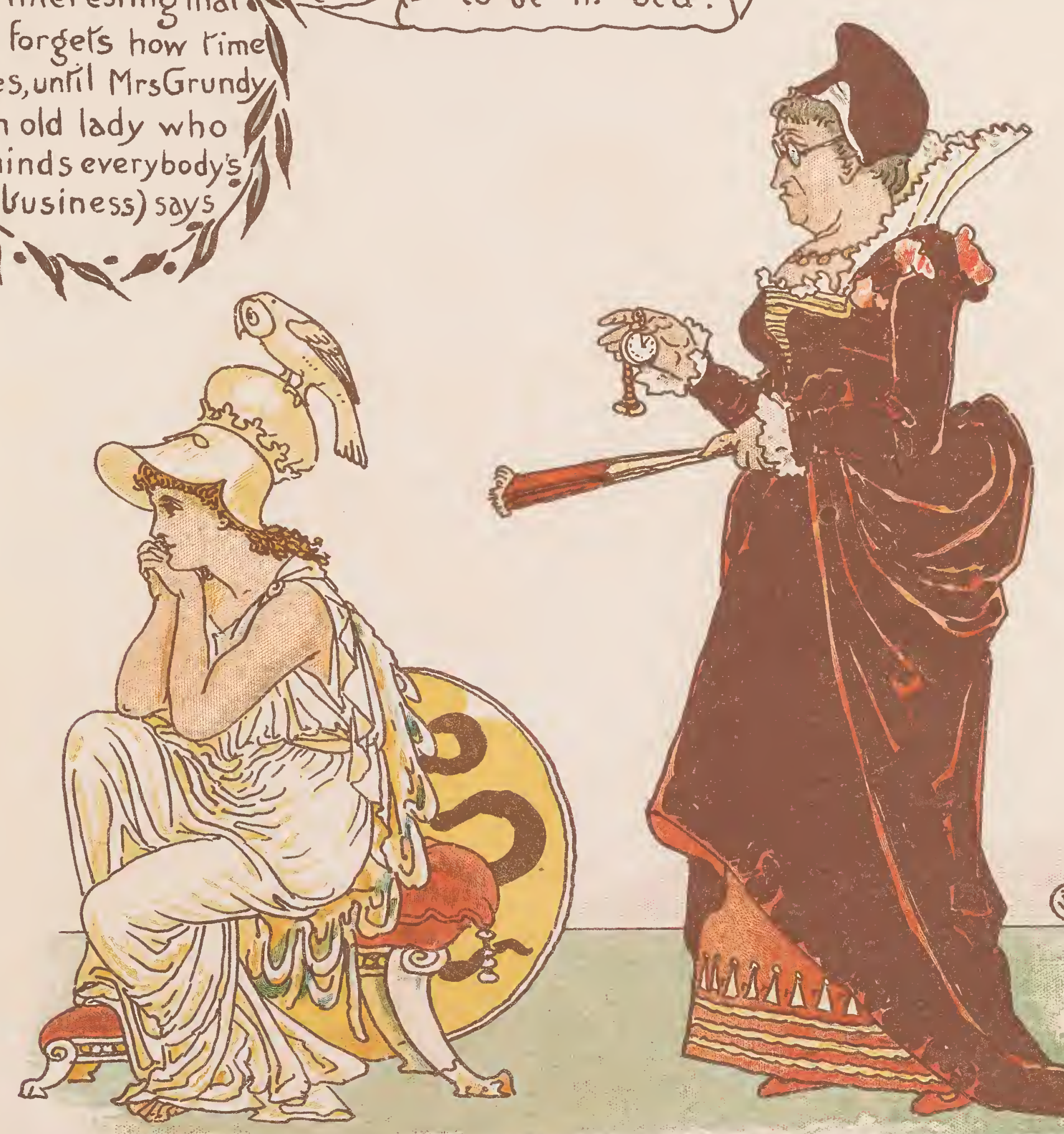


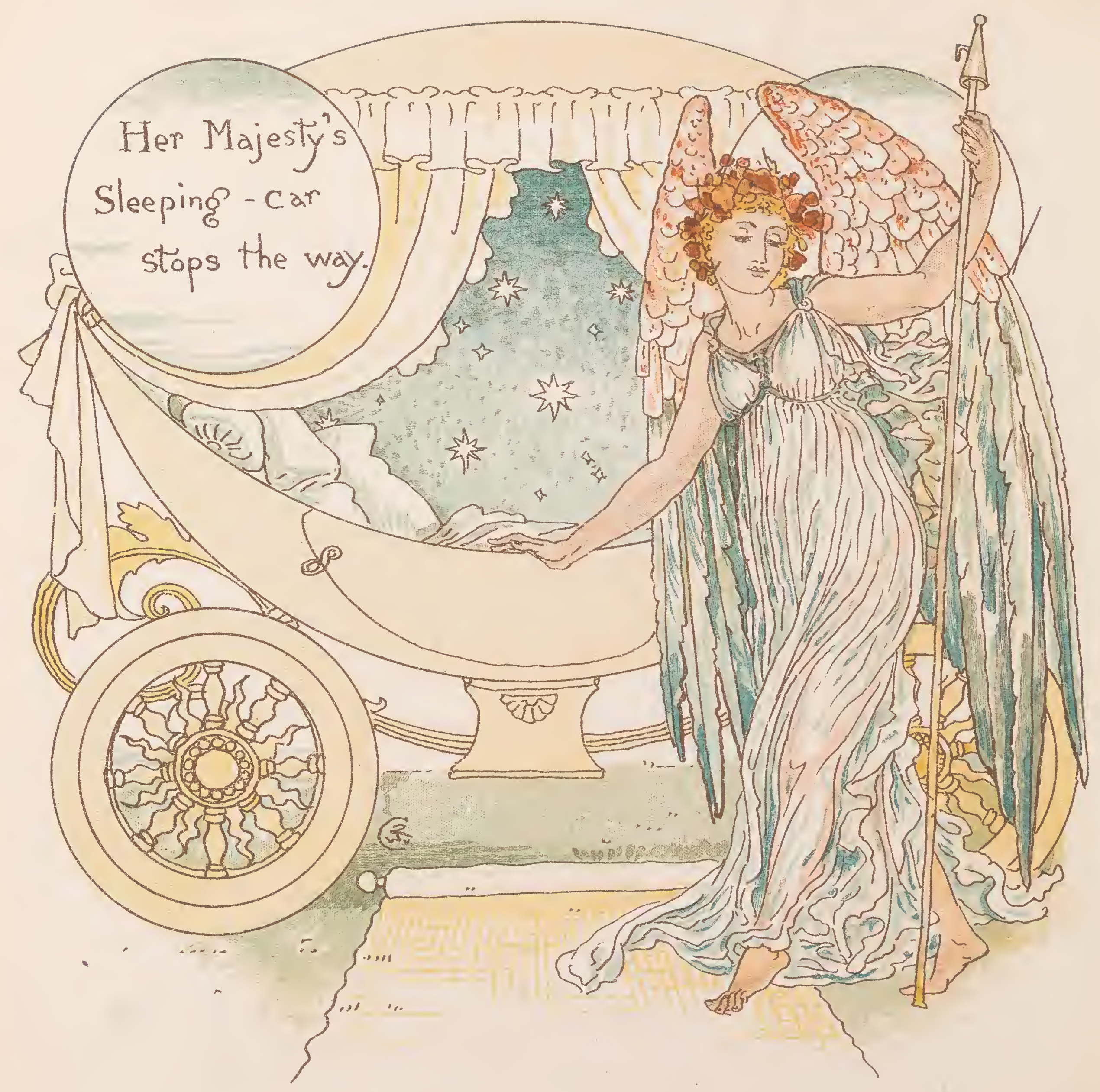




$$
8
$$




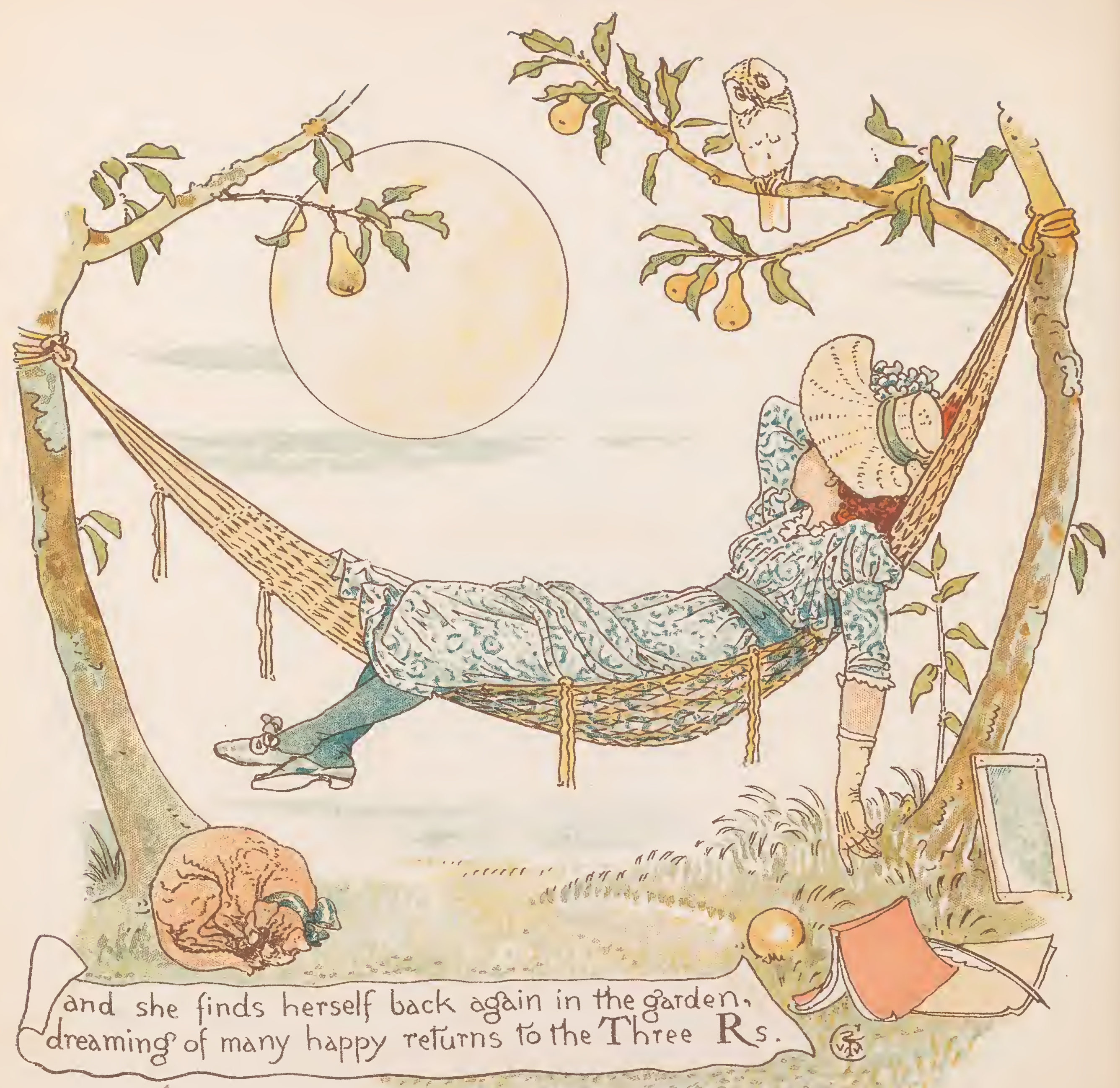




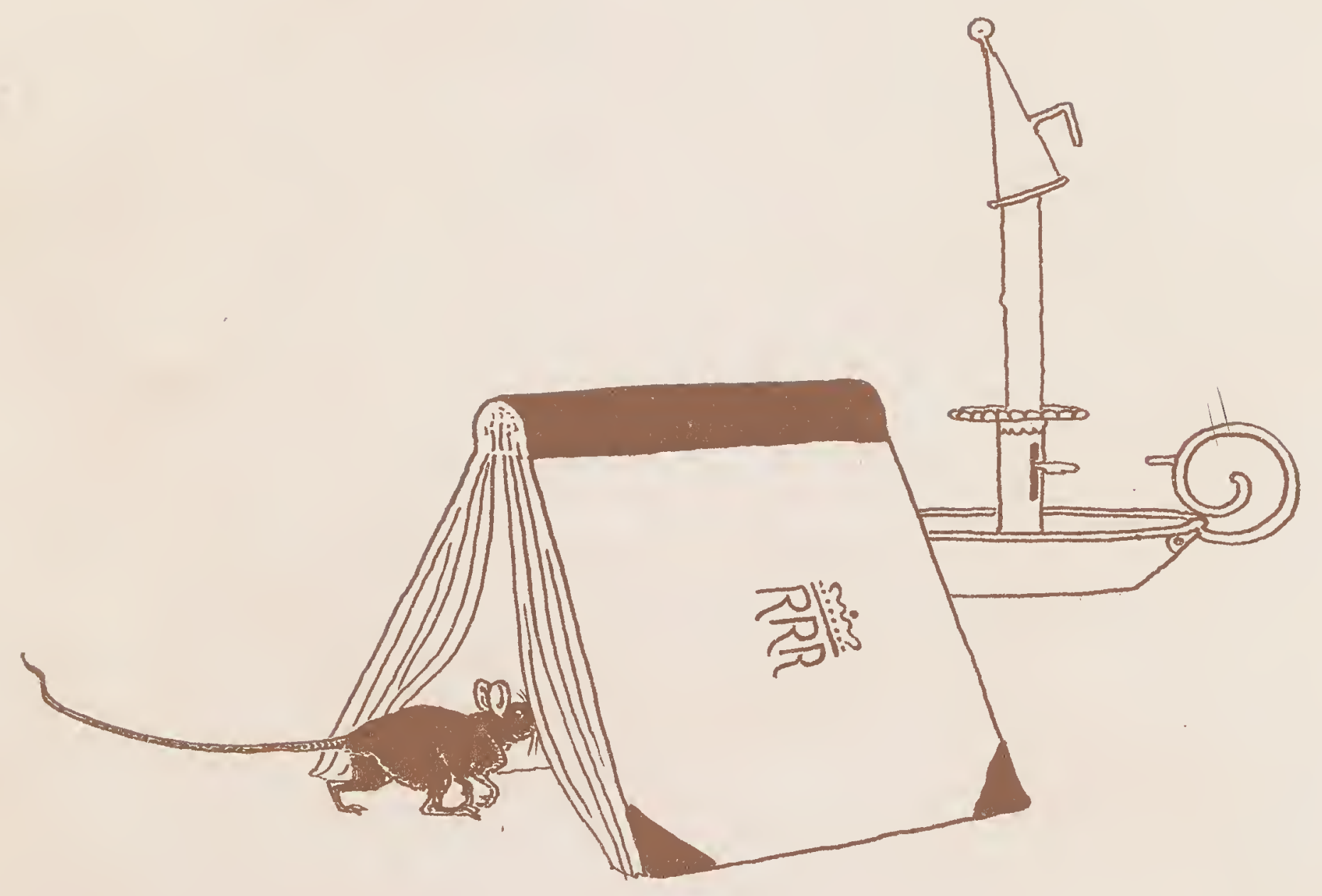





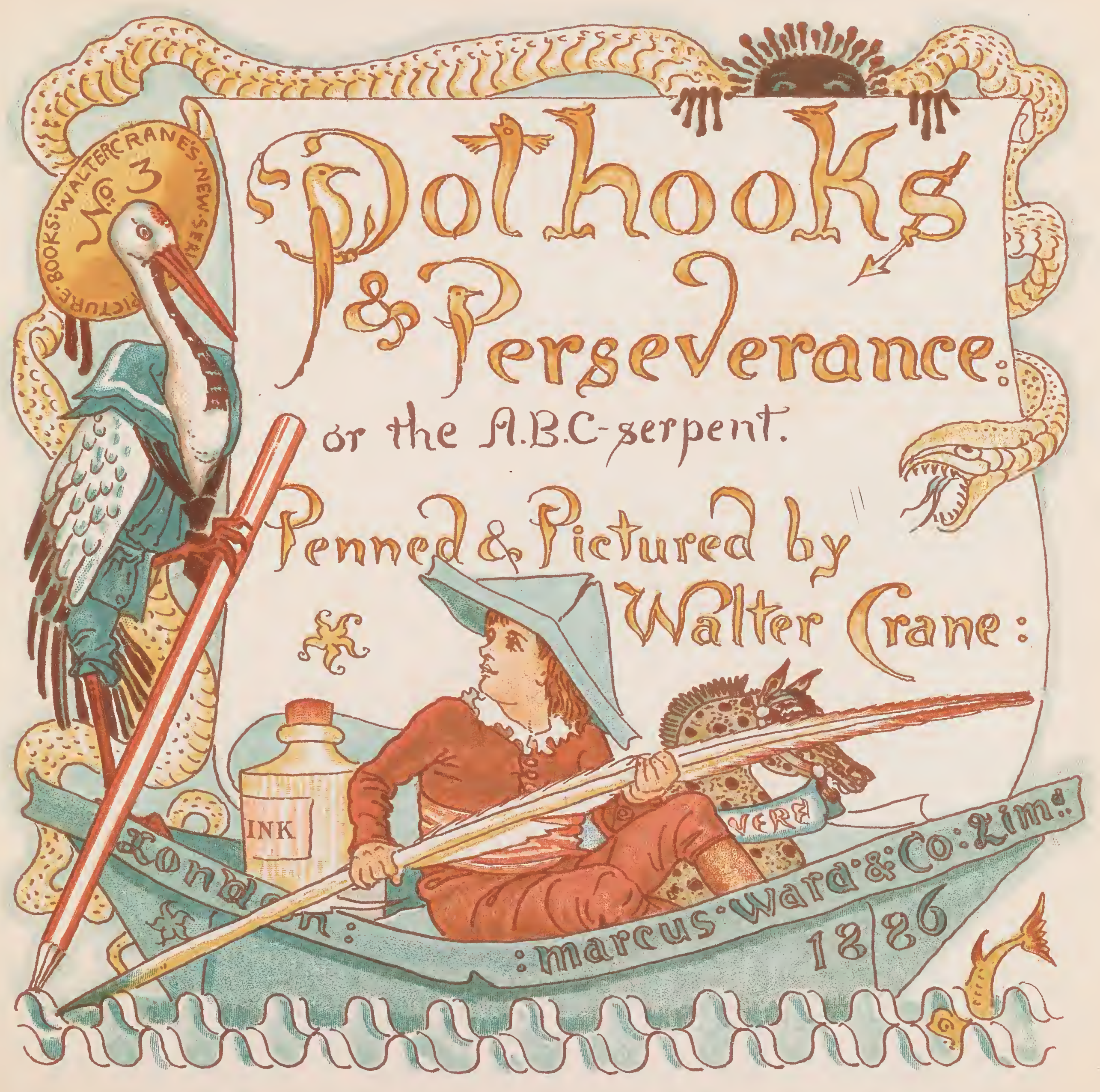




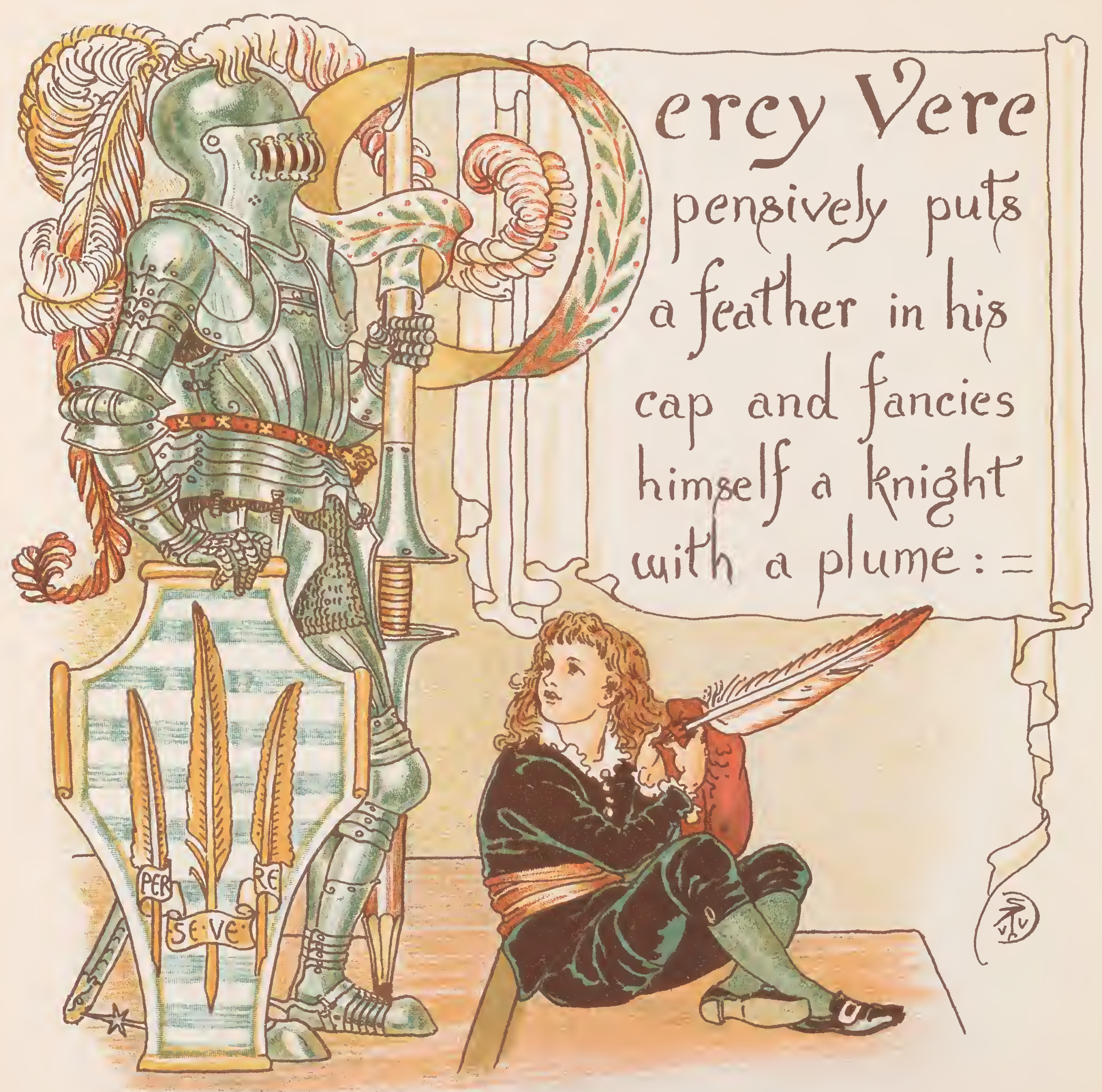




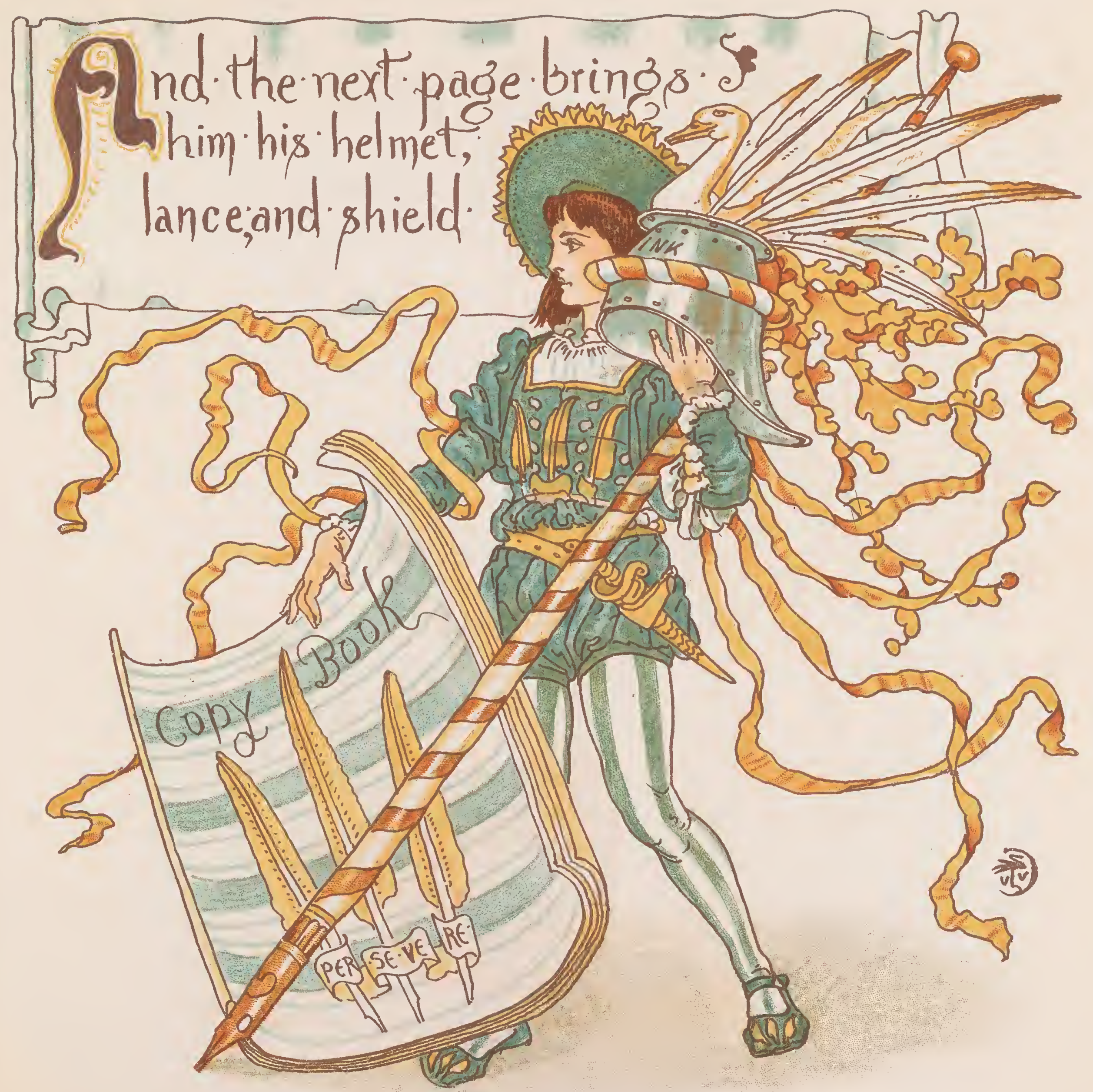




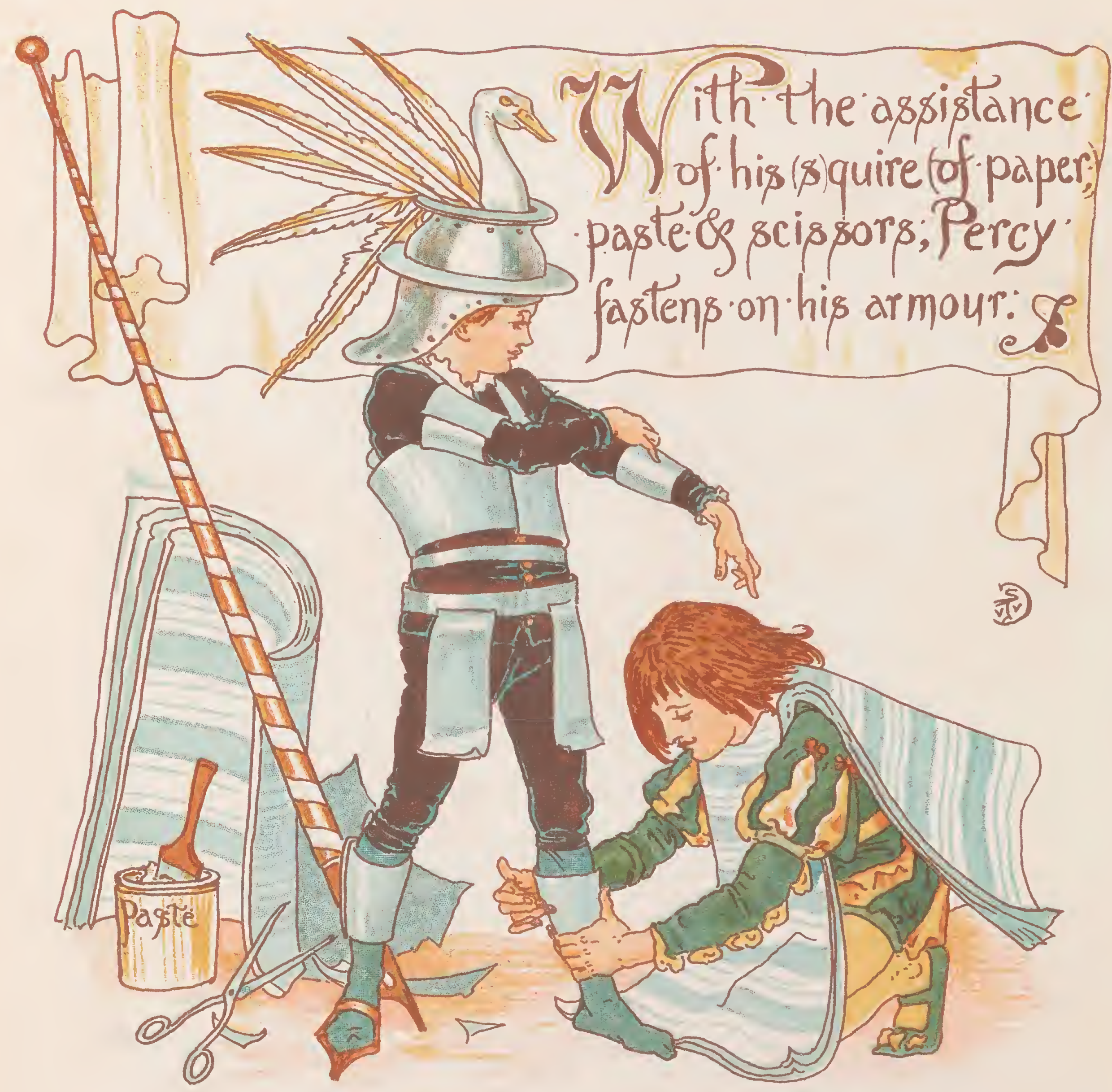




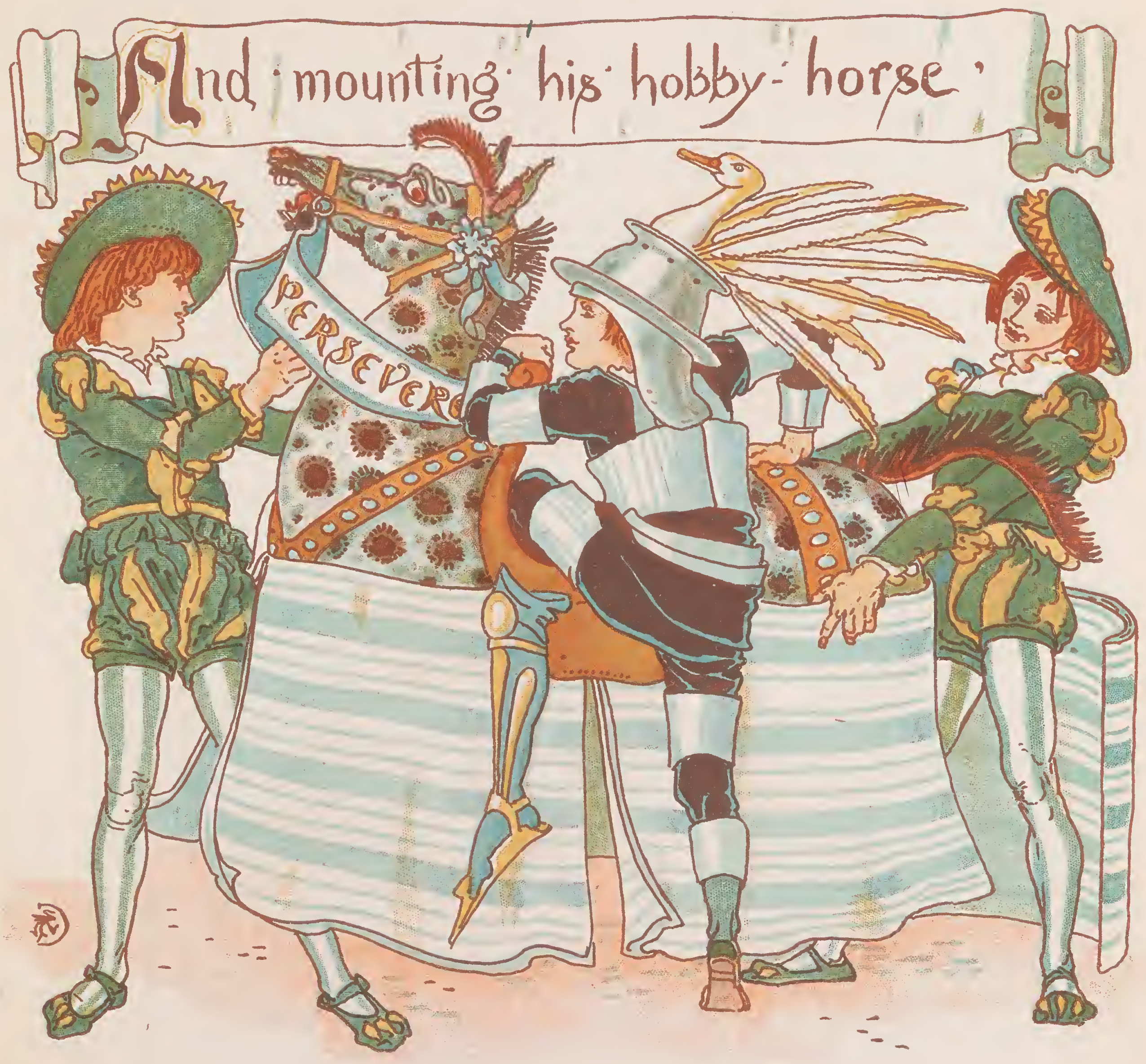




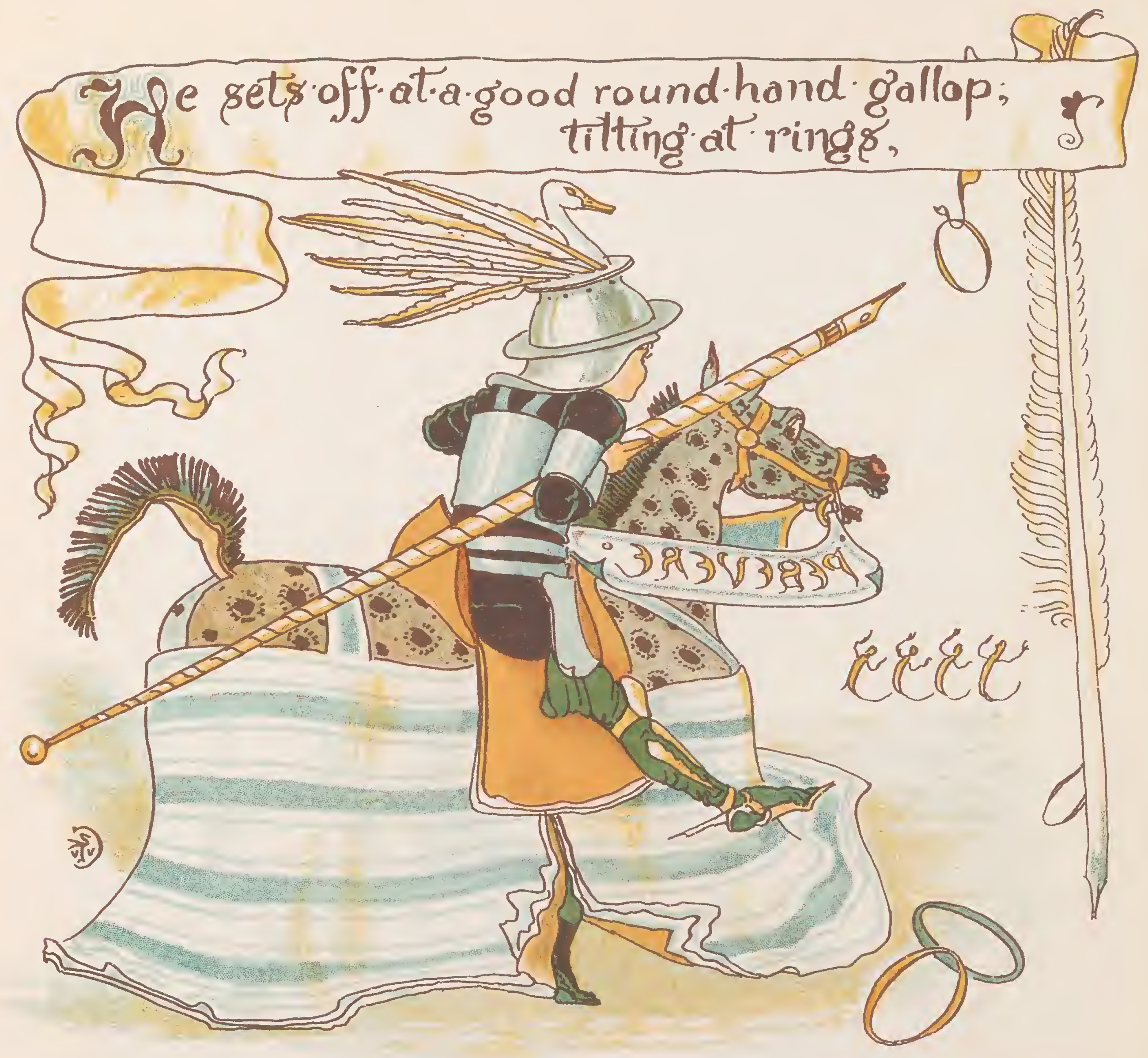




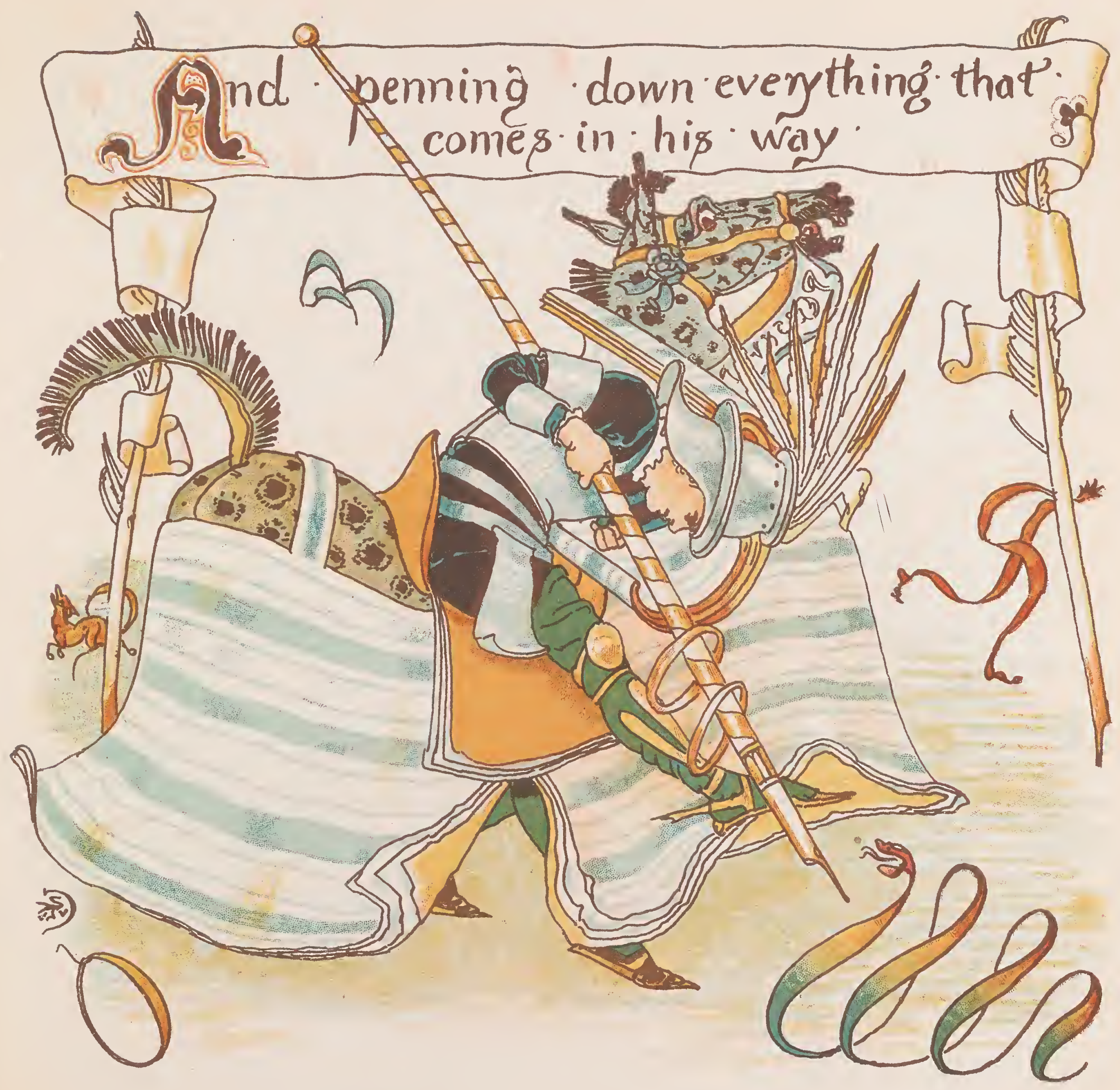




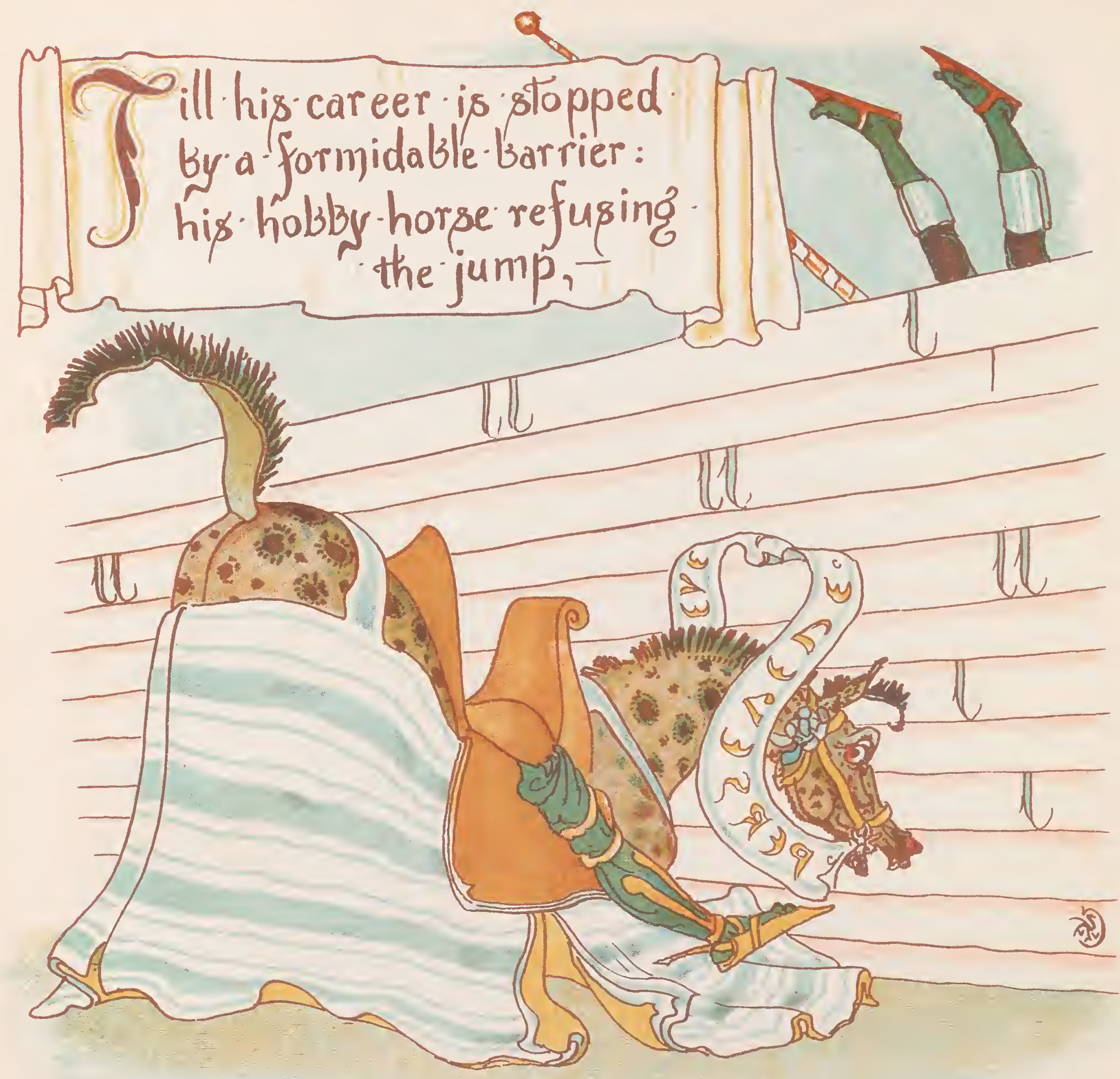




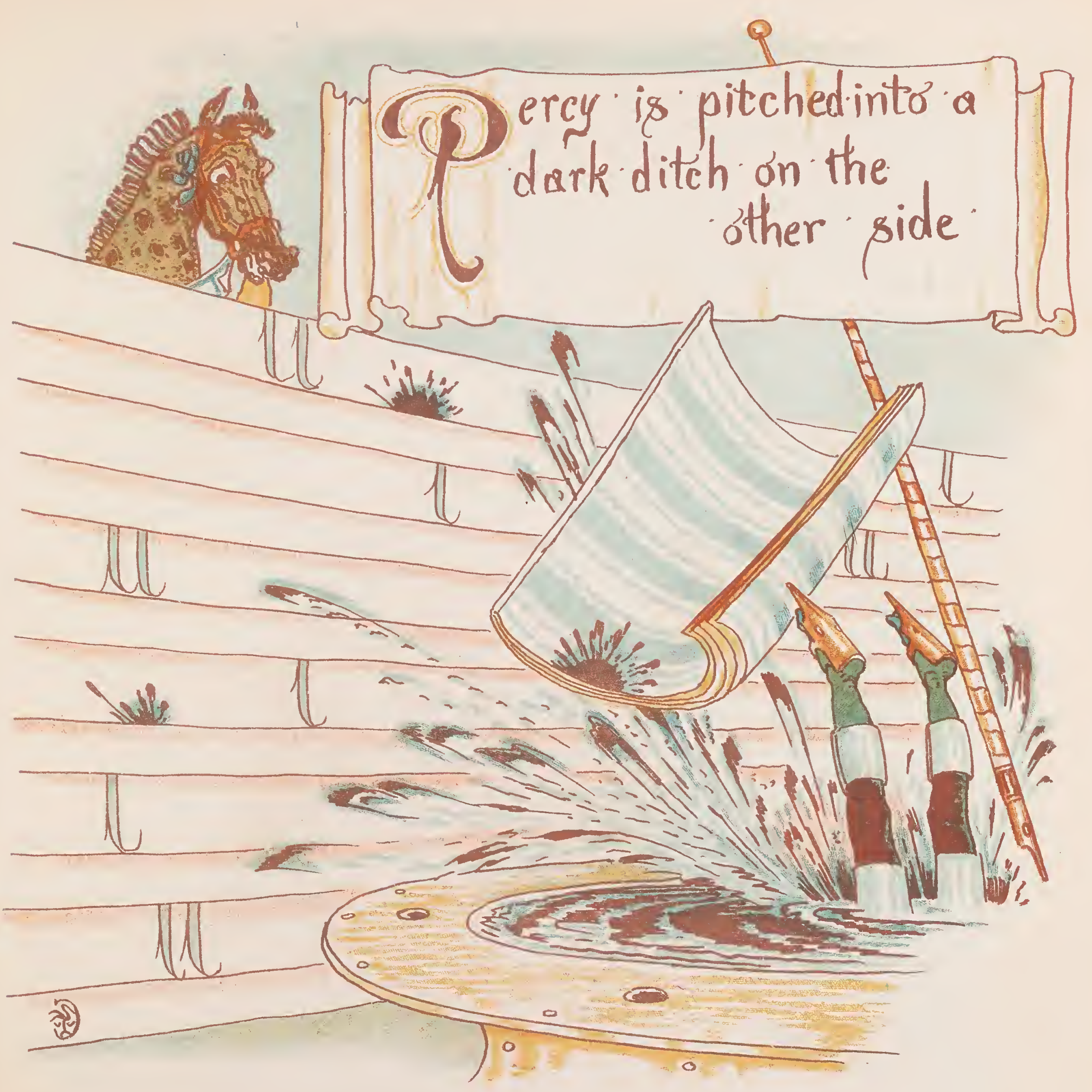




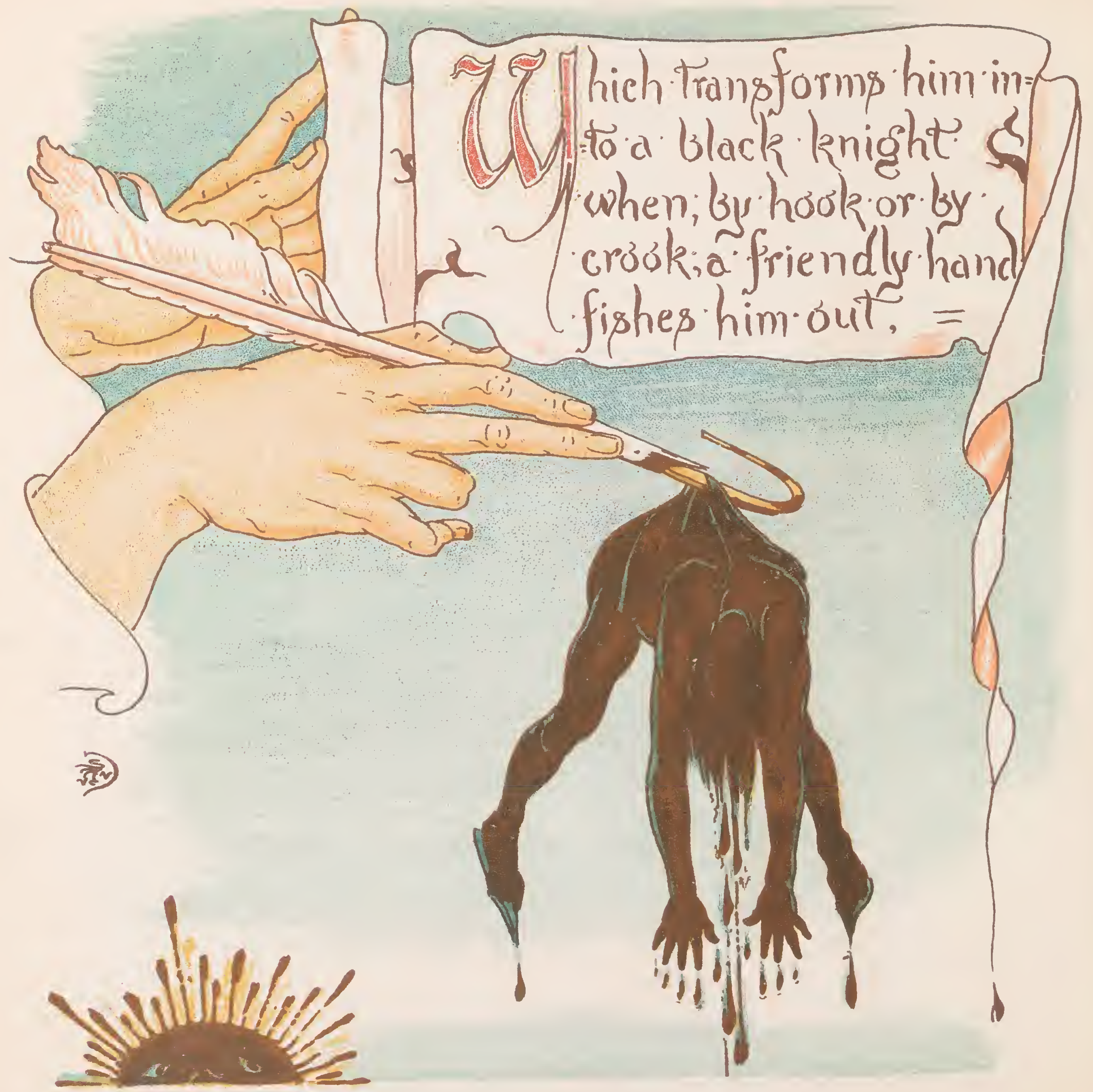




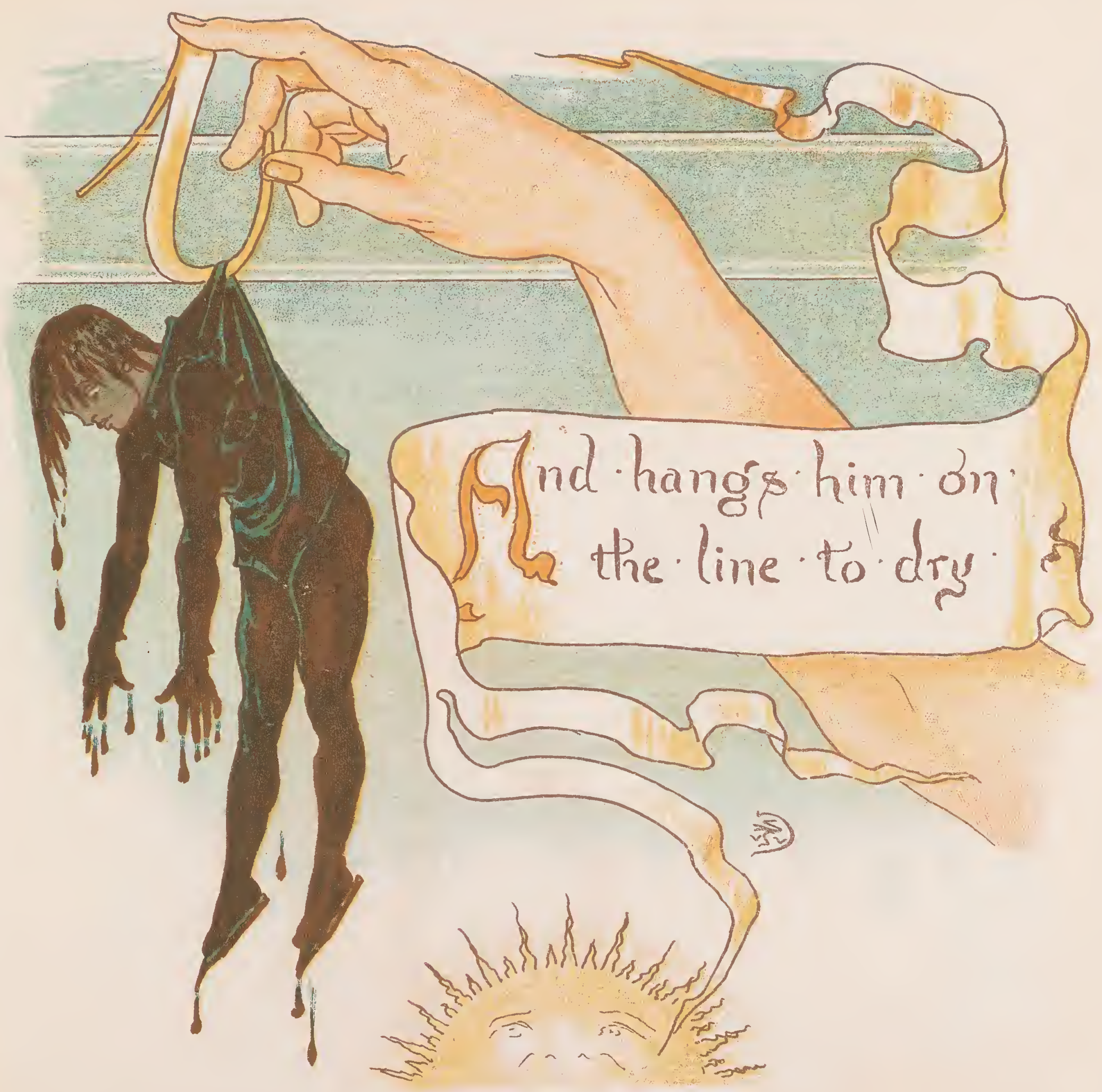




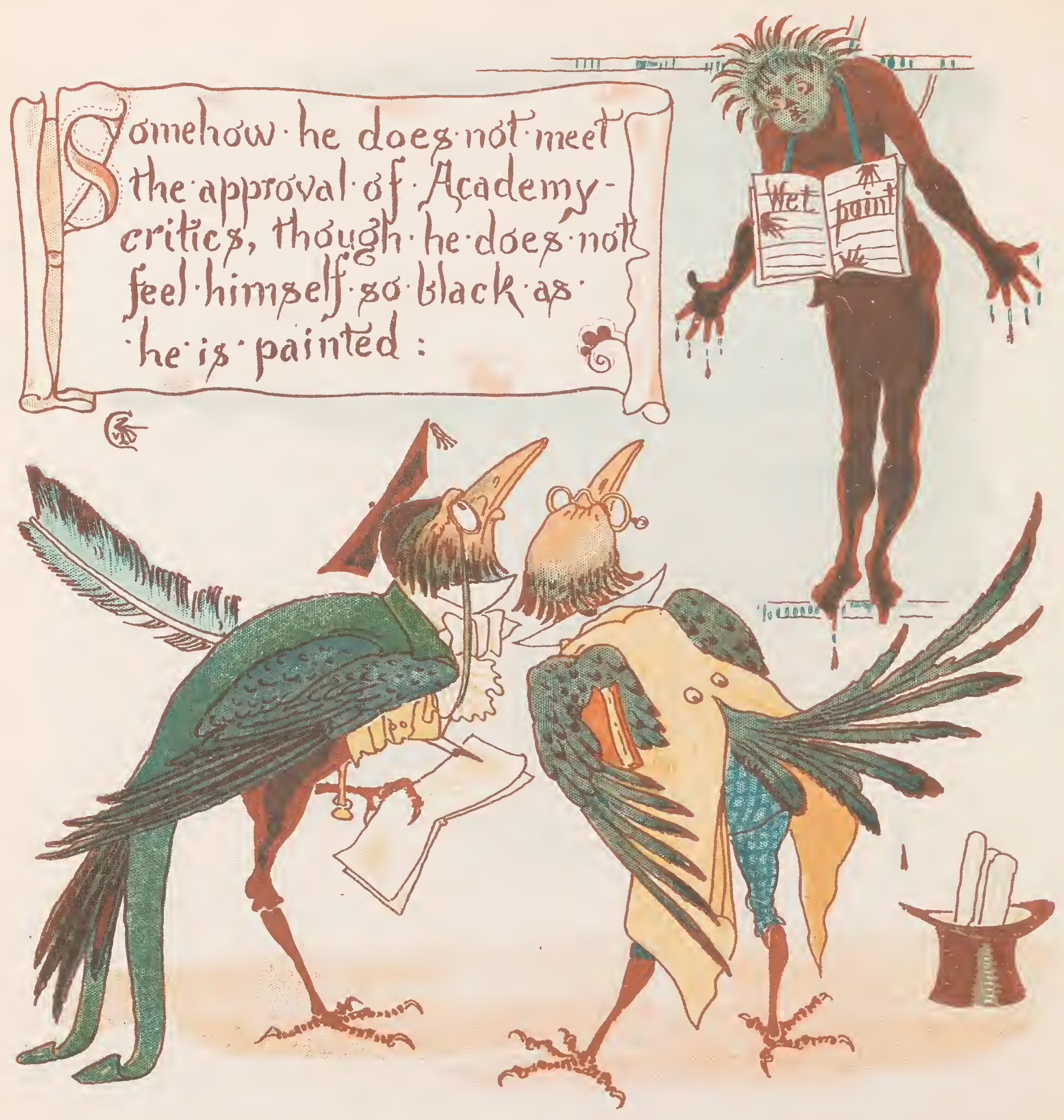




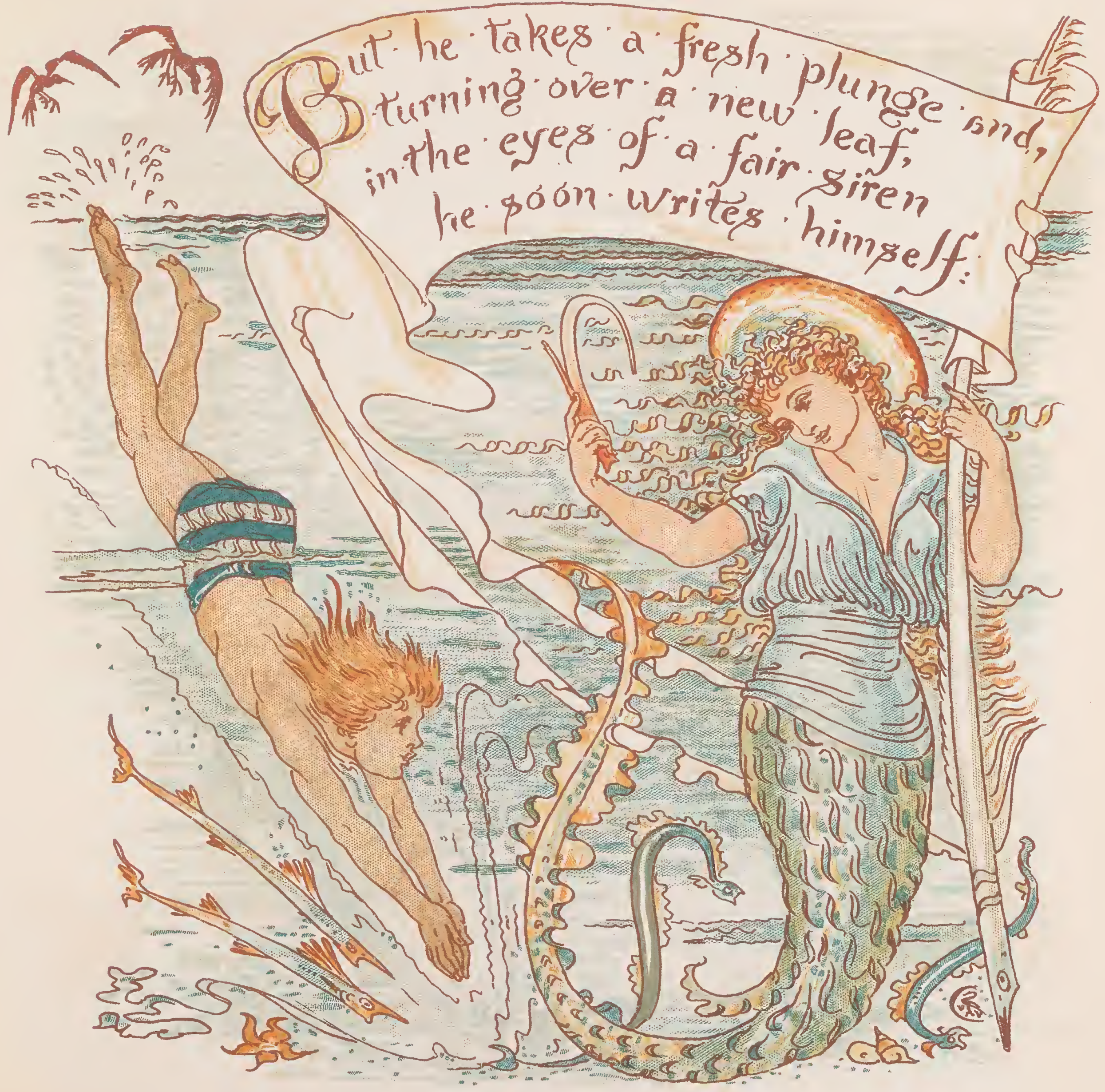


Roming up again with a Capital appetite, (C) a fter a long course of pothooks and F hangers, he is

$\left\{\begin{array}{l}\text { transported to find } \\ \text { it is dinner.time, } \\ \text { feeling ready for any }\end{array}\right.$ 


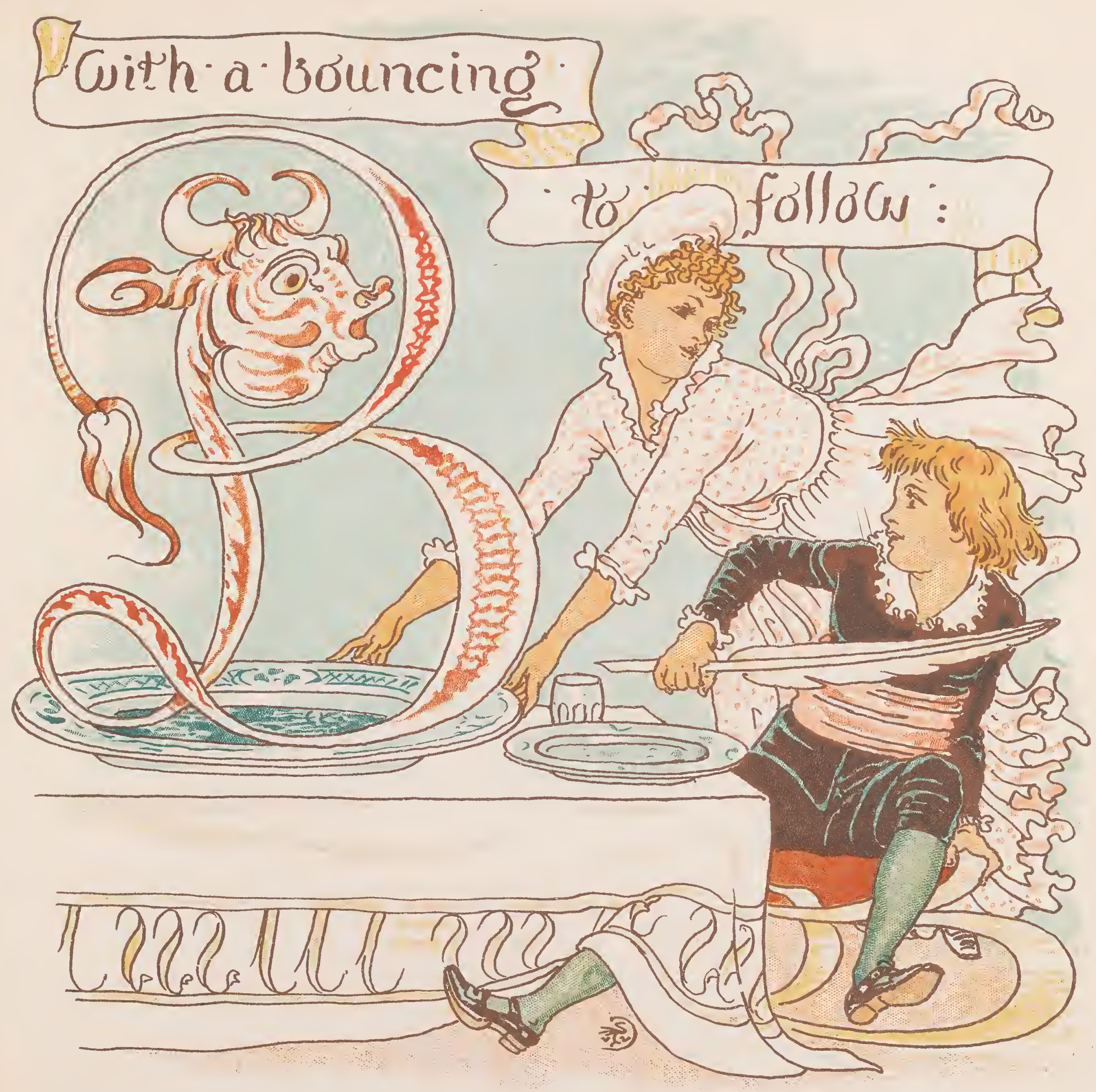




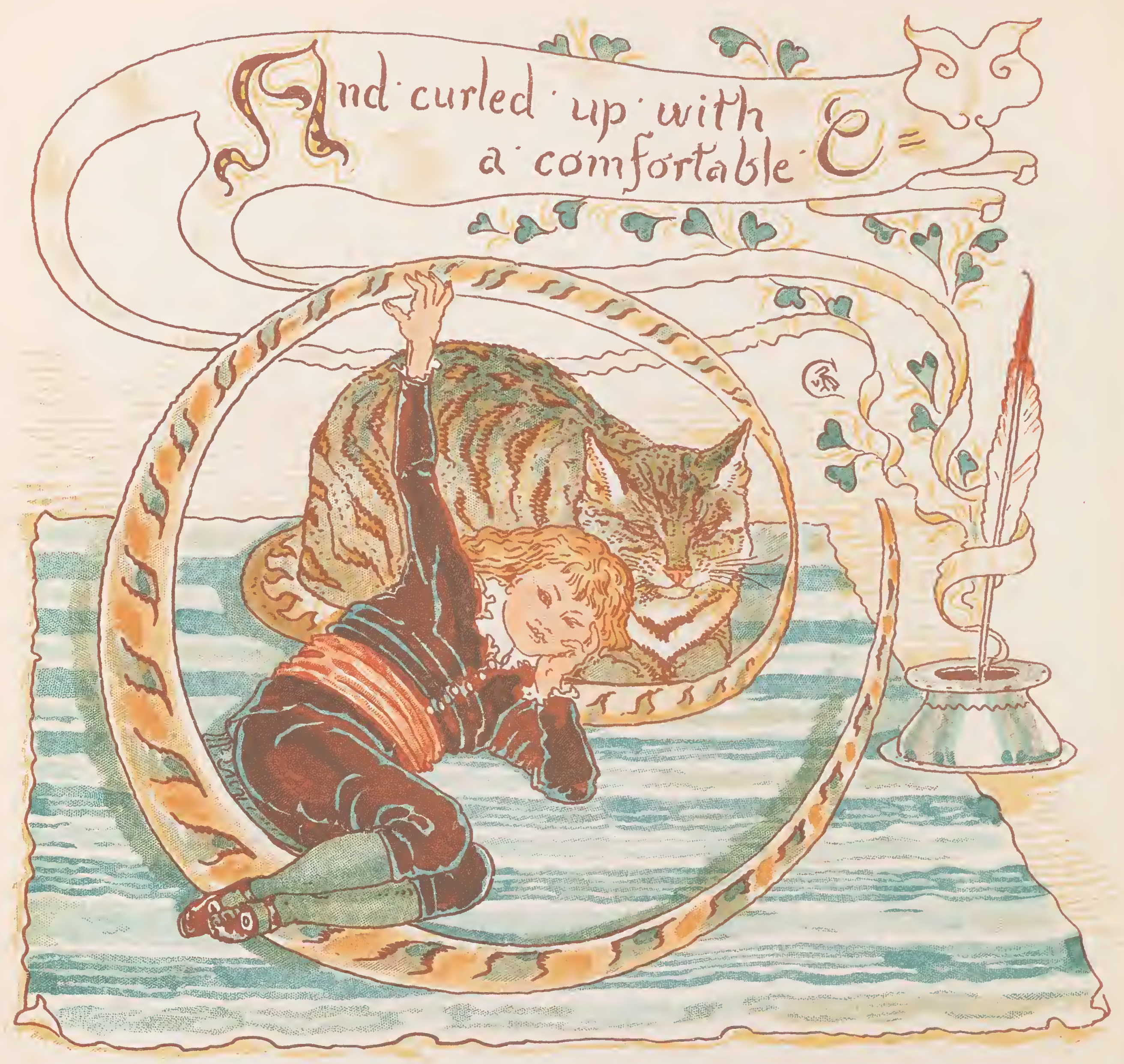




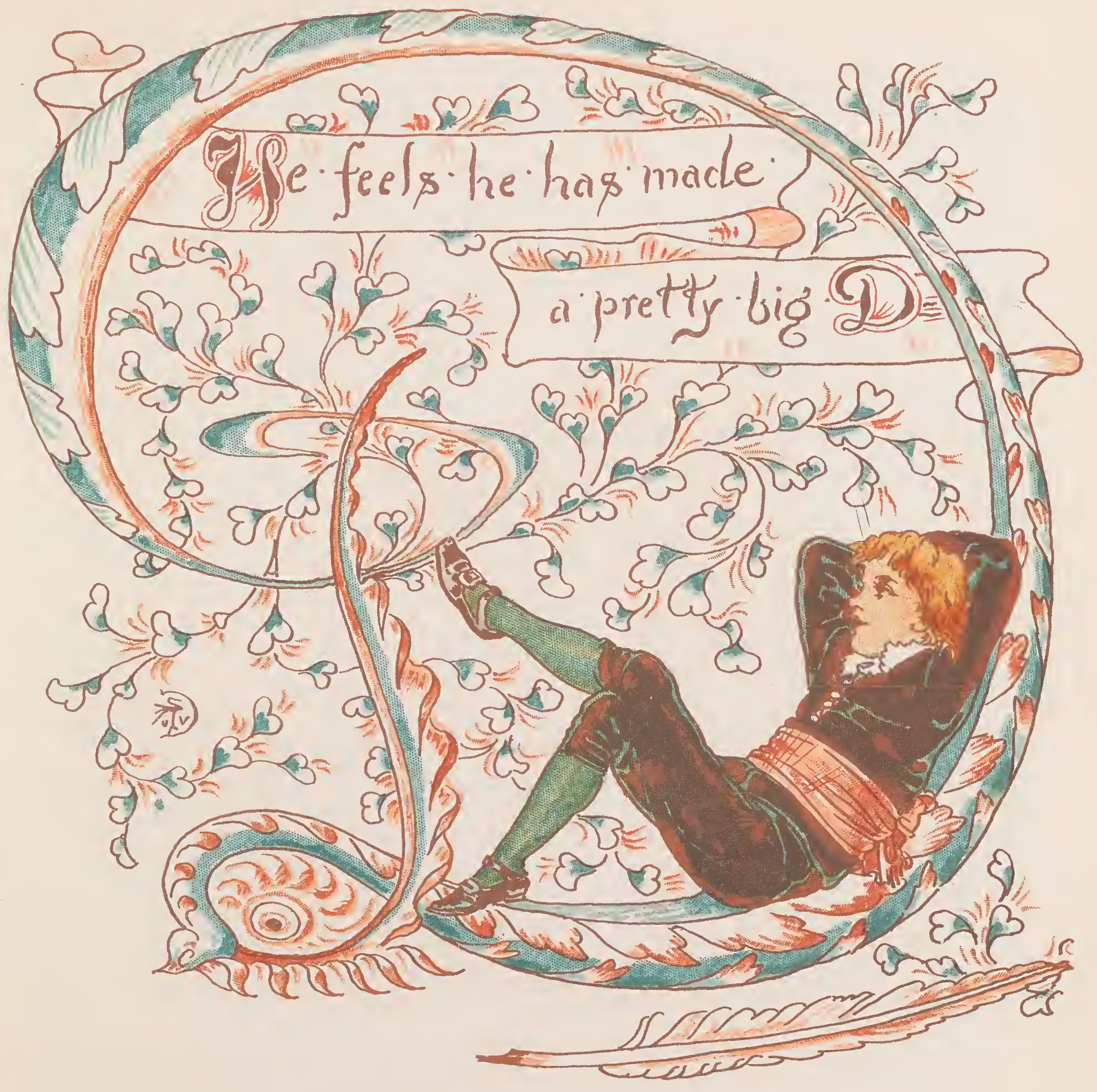




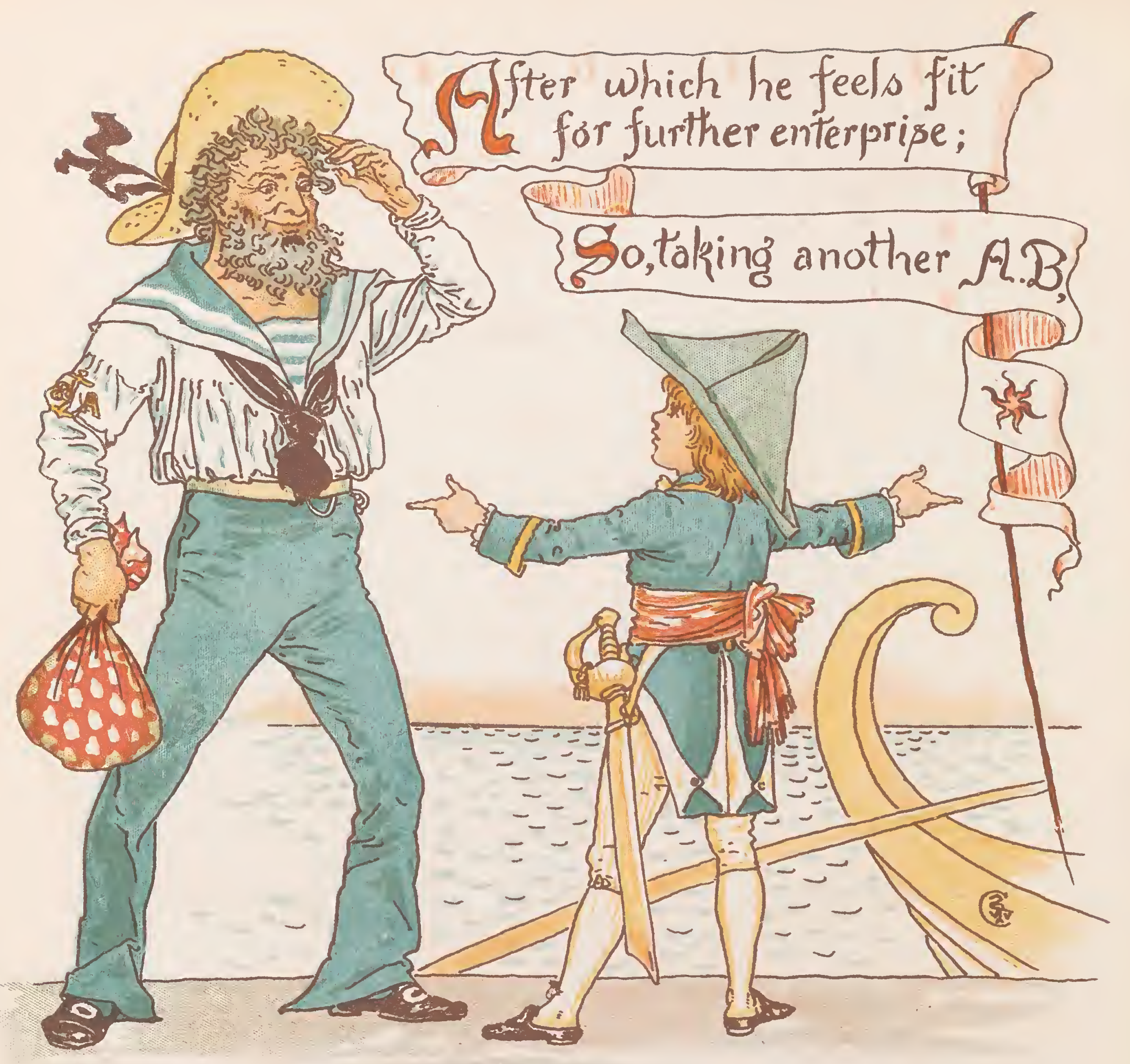




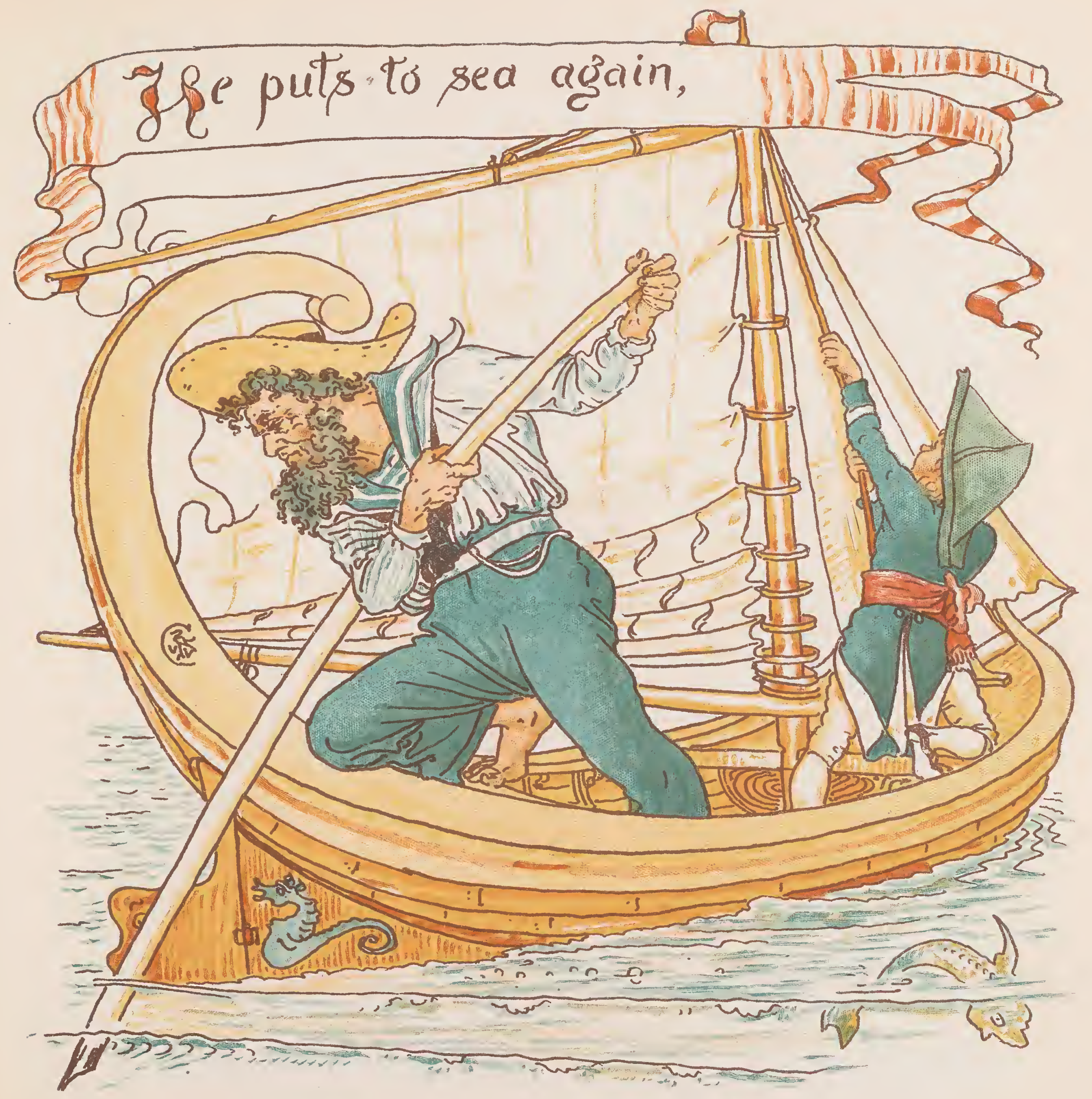




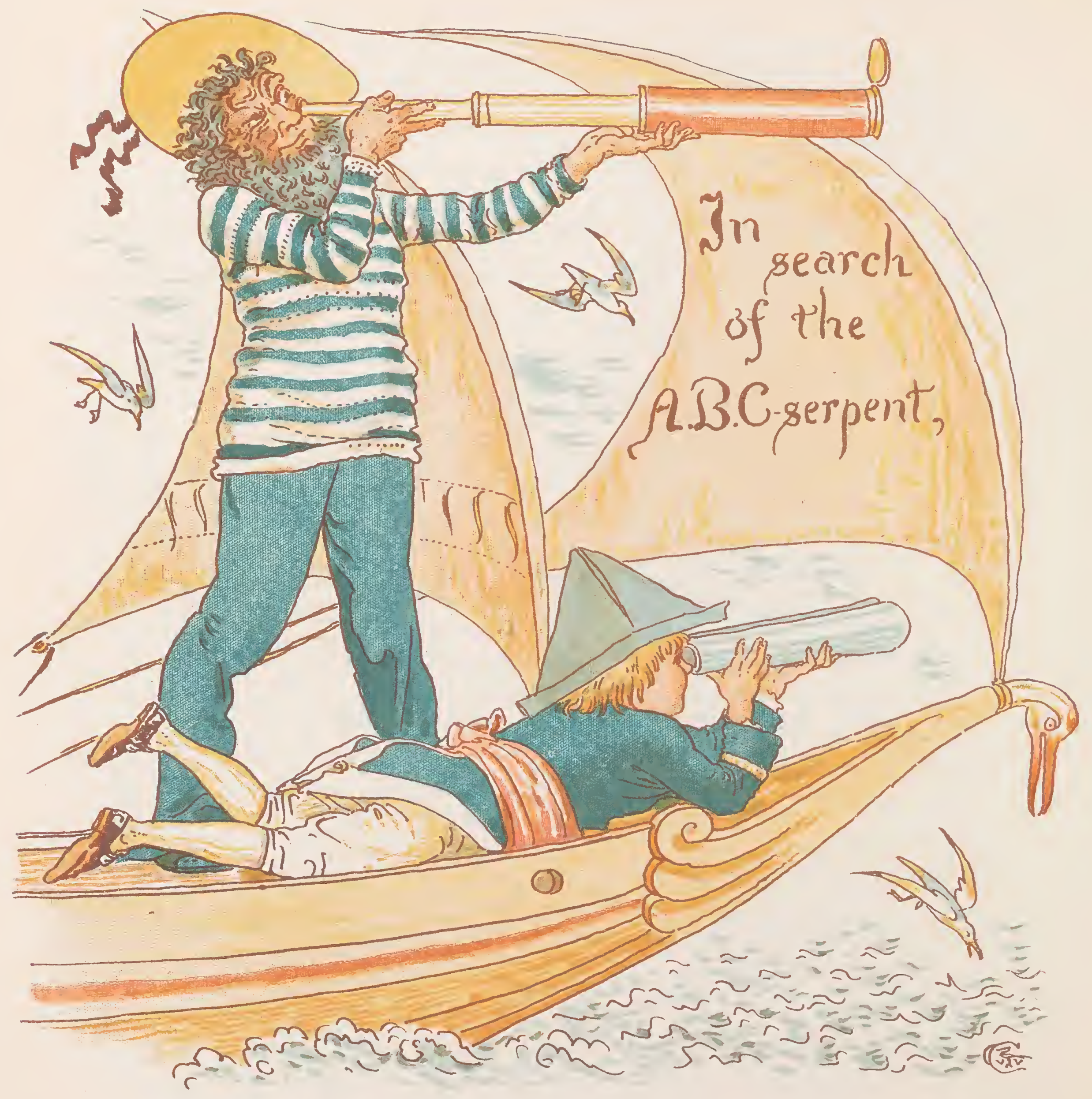




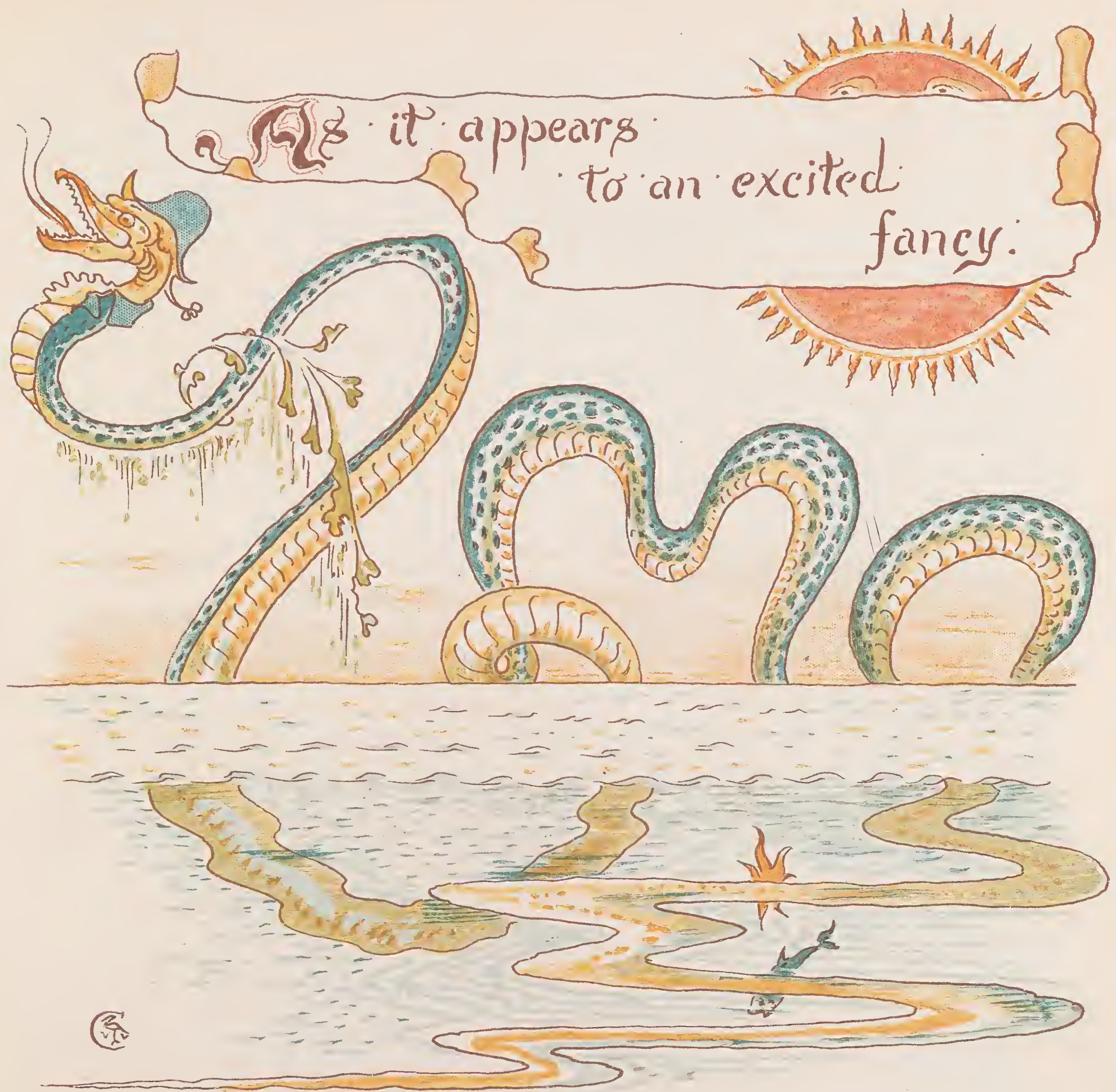




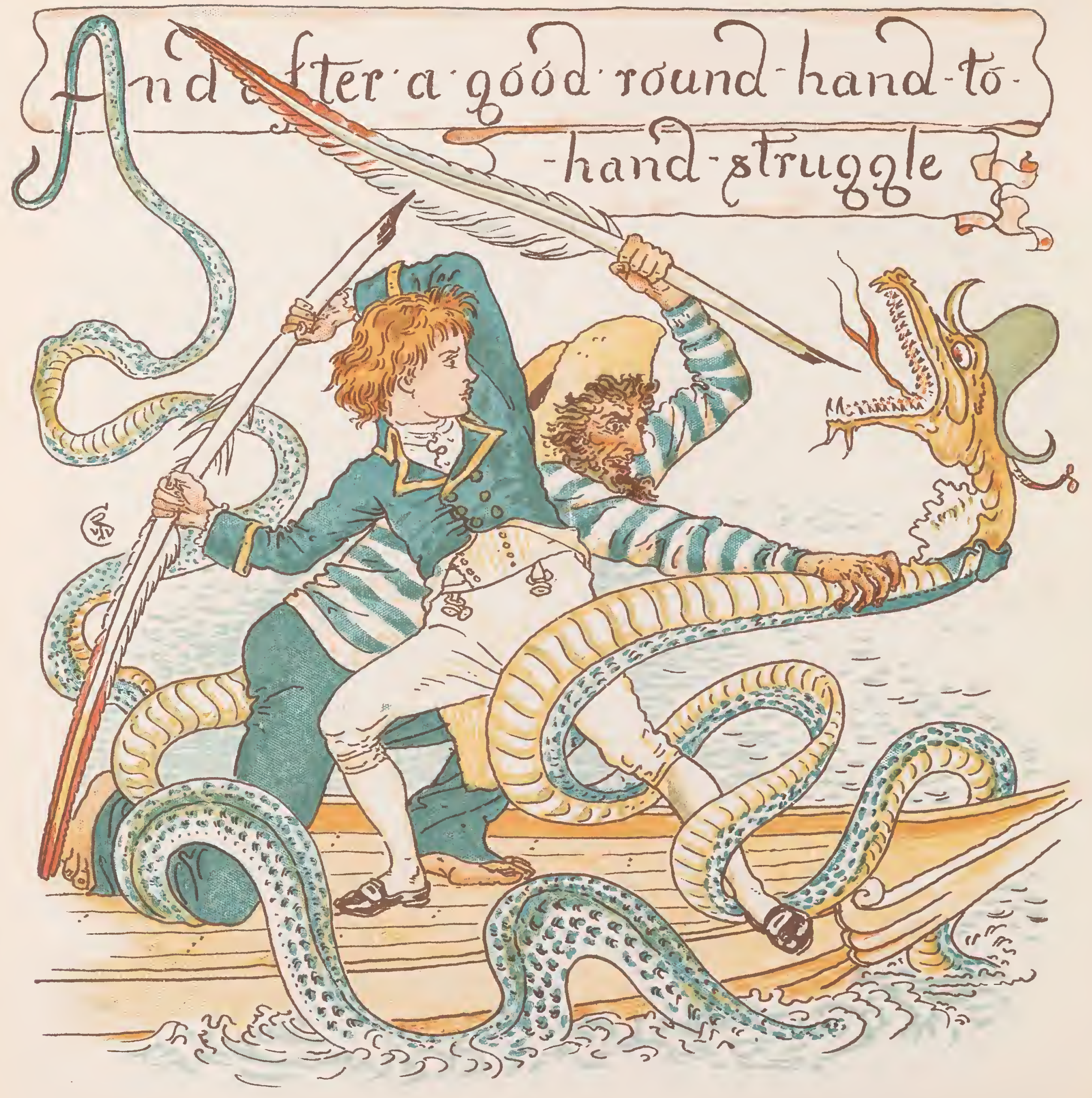




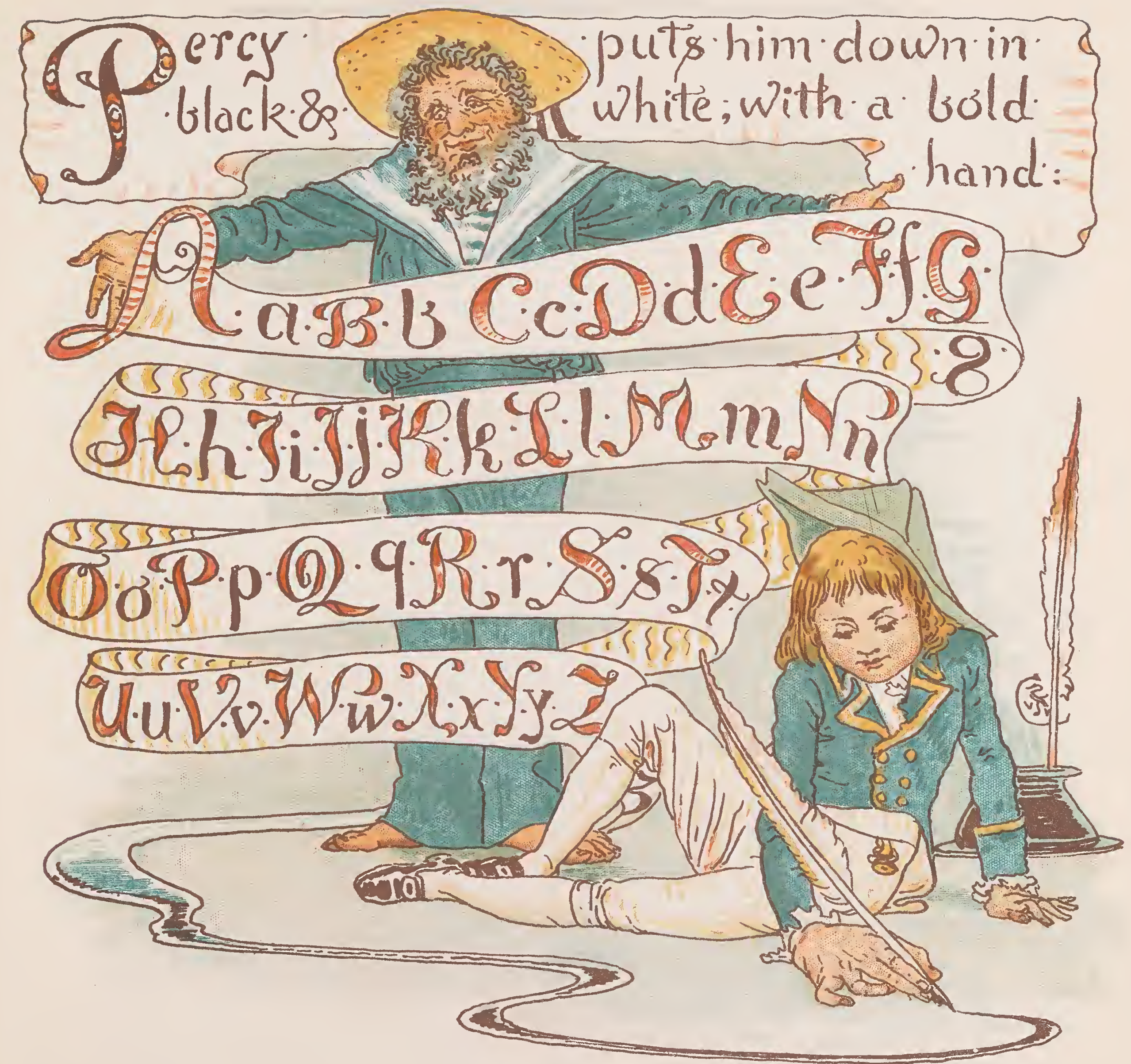




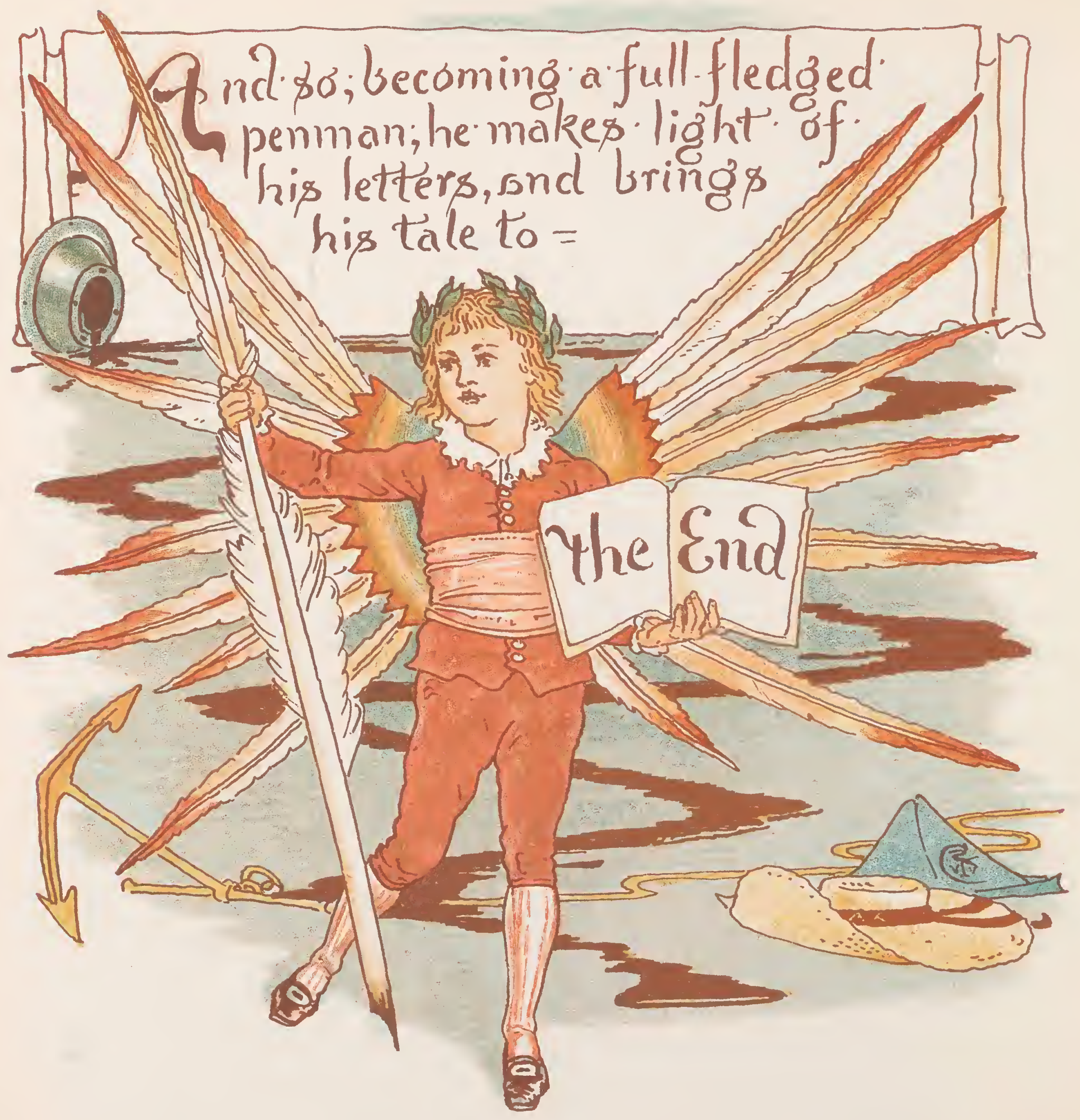




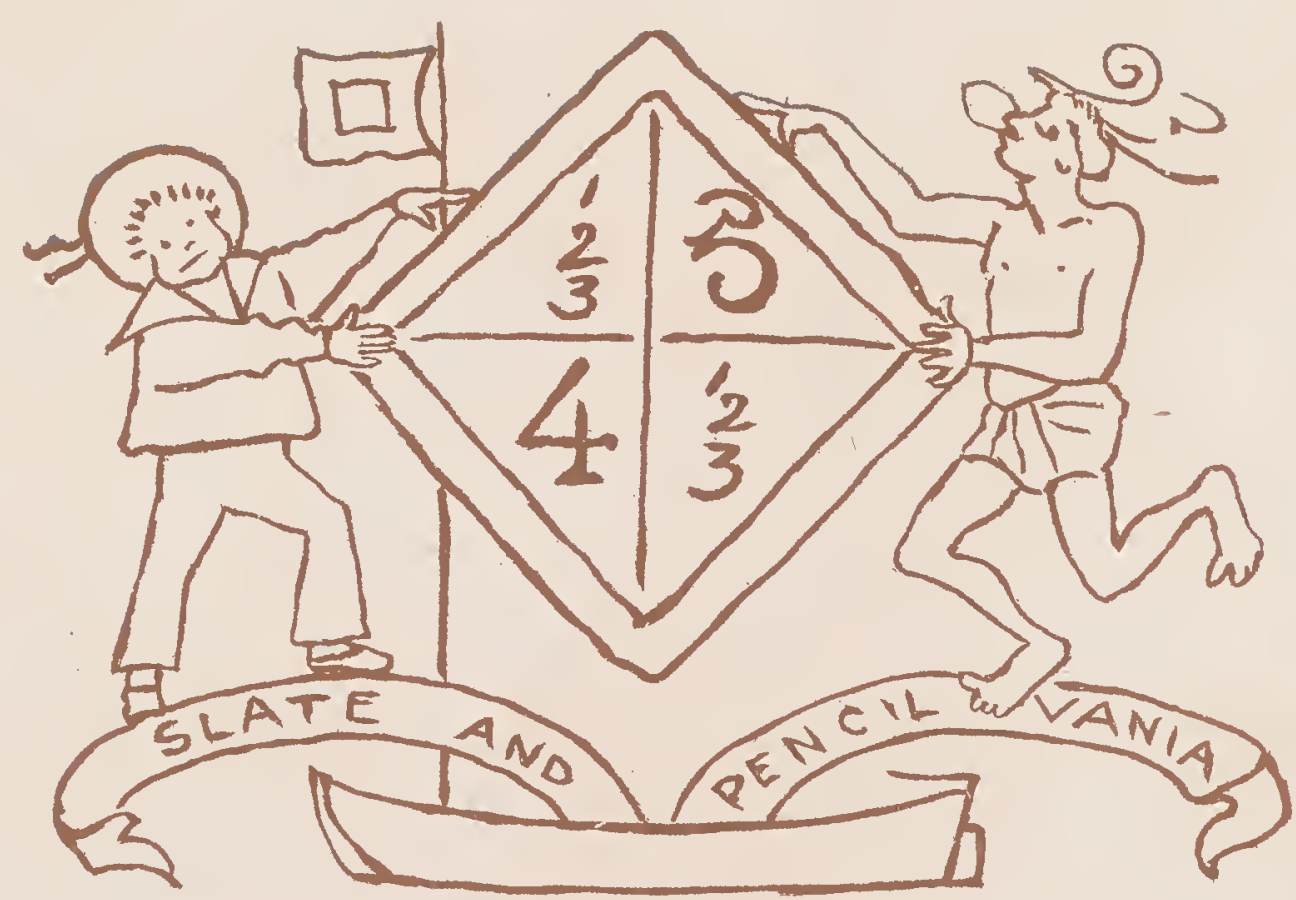




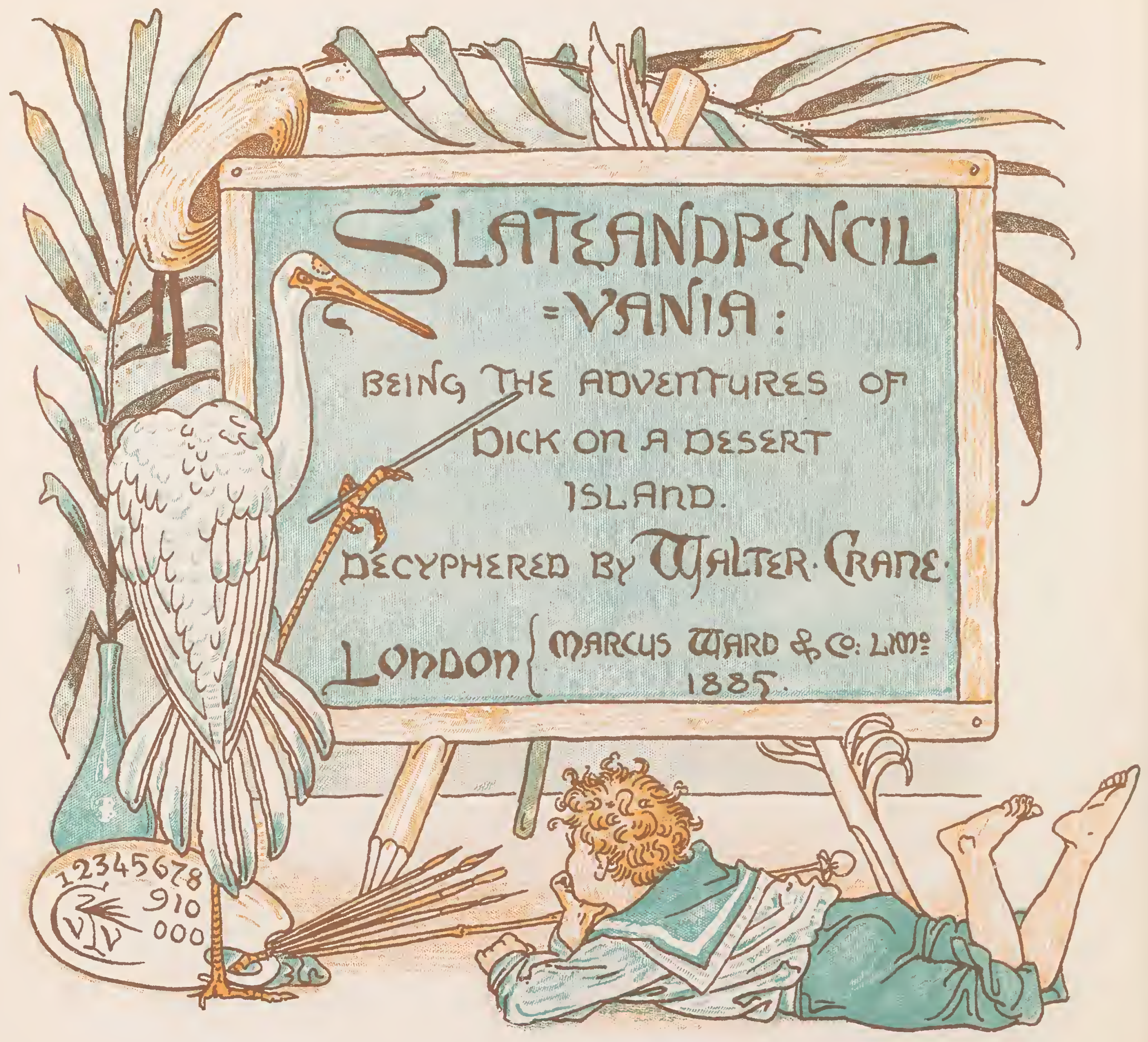




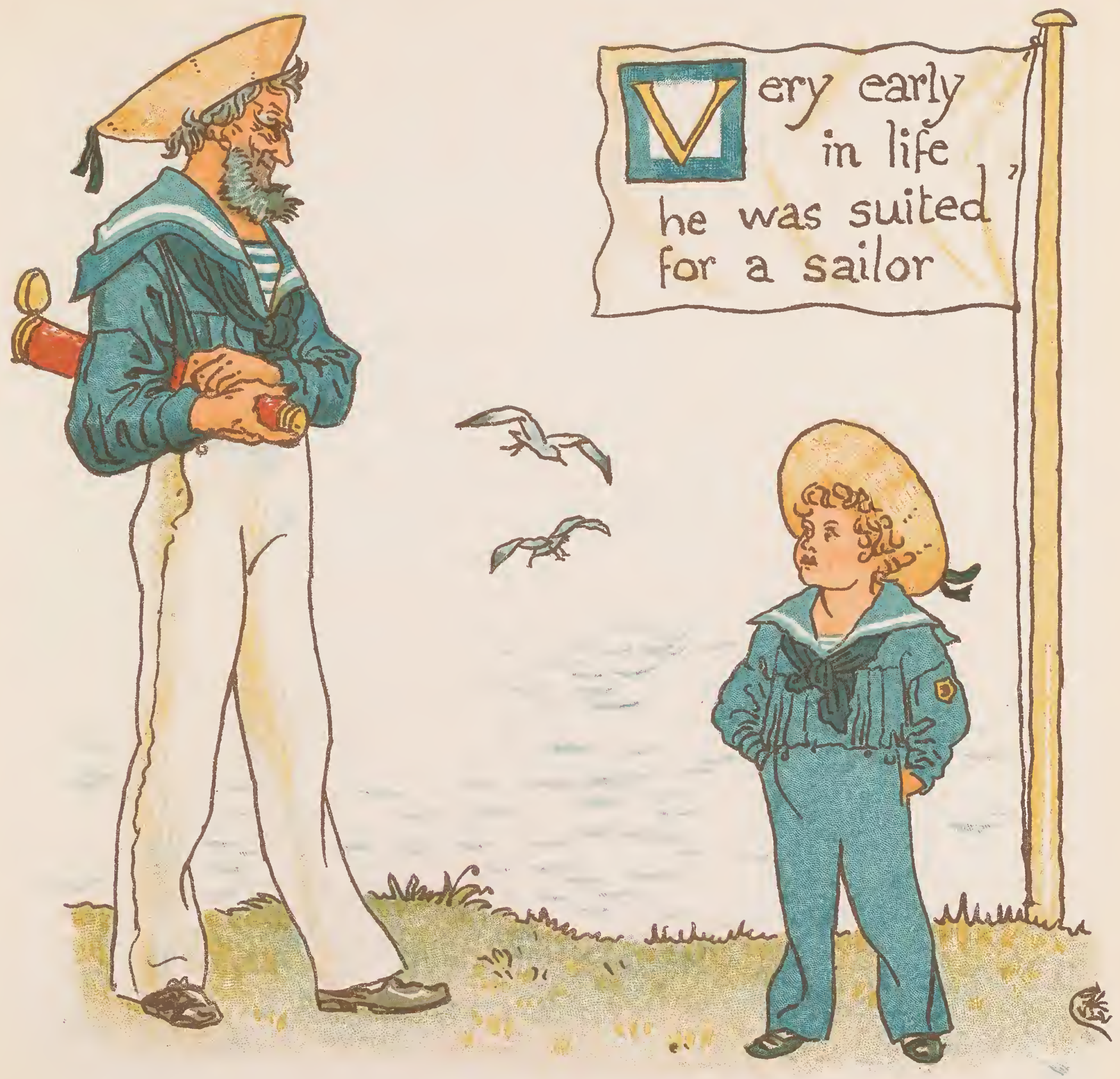


Fand, an rhe seaside, (Chas houghts of voyaging:

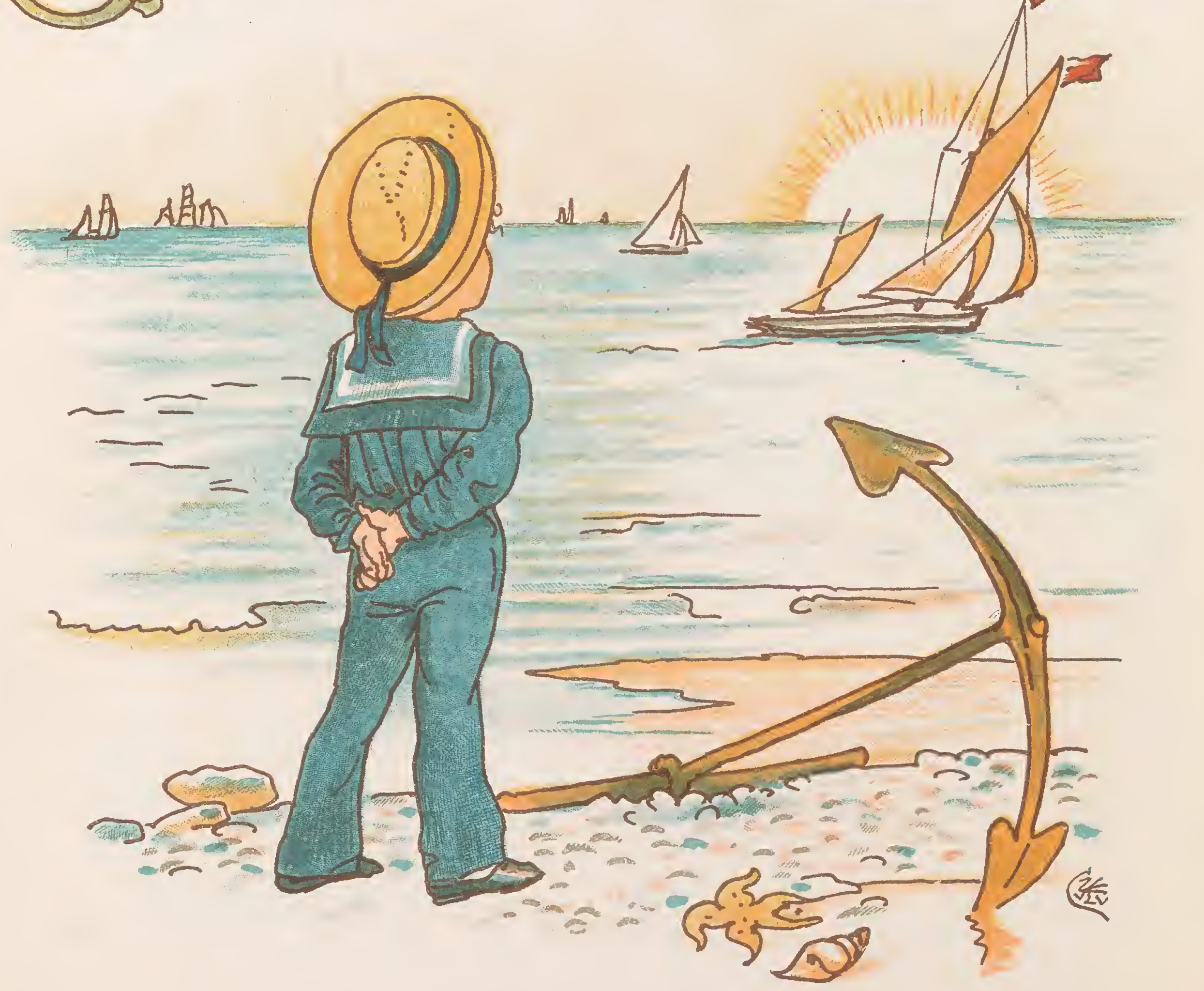




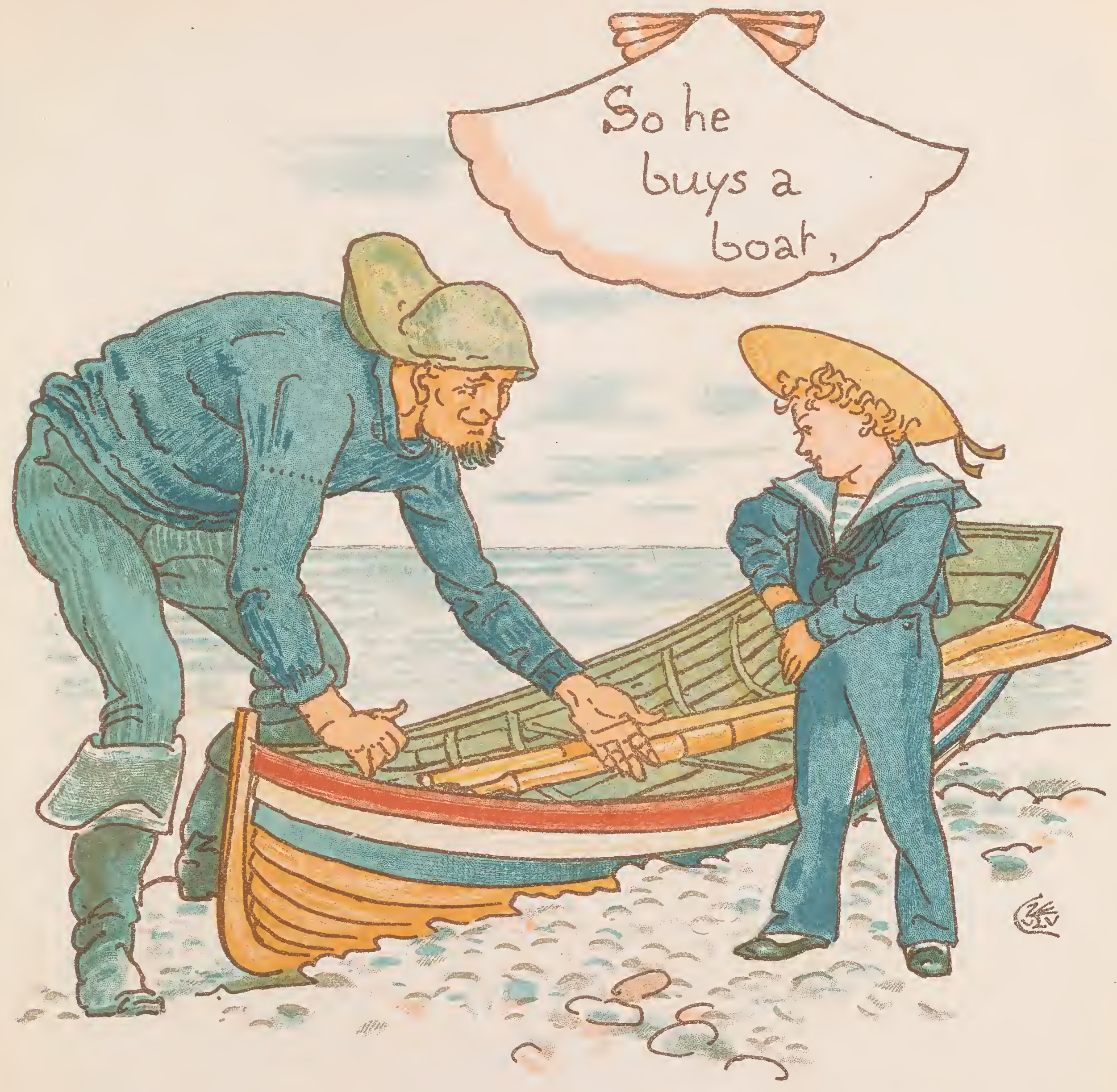




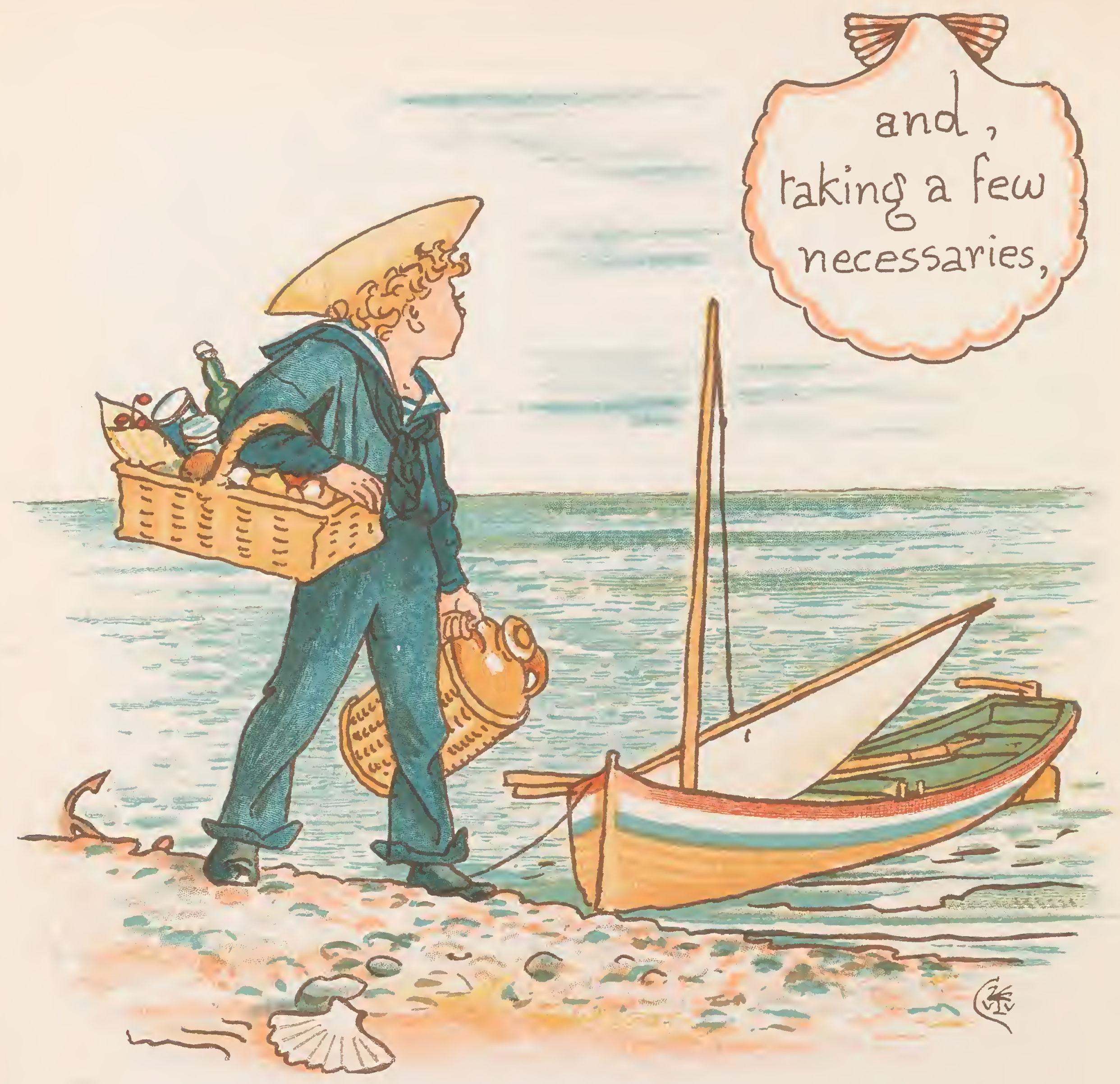




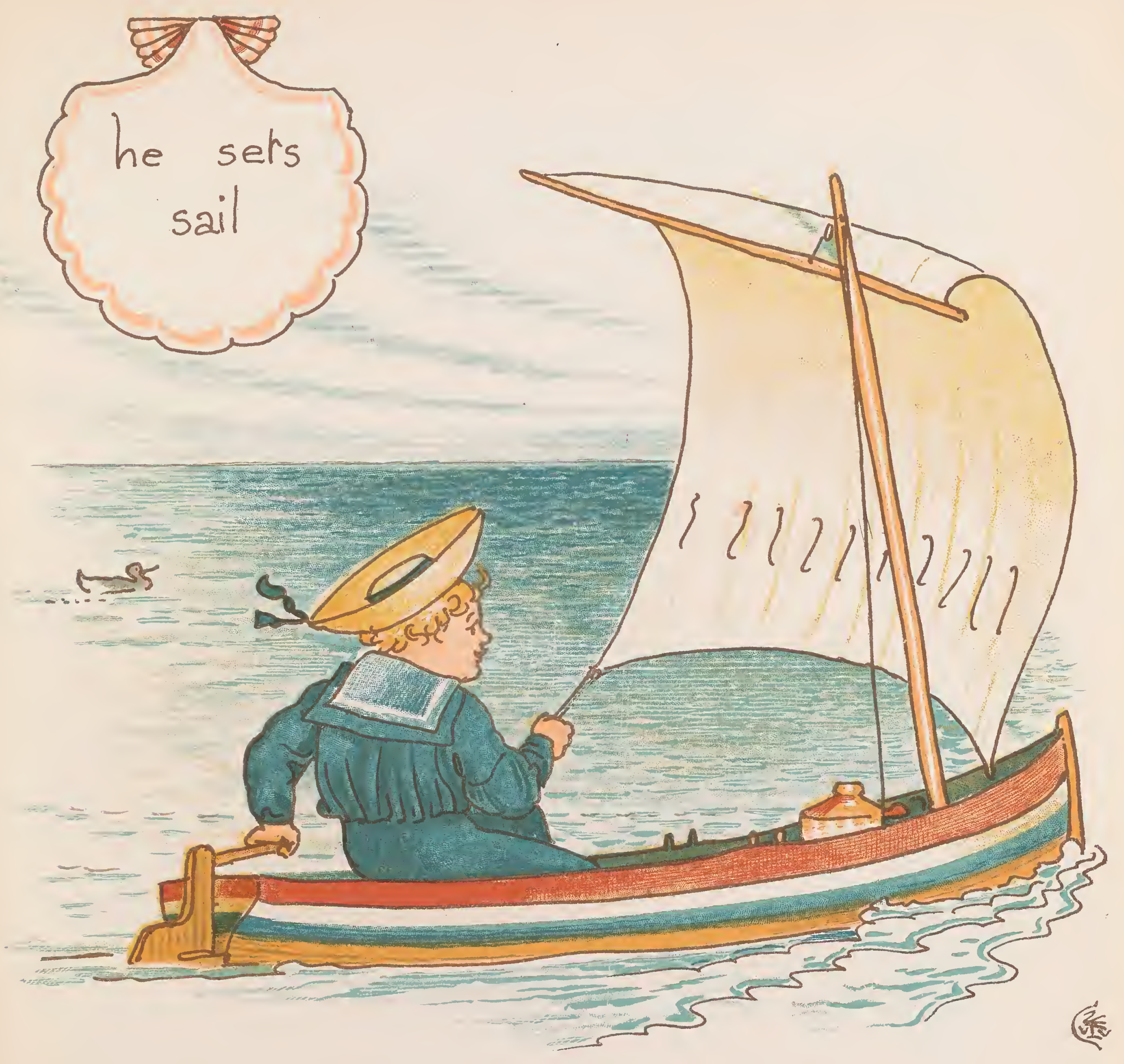




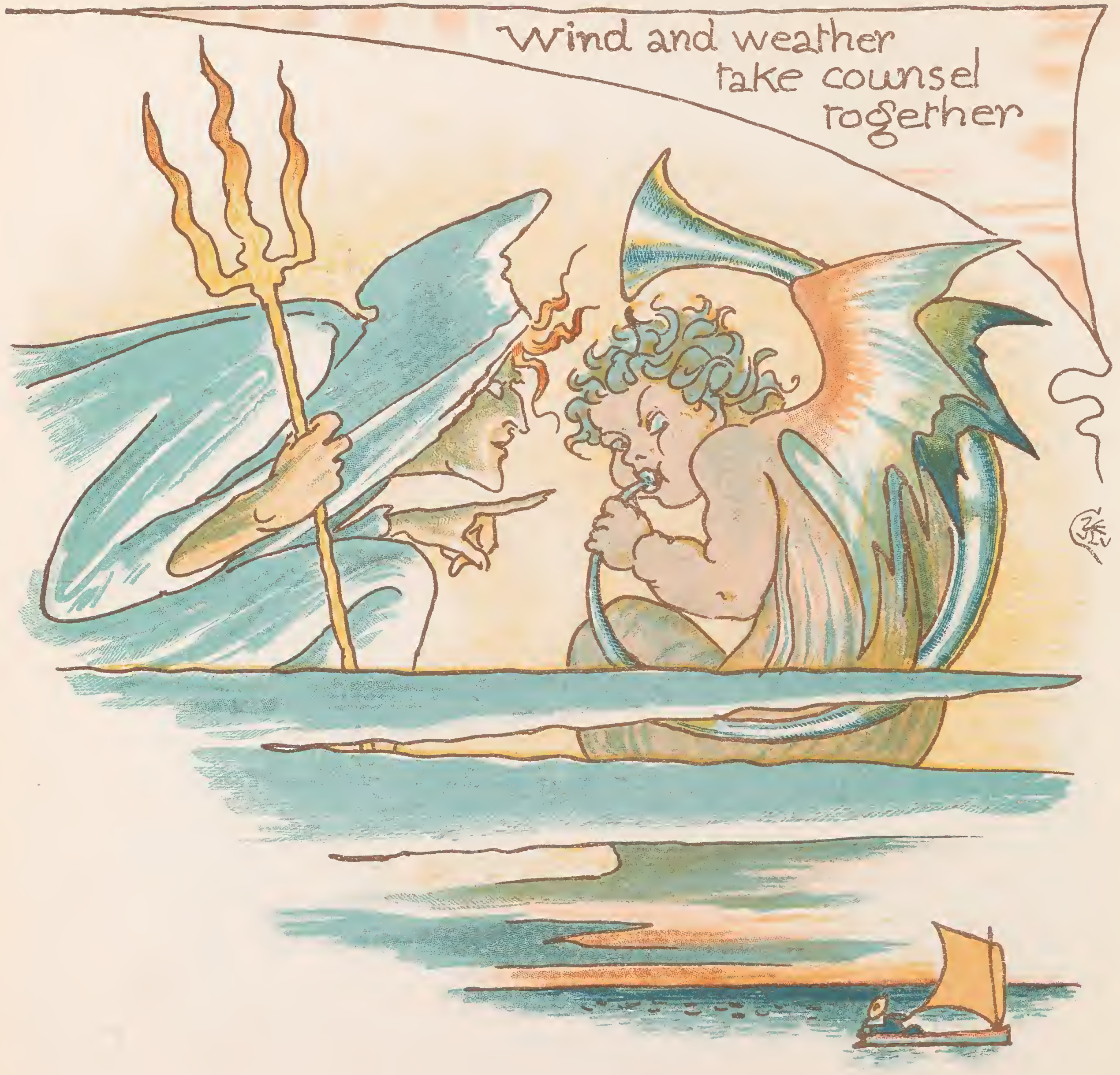




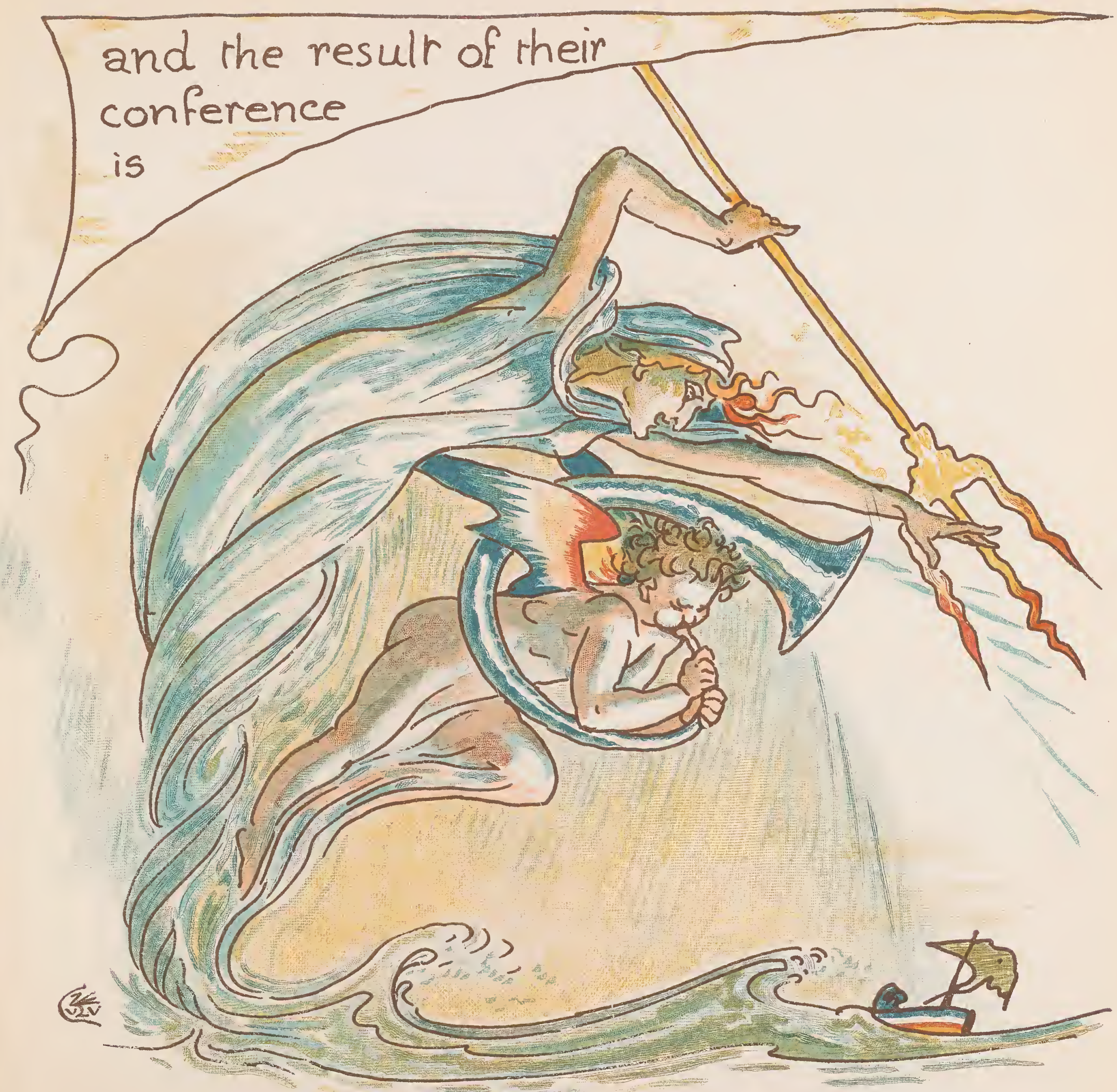




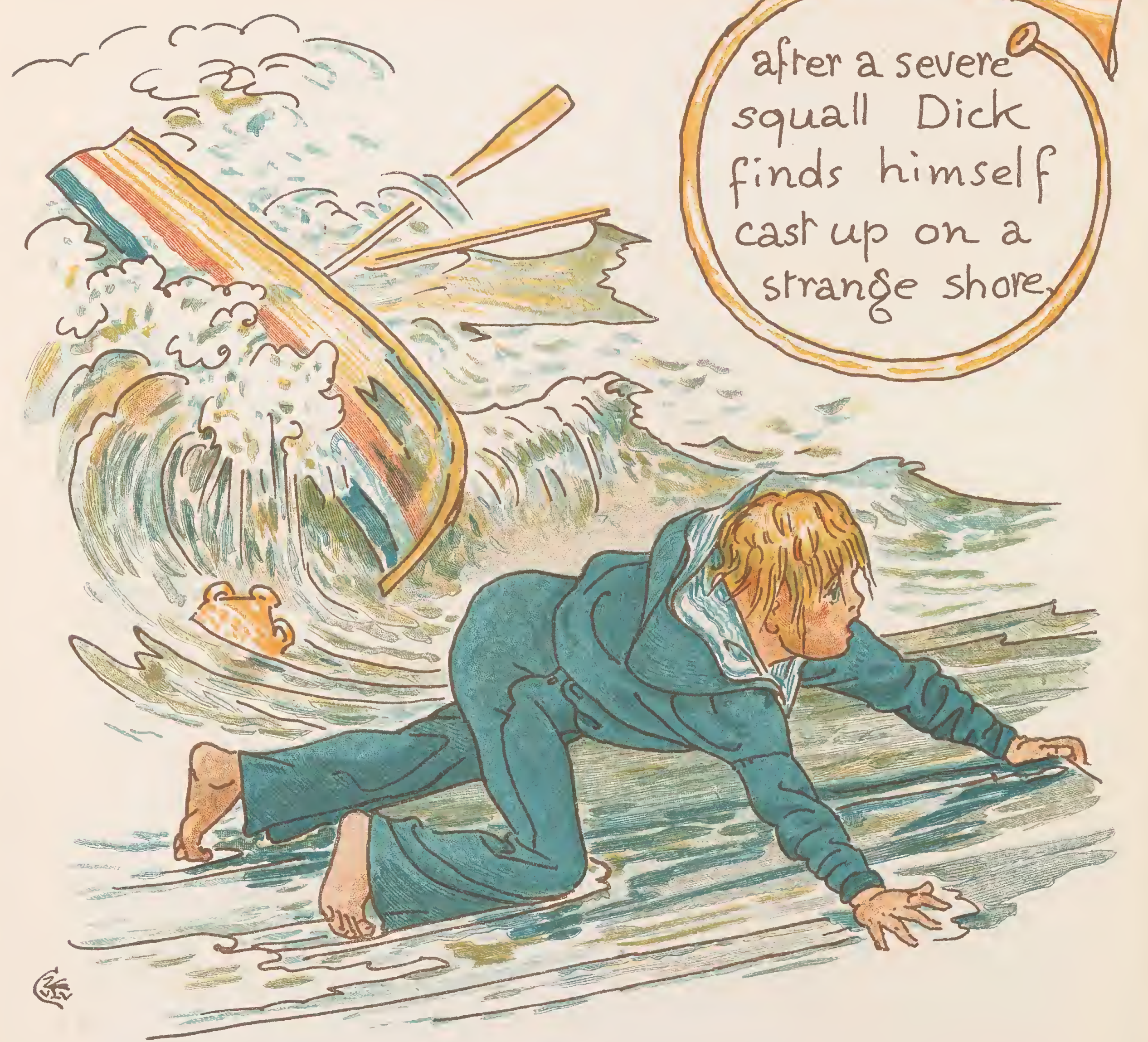




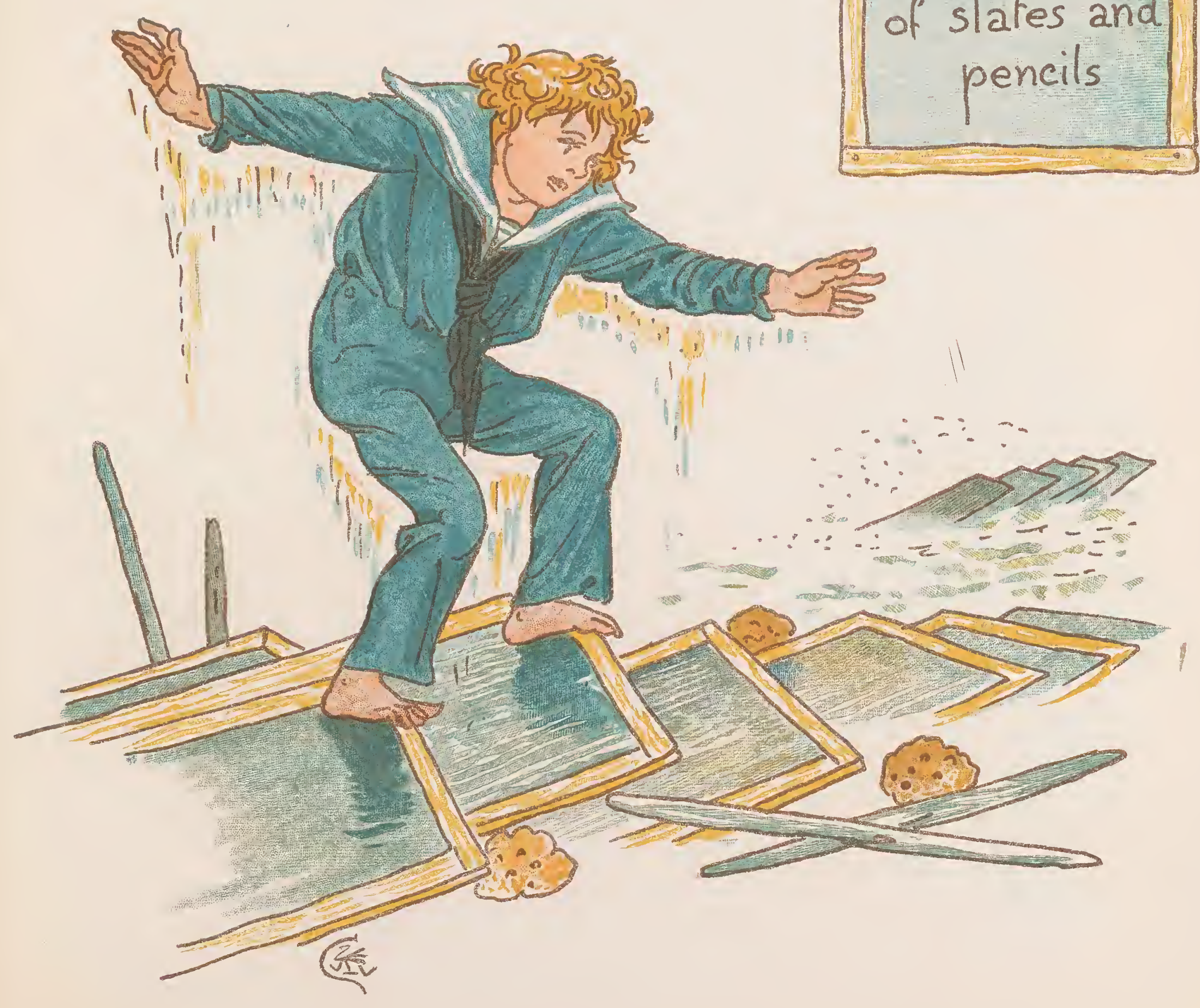




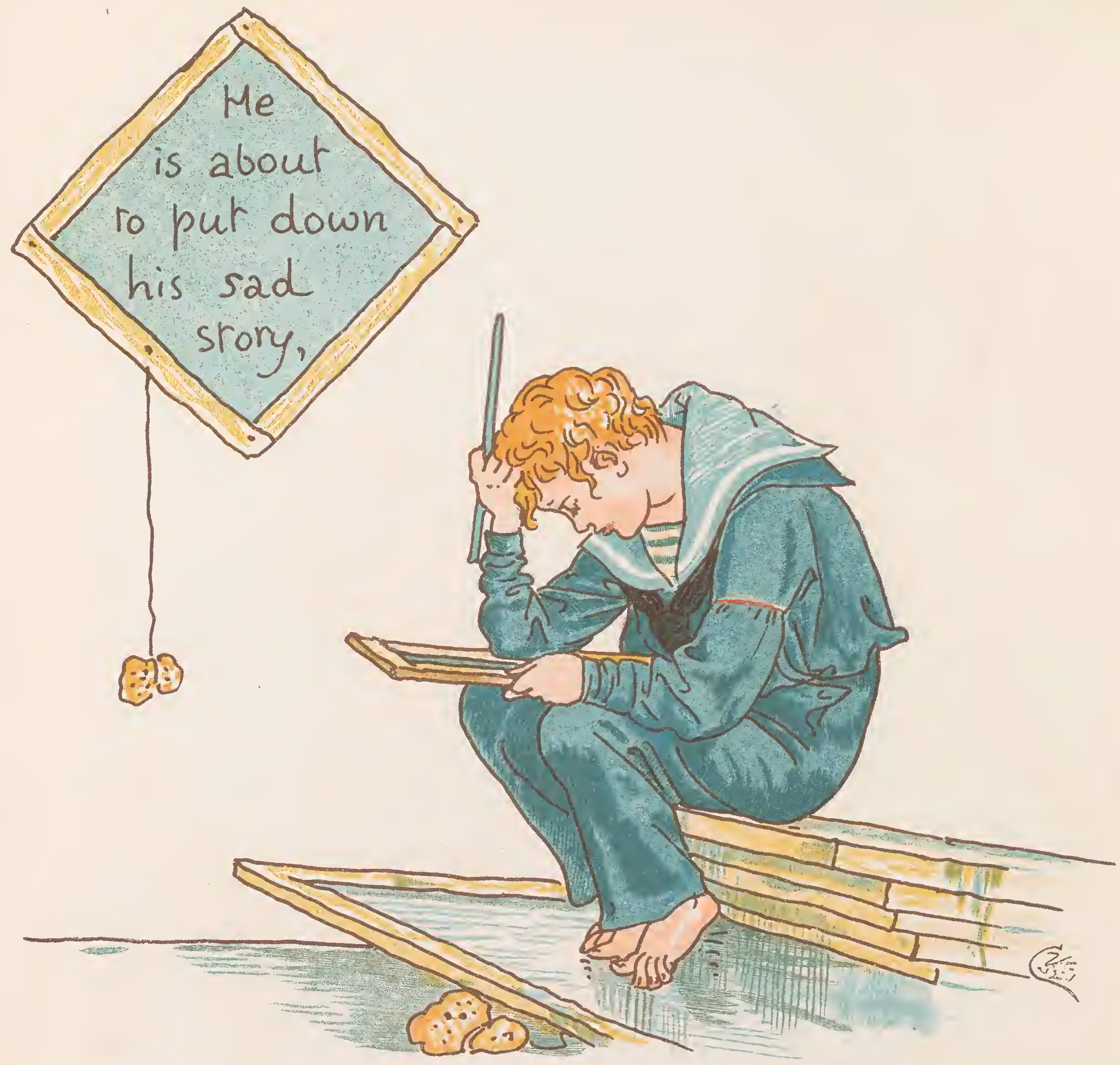




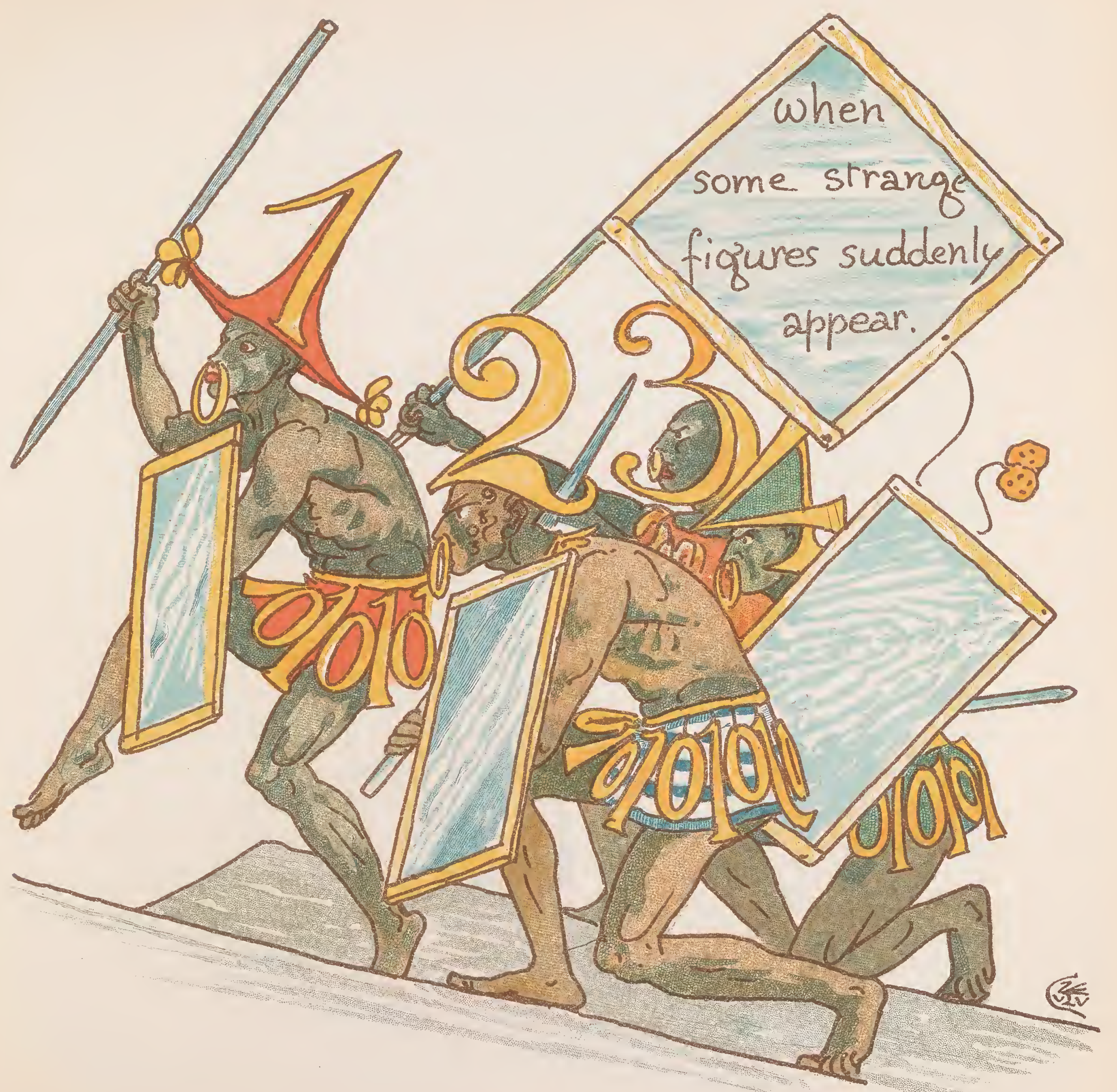




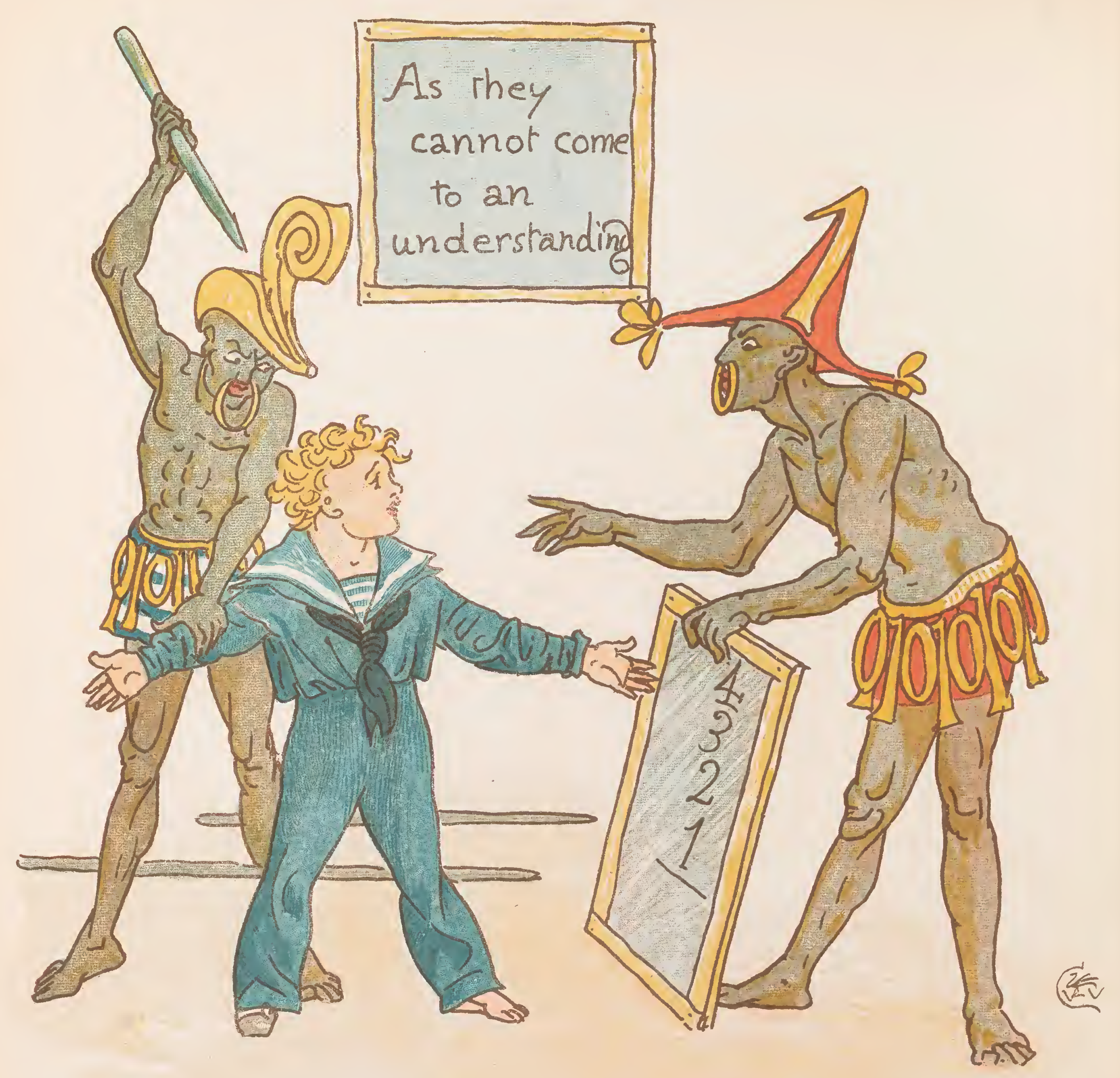




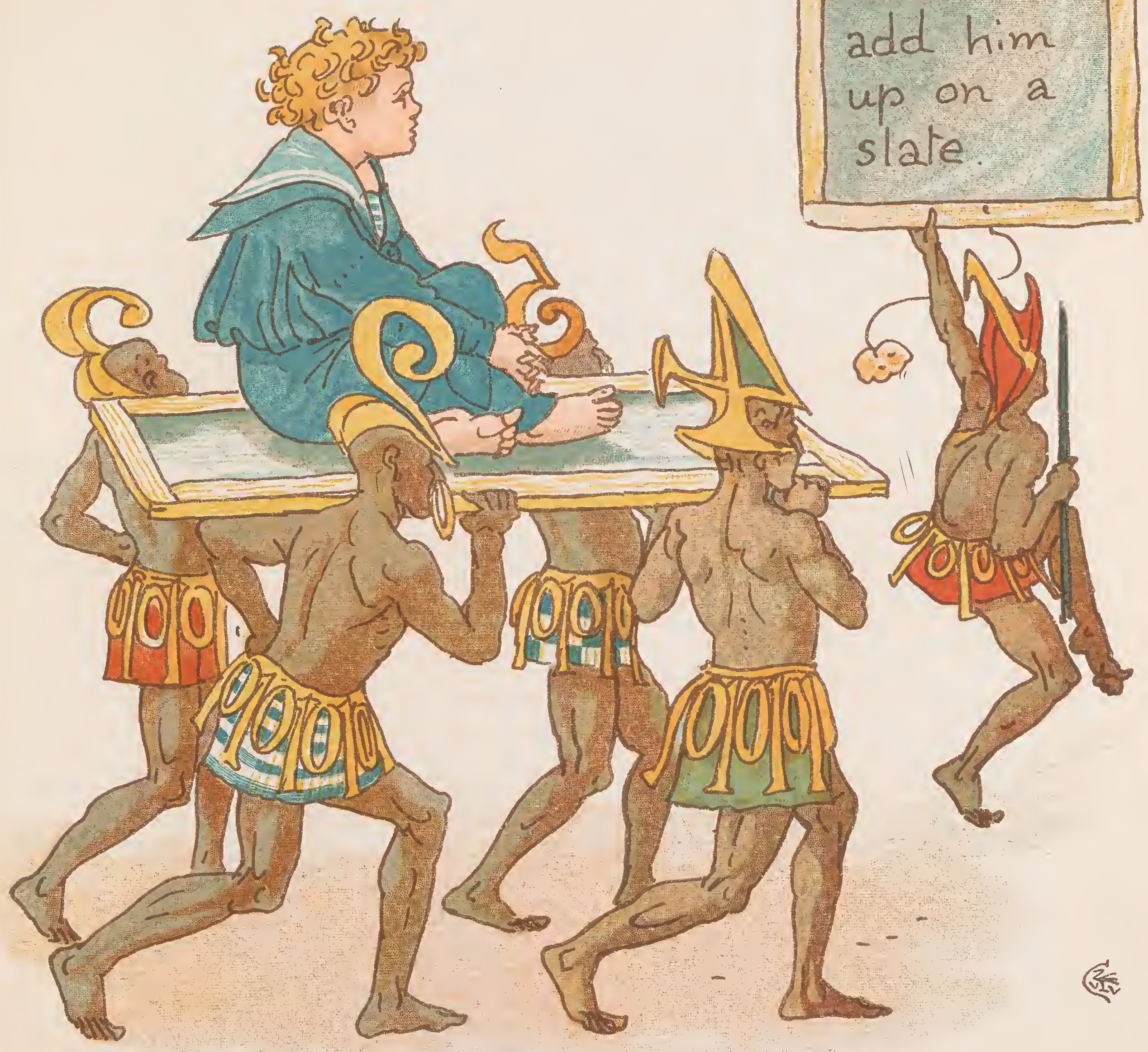

The natives

add him up on a slate. 


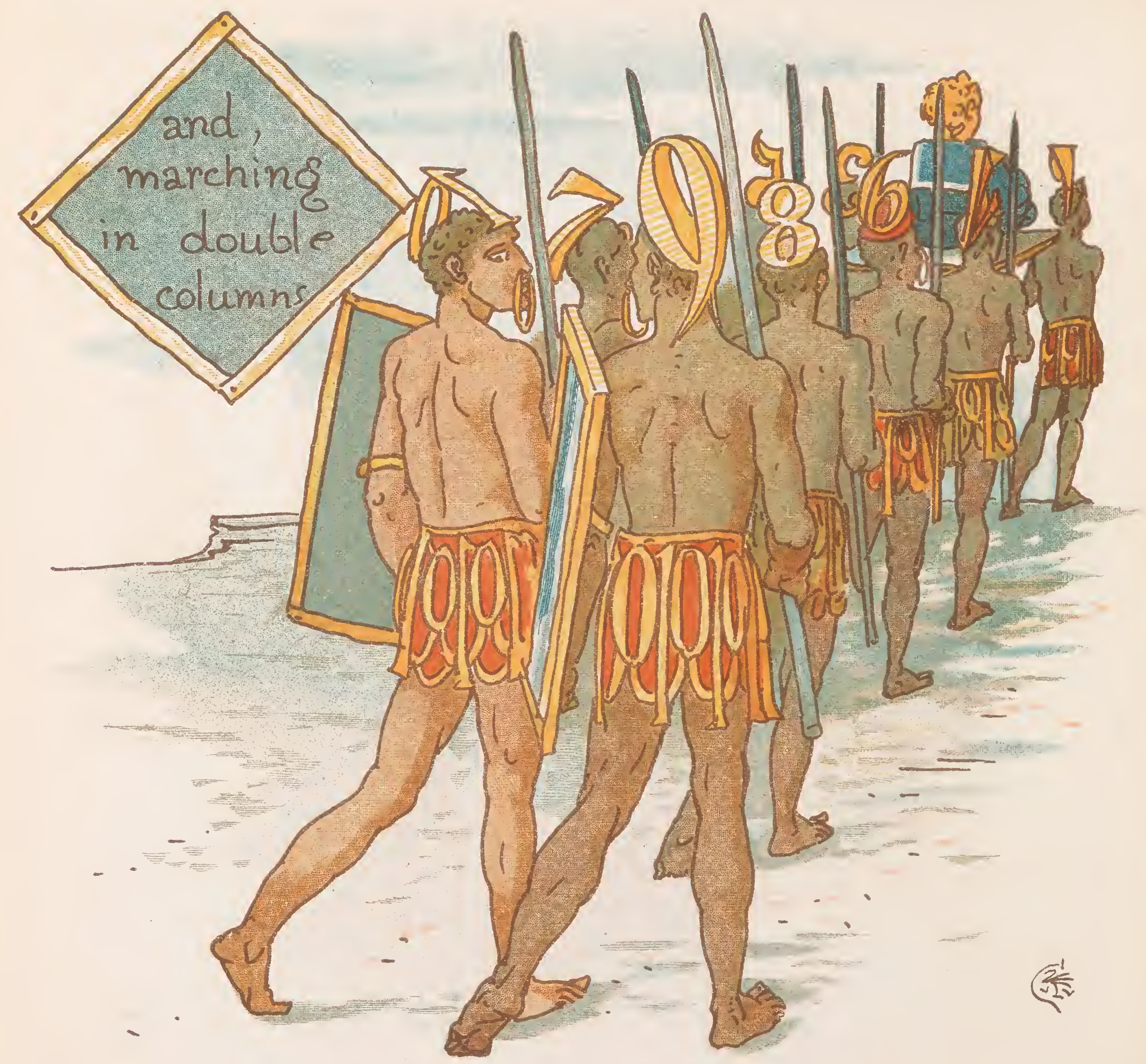




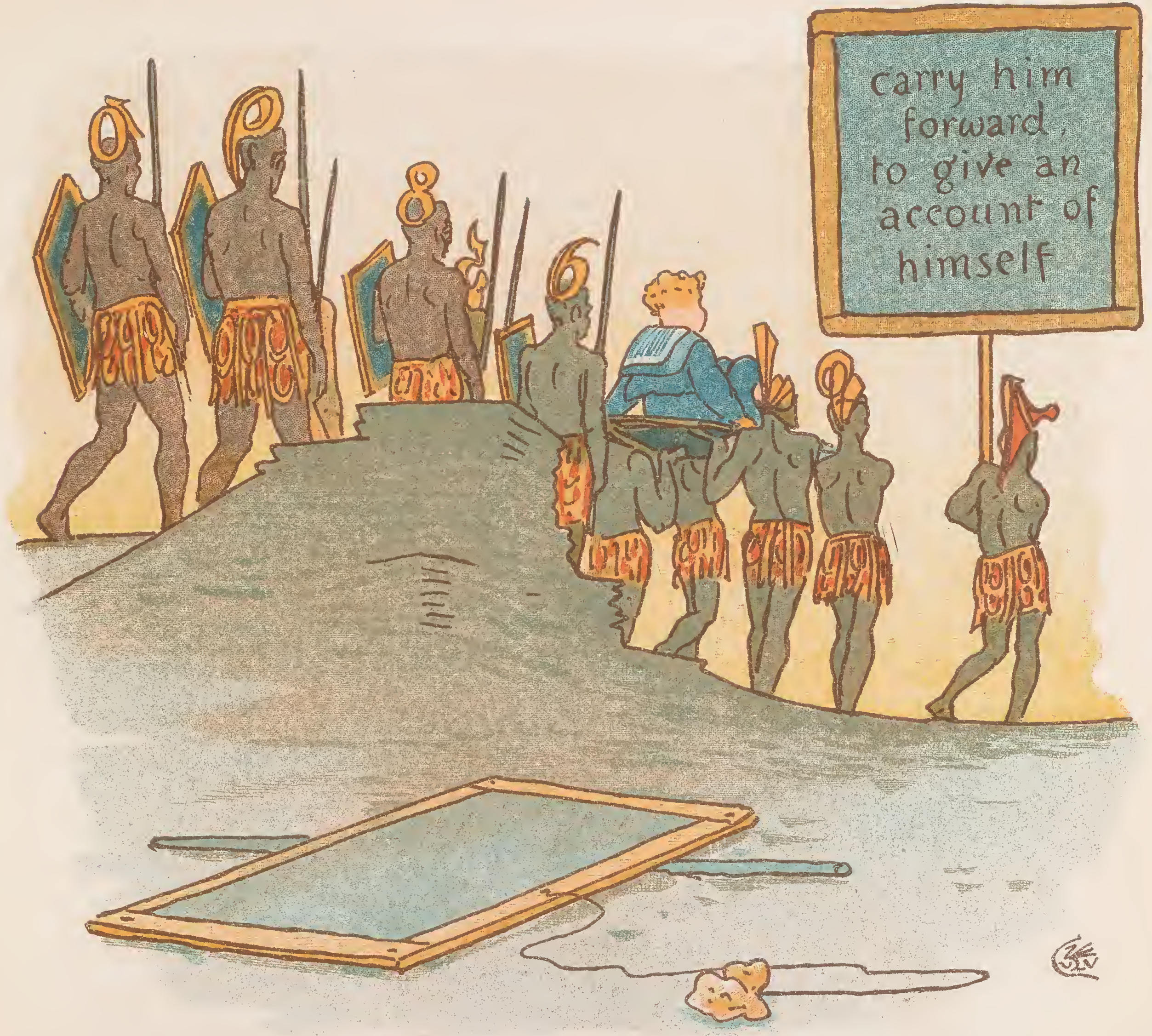




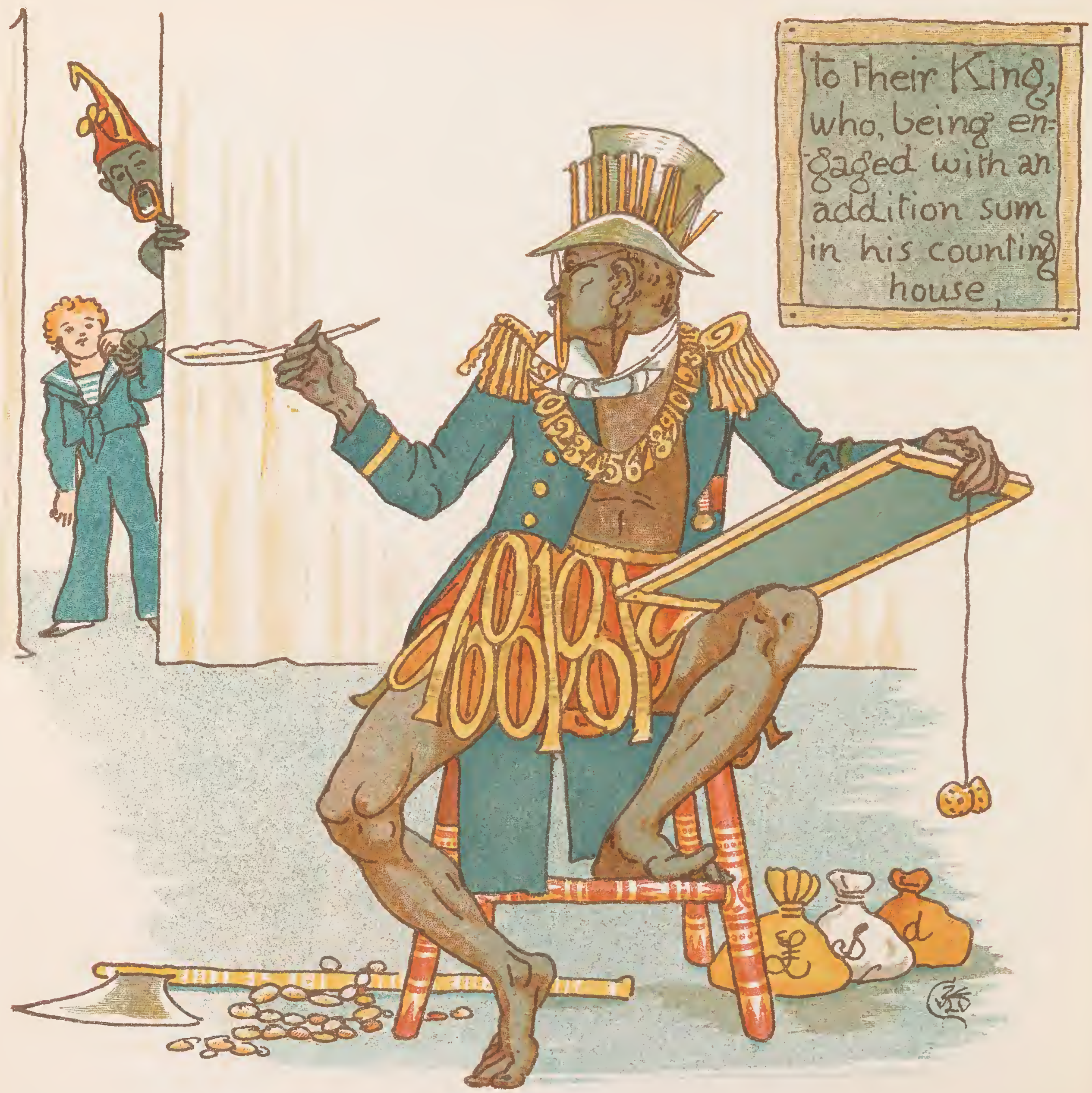




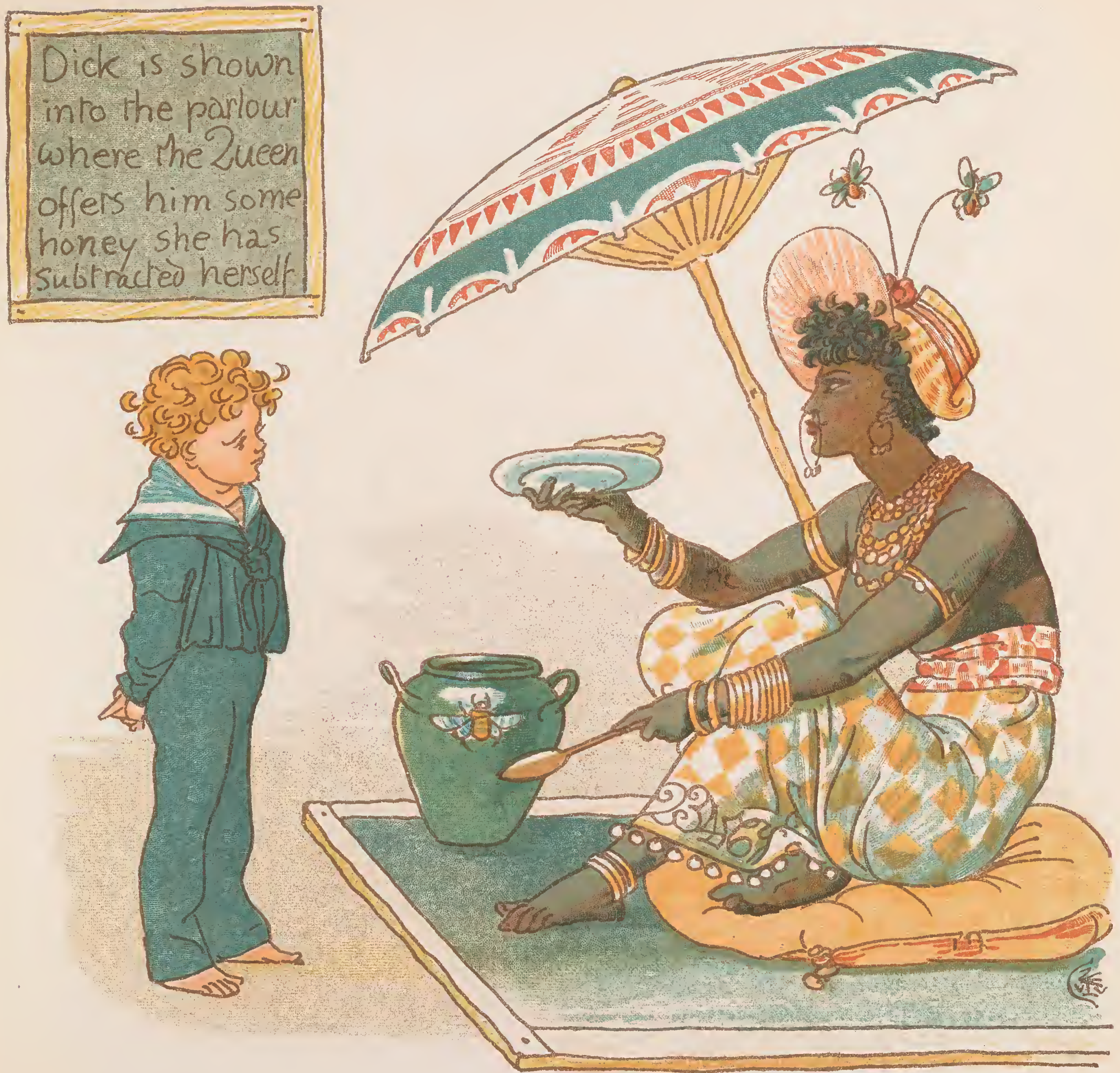





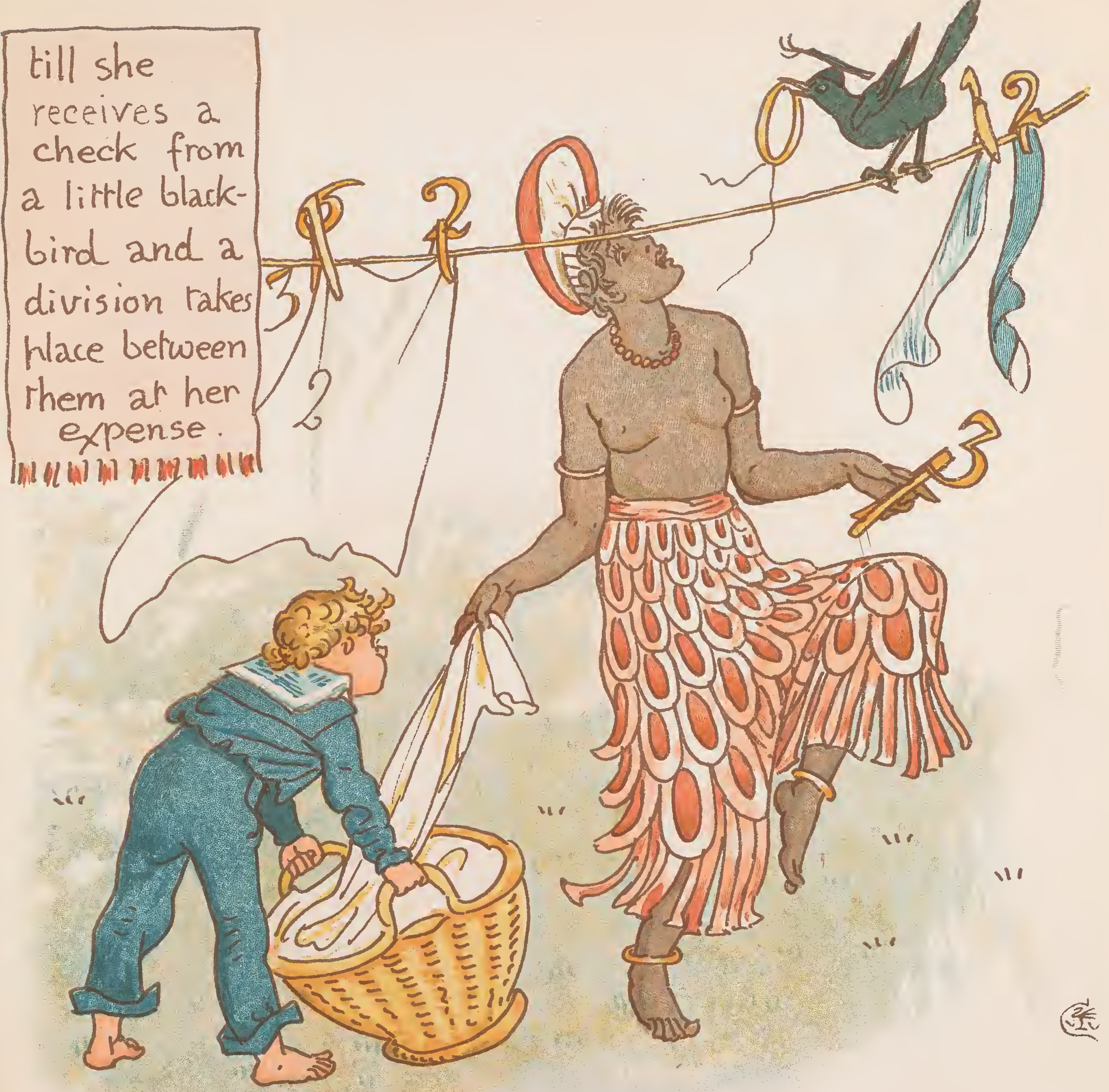




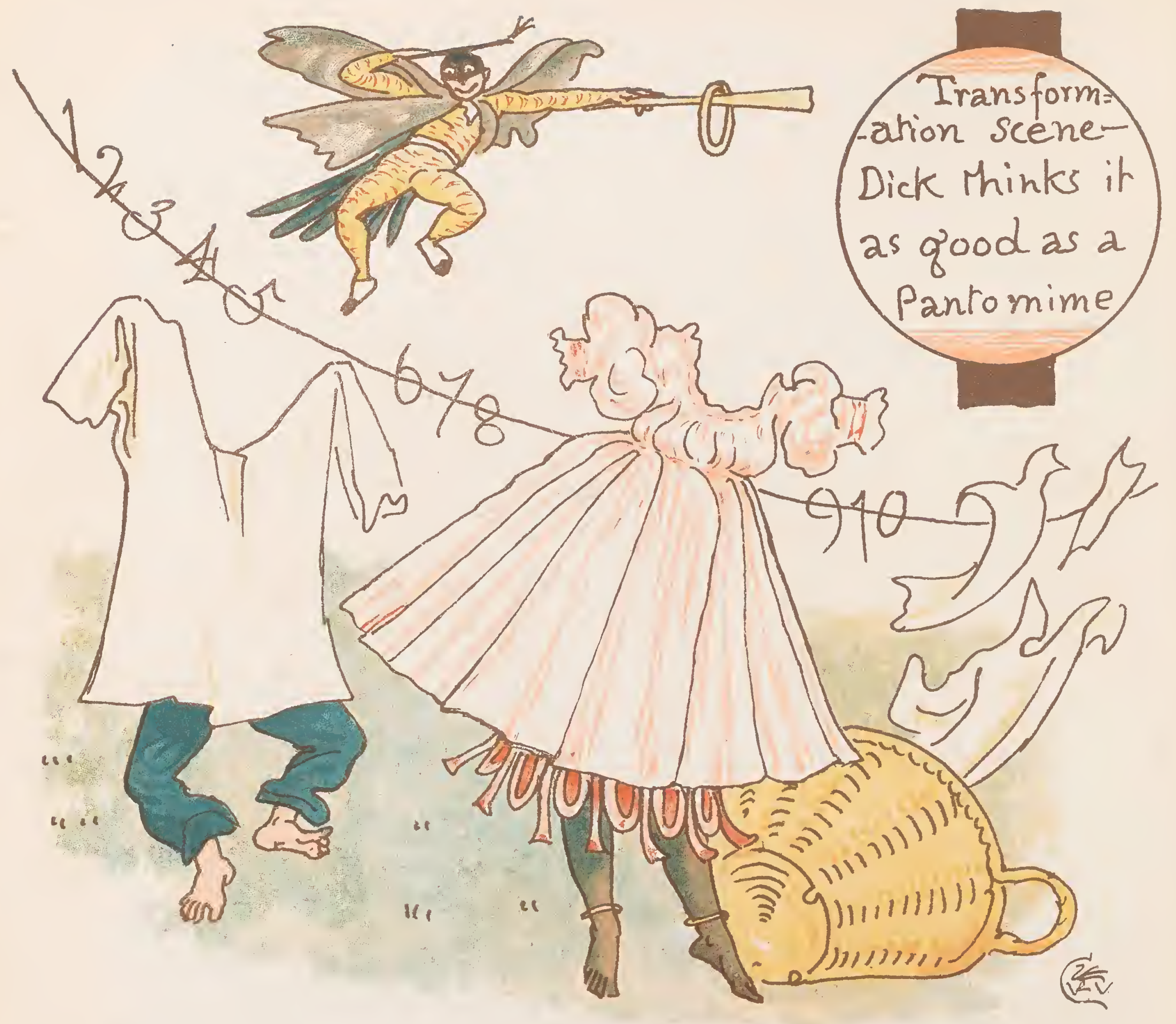




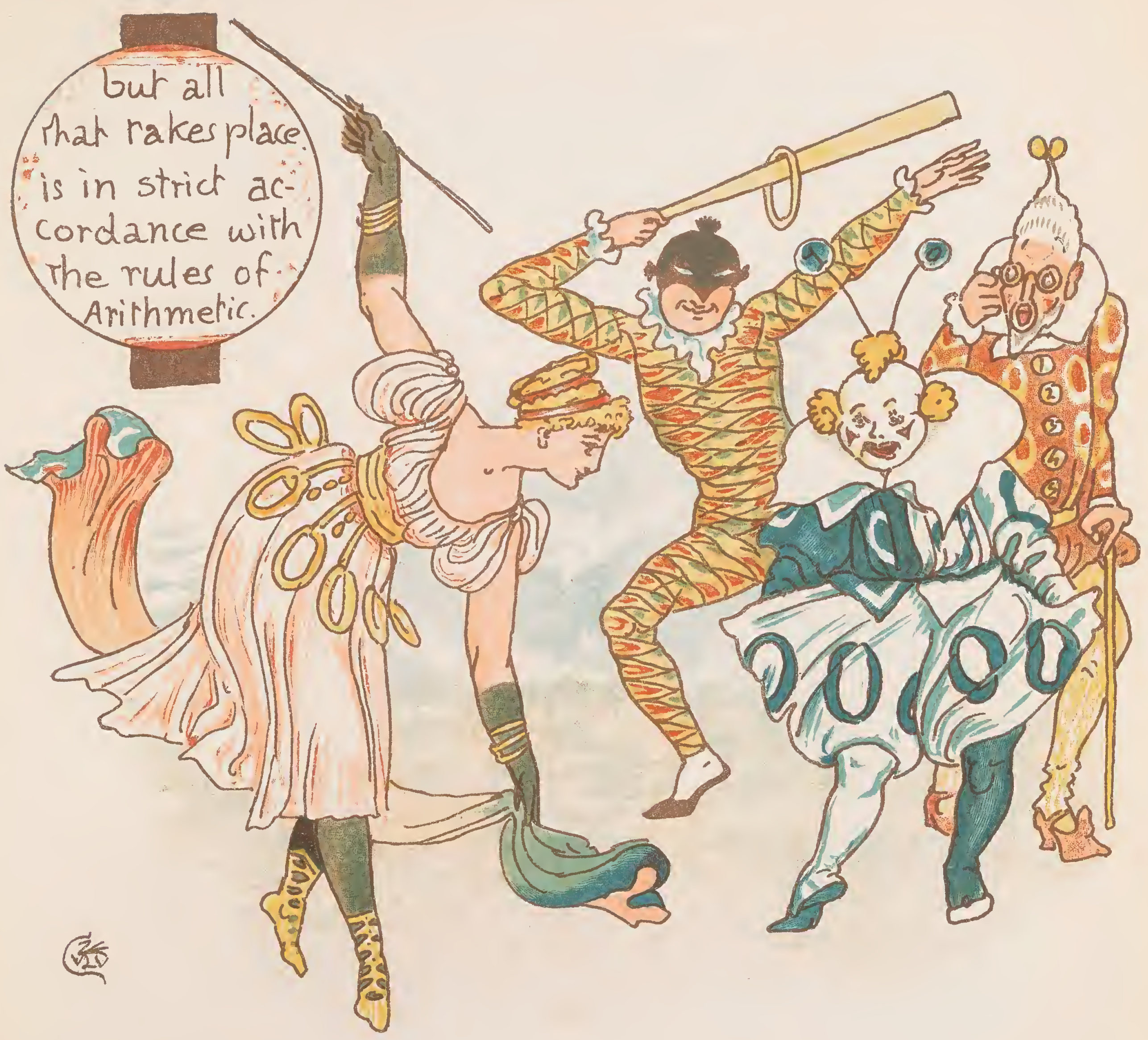




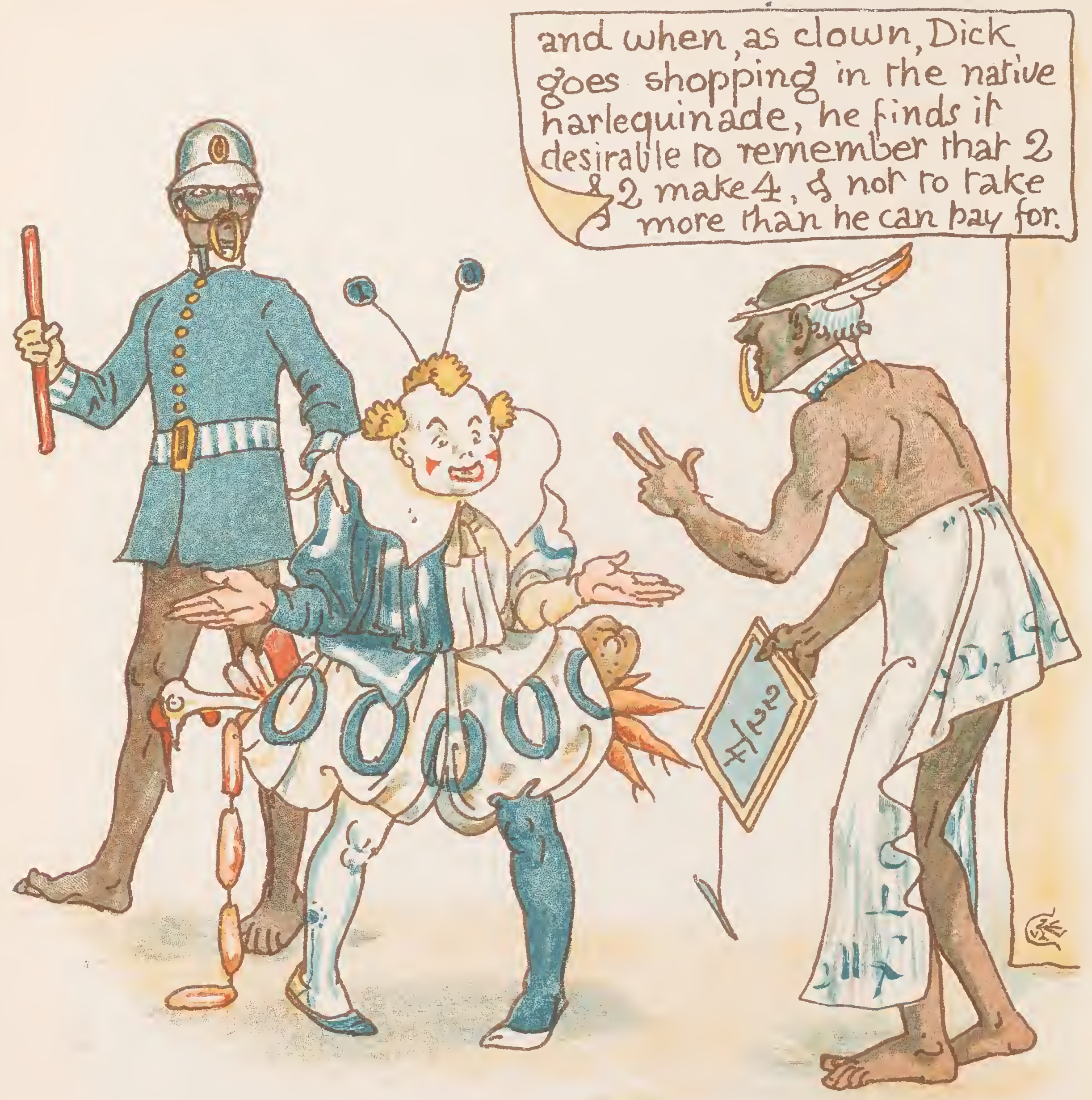




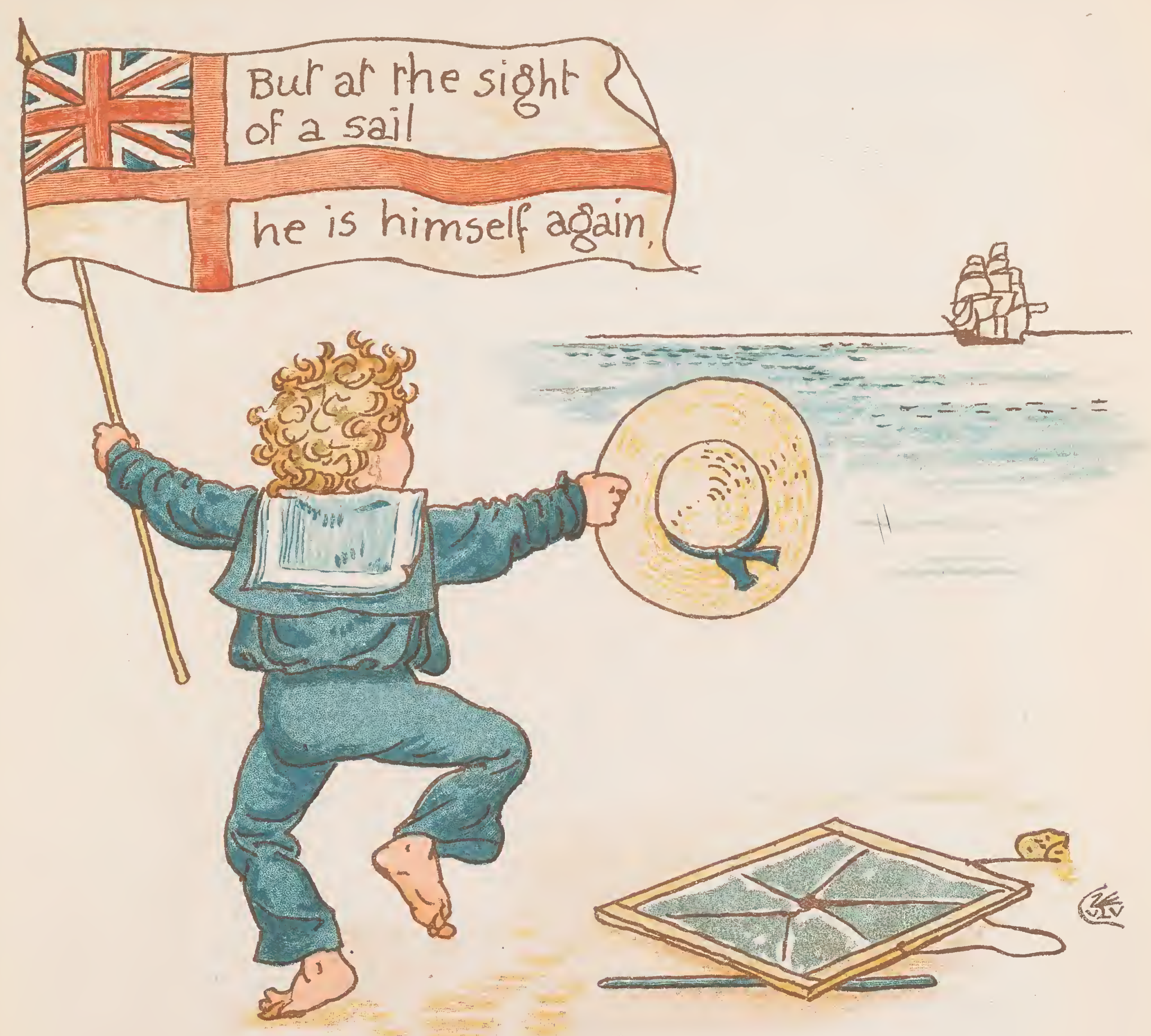




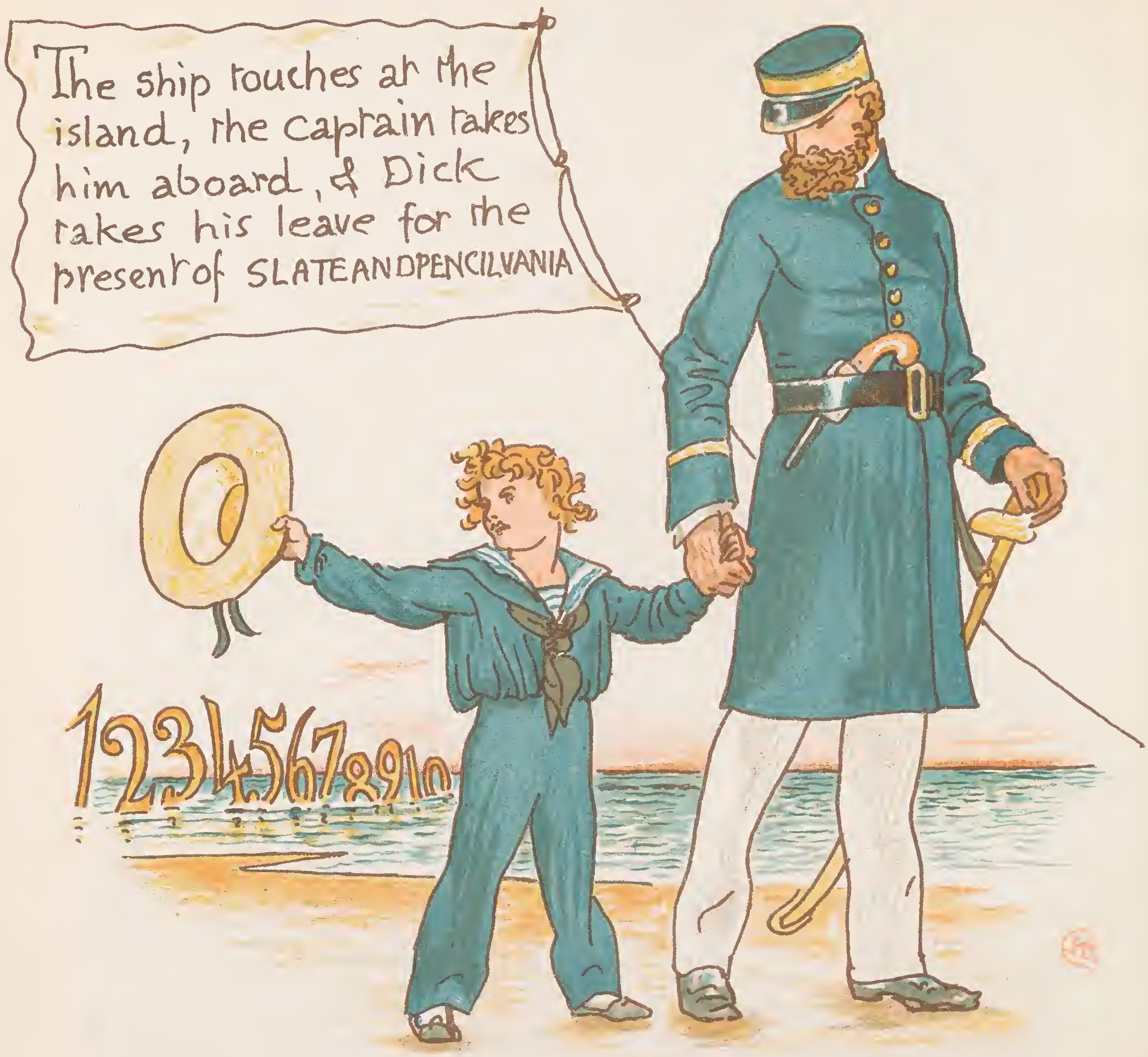




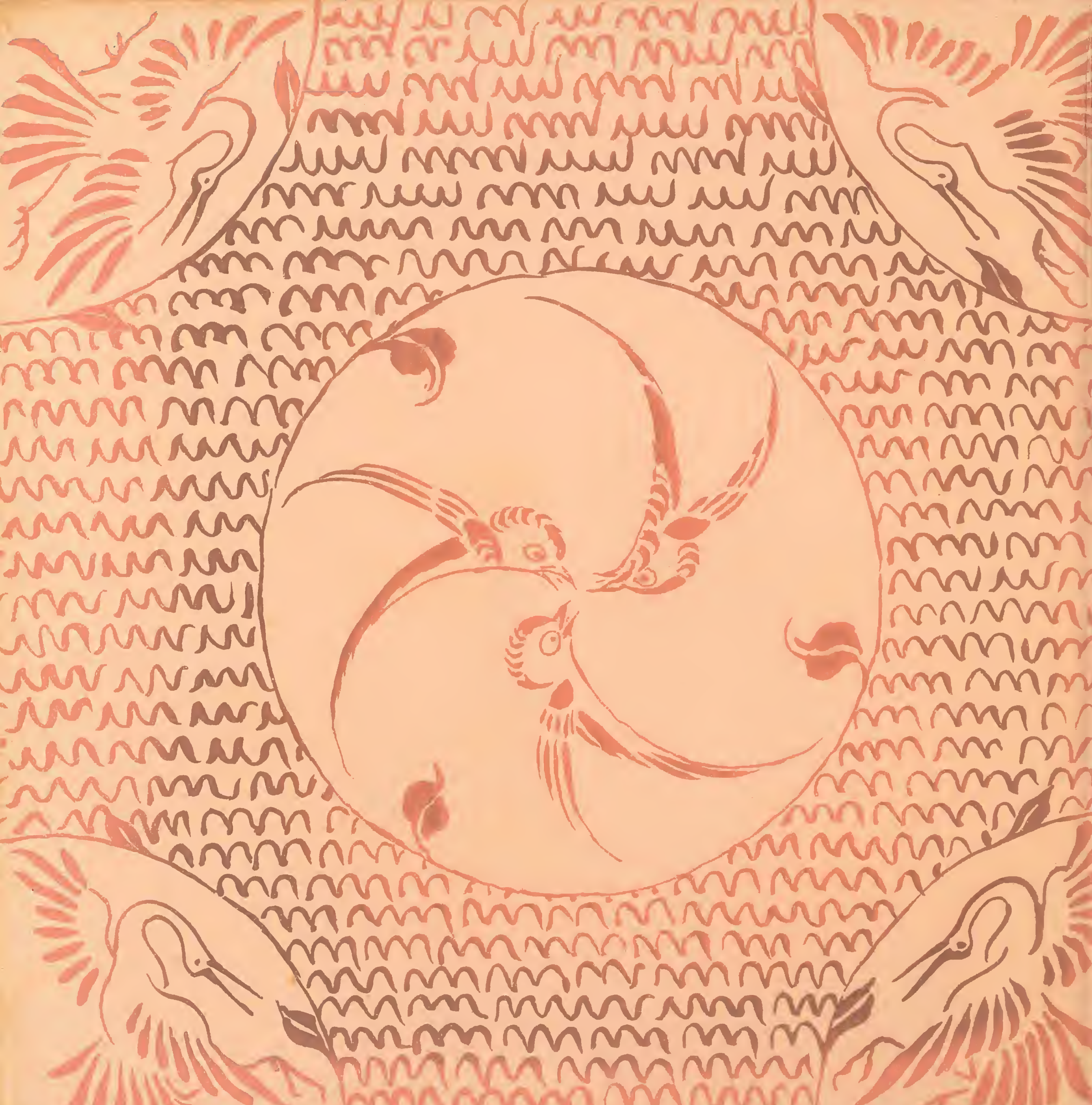




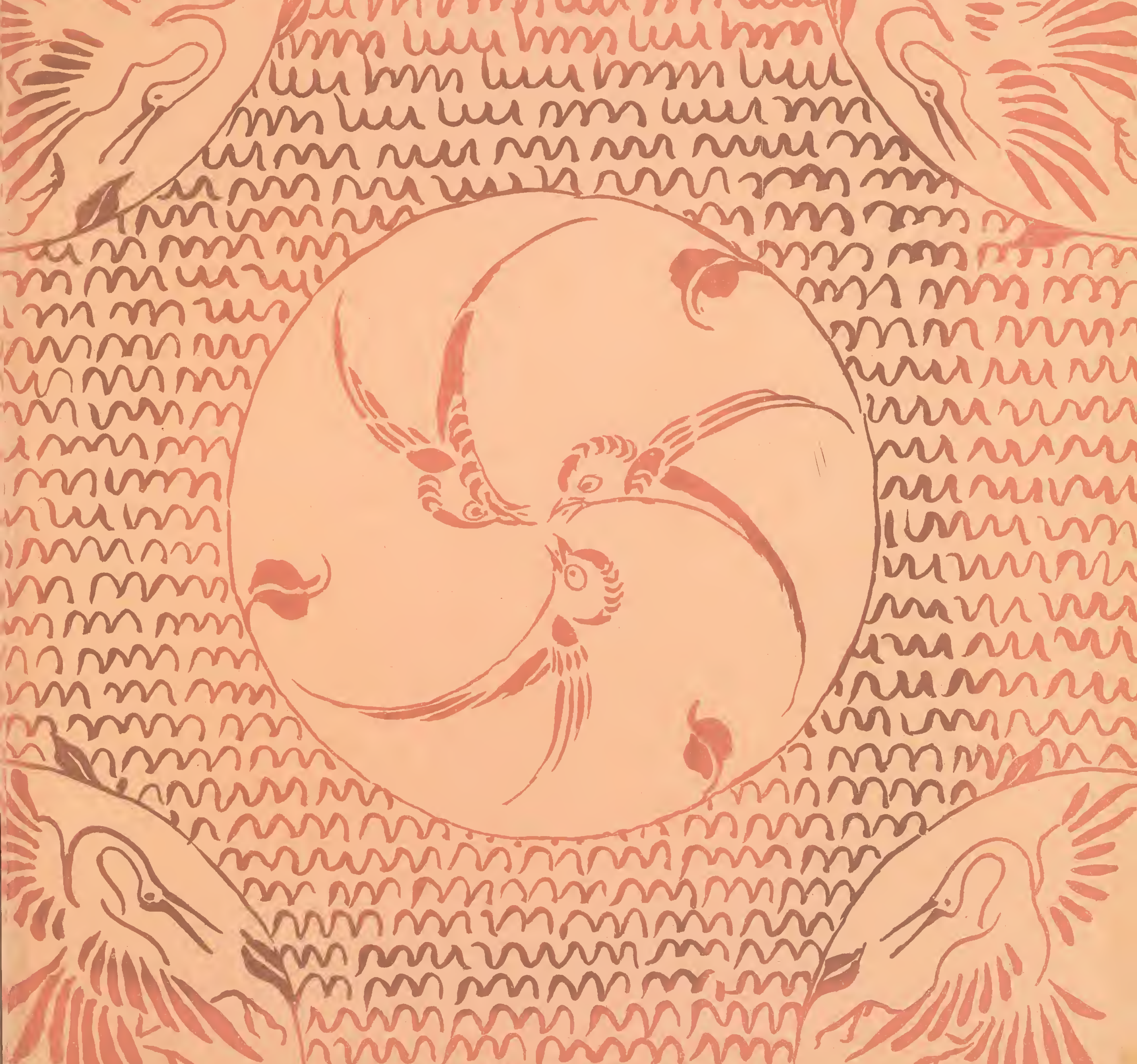


